\title{
Recommendations for Interdisciplinary Design of Buildings and Other Facilities in Rural East Africa
}

\author{
A Project Report \\ Presented to \\ the Faculty of California Polytechnic State University \\ San Luis Obispo, California
}

In partial fulfillment

of the Requirements for the Degree

Master of Science in Architecture with a Specialization in Architectural Engineering

by

David Lambert

March 2010 
(C) 2010

David Anthony Kugler Lambert ALL RIGHTS RESERVED 
COMMITTEE PAGE

TITLE: Recommendations for Interdisciplinary Design of Buildings and Other Facilities in Rural East Africa

AUTHOR: David Lambert

DATE SUBMITTED: March 16, 2010

COMMITTEE CHAIR:

Professor Craig Baltimore, Ph.D., S.E.

COMMITTEE MEMBER:

Professor Kevin Dong, S.E.

COMMITTEE MEMBER:

Professor James Mwangi, Ph.D., P.E. 


\begin{abstract}
Recommendations for Interdisciplinary Design of Buildings and Other Facilities in Rural East Africa

David Anthony Kugler Lambert
\end{abstract}

Development and aid focused non-governmental organizations operating in rural East Africa face unique challenges in the design and construction of buildings and other facilities in support of their efforts. Failure to address these issues can result in financial consequences hindering success and there is very little information available providing recommendations or guidelines. A summary of the design of the Same Polytechnic, a vocational training school located in northern Tanzania, details the comprehensive process involving the multiple parties of an interdisciplinary design team each requiring specific information to evaluate the many factors involved. The lessons learned and information gathered during the design process will serve as a set of basic guidelines that will help future projects address the more serious challenges encountered when building in rural East Africa. 


\section{ACKNOWLEDGEMENTS}

Were it not for the support and guidance of the following individuals this achievement could not have been accomplished:

Associate Professor Craig Baltimore, Ph.D., S.E. Associate Professor Kevin Dong, S.E.

Assistant Professor James Mwangi, Ph.D., P.E.

Special thanks to the design team members whose many hours of tireless work made this project a reality:

$\underline{\text { Planning Team }}$

Mrs. Jennifer Venema

Mr. Michael Austin $\underline{\text { Architecture Team }}$

Miss. Jullie Reynolds

Mrs. Kim Strickland

Prof. Curtis Illingworth $\underline{\text { Structural Team }}$

Mr. Daniel Hall Mr. Timothy Wolf

Mr. David Saechao

Miss. Ashley Moraes

Landscape Team

Miss. Allison Crump

Miss. Lupe Monroy

Mr. Brett Thompson

Mr. Erik Wright

Thank you to Fr. Mansuetus Kimbwe Setonga for this amazing opportunity.

A special note of thanks to Prof. Craig Baltimore for his continued support, guidance and energy over the past 5 years

In memory of:

Fr. Angelo D'Agostino, S.J., M.D. - for his inspiration and for without his belief in my abilities I would have never made it to Africa in the first place.

Mr. Charles Lambert - beloved grandfather and the reason I became an engineer. 


\section{TABLE OF CONTENTS}

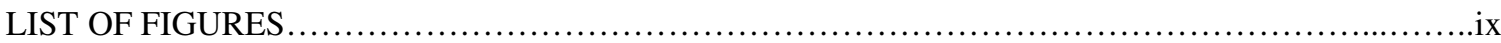

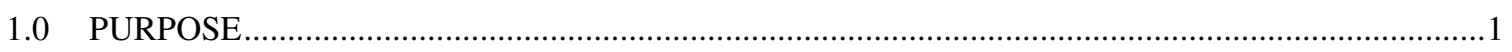

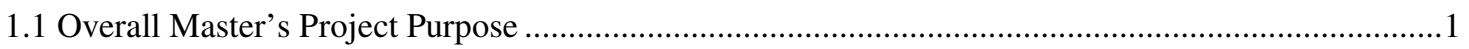

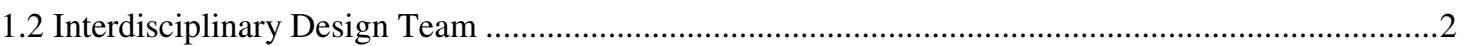

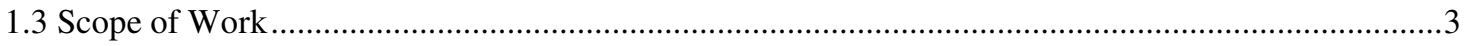

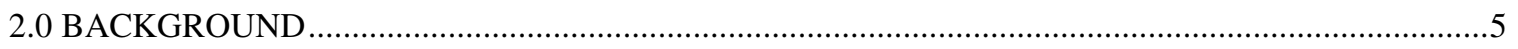

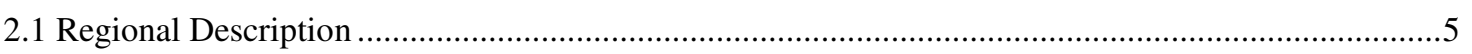

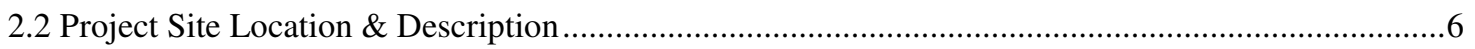

3.0 SAME POLYTECHNIC PROJECT DESCRIPTION .................................................................

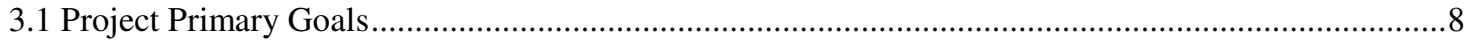

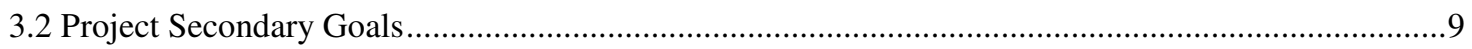

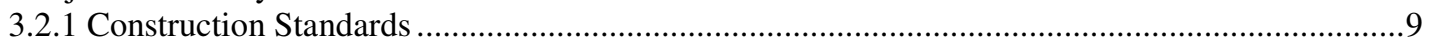

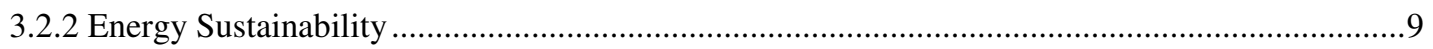

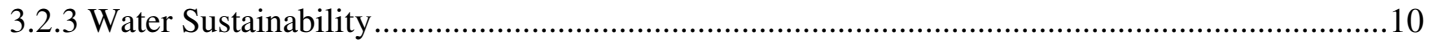

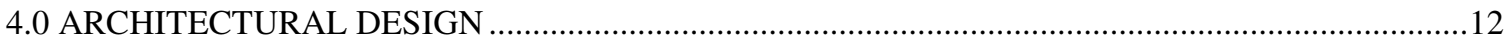

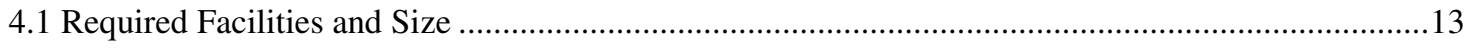

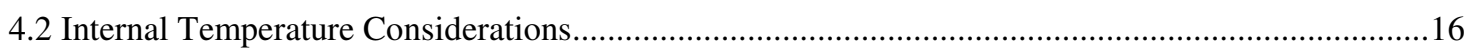

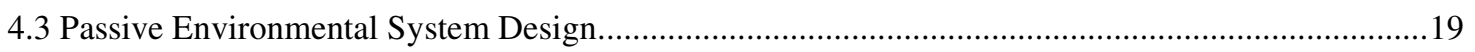

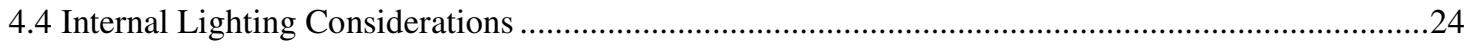

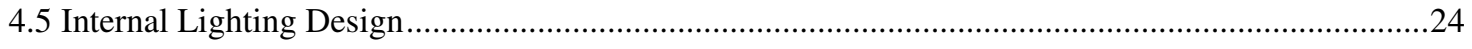

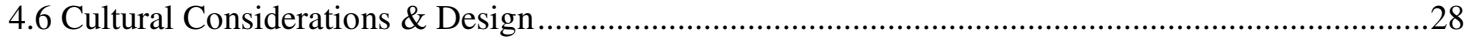

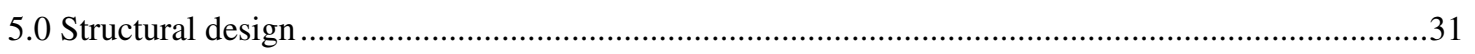

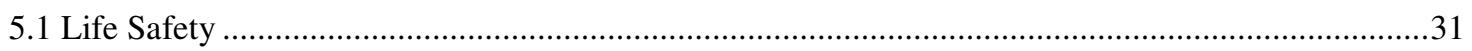

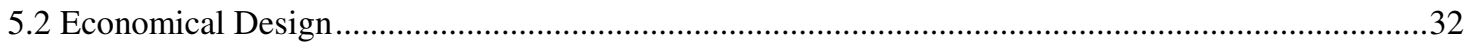

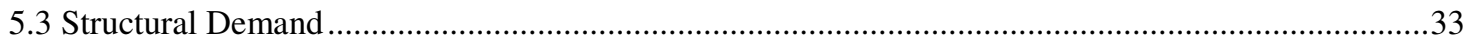

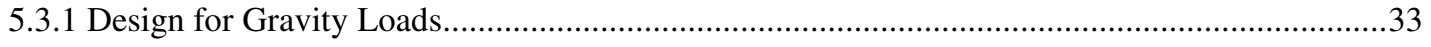

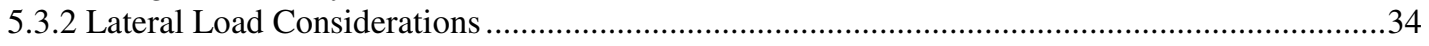

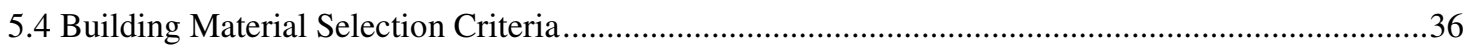

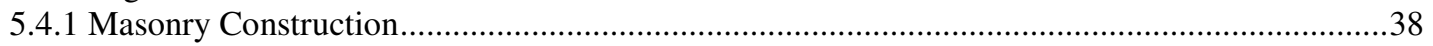

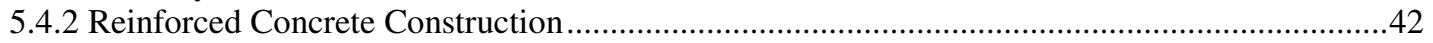

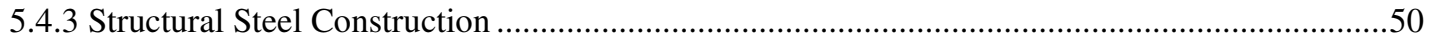

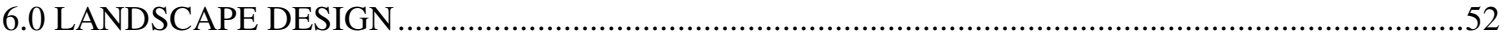

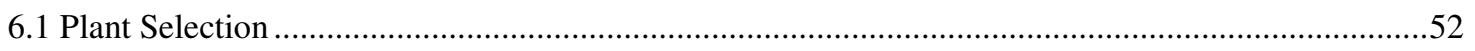

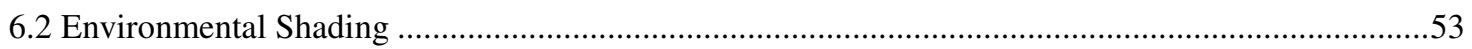




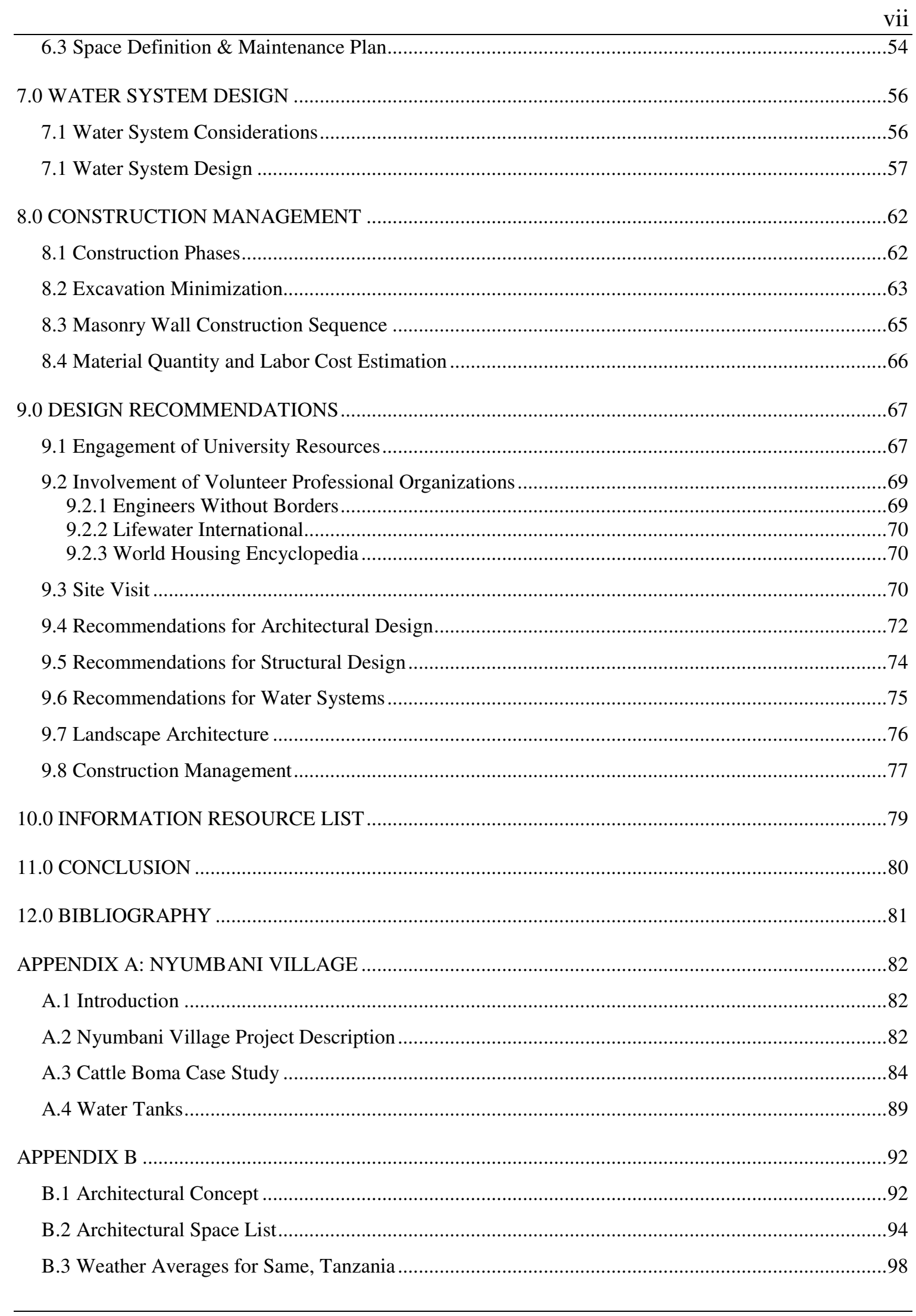


APPENDIX C: MATERIALS PRICE LIST ………….......................................................................... 99

C.1 Prices Quoted by Five Star Hardware, Moshi, TZ ......................................................................99

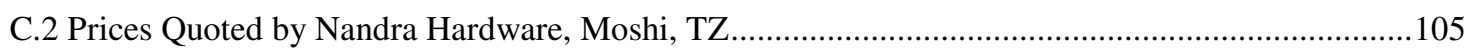

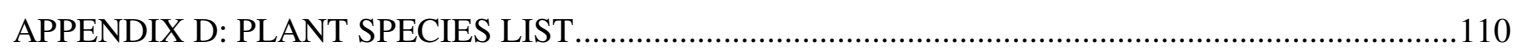




\section{LIST OF FIGURES}

Figure 2 a: Enlarged map of sub-Saharan Africa identifying location of the United Republic of Tanzania.......

Figure 2 b: : Map of Tanzania showing regional borders with the Kilimanjaro Region highlighted in red.

Figure 2 c: : Map of Kilimanjaro Region showing district borders with the District of Same highlighted in red.

Figure $2 \mathrm{~d}$ : Enlarged map showing detailed project site location with topographic features ......................... 8

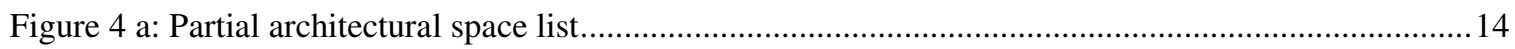

Figure 4 b: Classroom layout showing repetition of the same building plan ..............................................16

Figure $4 \mathrm{c}$ : Air vents placed in the wall of a church - Makanya, Tanzania.................................................19

Figure $4 \mathrm{~d}$ : Detail of ventilation provided by pre-manufactured hollow masonry units - Makanya,

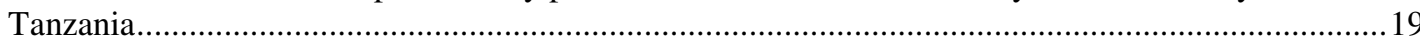

Figure 4 e: Elevation of typical building with double roof passive environmental control system...............20

Figure $4 \mathrm{f}$ : Diagram illustrating the mechanism for the double roof environmental system ........................21

Figure $4 \mathrm{~g}$ : Diagram illustrating the mechanism for providing natural air ventilation ....................................23

Figure $4 \mathrm{~h}$ : Diagram illustrating the mechanism for using natural daylight for interior lighting ..................26

Figure 4 i: Diagram showing the appropriate orientation of the building plan to the path of the sun ...........26

Figure 4 j: Illustration showing appropriate placement of windows in building walls..................................28

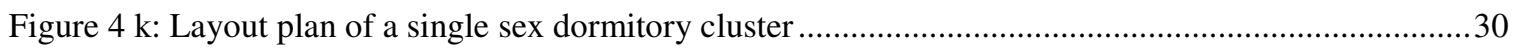

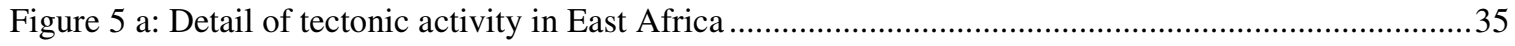

Figure 5 b: Seismic hazard map of northern Tanzania (USGS 2007) ...........................................................

Figure $5 \mathrm{c}$ : Clay bricks prepared for firing - Makanya, Tanzania...................................................................

Figure $5 \mathrm{~d}$ : Clay bricks in the process of firing - Makanya, Tanzania ........................................................39

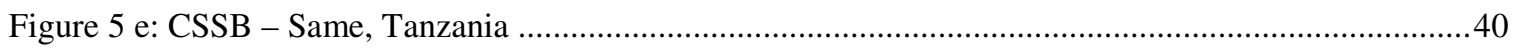

Figure $5 \mathrm{f}$ : Wet mix poured into brick press..........................................................................................

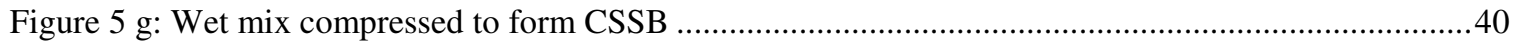

Figure 5 h: Fresh CSSB removed from press chamber and placed for curing .............................................40

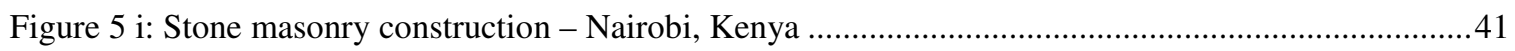

Figure $5 \mathrm{j}$ : Volcanic stone bricks prepared and ready for transport to construction site - Moshi, Tanzania.

Figure $5 \mathrm{k}$ : Partial building collapse due to saturation of adobe masonry - Same, Tanzania........................42

Figure 5 1: Steel reinforcing bars for sale - Same, Tanzania ................................................................... 44

Figure $5 \mathrm{~m}$ : Illustration of reinforced concrete columns and bond beam structural system ...........................44 
Figure 5 n: Side view illustration of a reinforced concrete column embedded in an unreinforced masonry wall.

Figure 5 o: Detail illustration of a reinforced concrete bond beam connected to a reinforced concrete column and resting on top of an unreinforced masonry wall...........................................45

Figure 5 p: Section view of a typical masonry wall with steel wire mesh reinforcement ..........................46

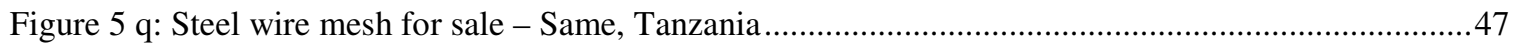

Figure $5 \mathrm{r}$ : Spawling of plaster off of an unreinforced adobe masonry building - Same, Tanzania ............47

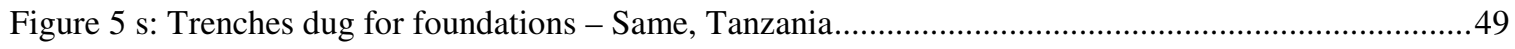

Figure 5 t: Foundation trenches filled with reinforced concrete spread footings - Nyumbani

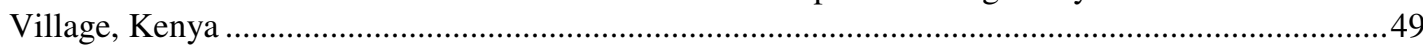

Figure $5 \mathrm{u}$ : Foundation prepared with coarse stone - Same, Tanzania ..............................................49

Figure $5 \mathrm{v}$ : Foundation prepared with stone and compacted murram - Nyumbani Village, Kenya............49

Figure 5 w: Welded steel trusses prepared for construction - Nyumbani Village, Kenya ........................51

Figure 5 x: Structural welding during construction - Nyumbani Village, Kenya ..................................51

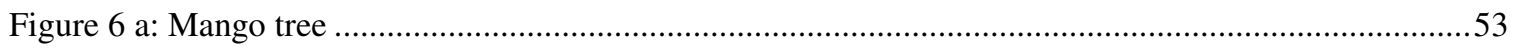

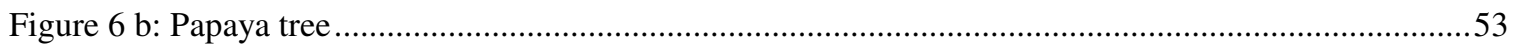

Figure 6 c: Shaded outdoor dining area - Elephant Motel, Same, Tanzania ..........................................54

Figure 6 d: Shaded outdoor area - Nyumbani Village, Kenya ......................................................54

Figure 6 e: Landscaping utilized to define footpaths - Nyumbani Village, Kenya................................55

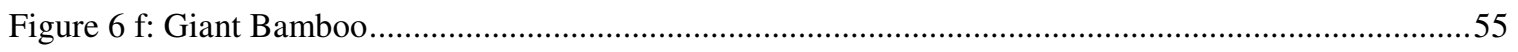

Figure 7 a: Simba Plastics plastic water tanks for sale - Same, Tanzania............................................57

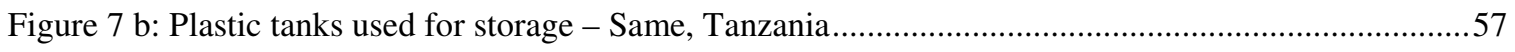

Figure 7 c: Plan view illustration of water system layout showing positioning and required distances between the different elements of the water system ................................................60

Figure $7 \mathrm{~d}$ : Side view diagram of septic tank and sand filter system ...............................................60

Figure 7 e: Rainwater collection gutter from building to water tank - Nyumbani Village, Kenya ..............61

Figure $7 \mathrm{f}$ : Water tank filled with water from rainwater collection - Nymbani Village, Kenya .................61

Figure 8 a: Illustration of increased excavation required to prepare site for buildings running into hill slope

Figure 8 b: Illustration of decreased excavation required to prepare site for buildings running along hill slope

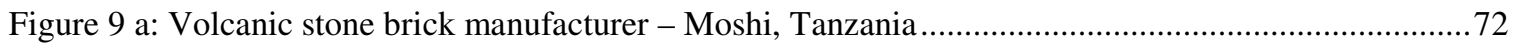

Figure 9 b: Experimental gypsum bricks - Makanya, Tanzania …...................................................72

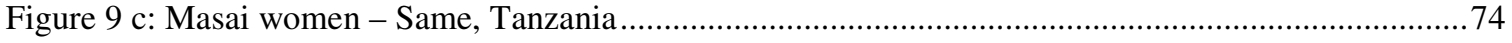

Figure $9 \mathrm{~d}$ : Severe cracking in the masonry of a newly constructed clinic - Makanya, Tanzania ...............78

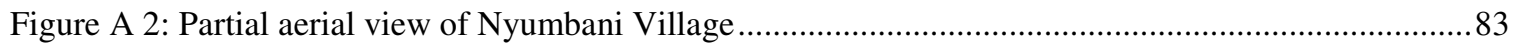

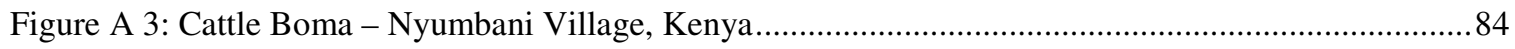


Figure A 4: Poorly mortared joints of the Cattle Boma masonry walls - Nyumbani Village, Kenya...........85

Figure A 5: Very dry mortar mixed in a pile on the ground in the morning and left exposed to the

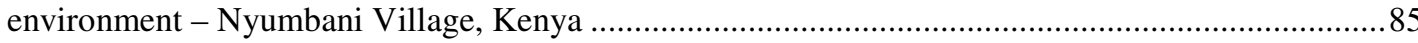

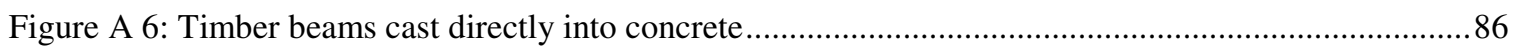

Figure A 7: Poorly assembled connection between timber beam and pole ............................................86

Figure A 8: Two pieces of timber spliced together to serve as a single beam supporting the second floor of the Cattle Boma - Nyumbani Village, Kenya.............................................................8. 87

Figure A 9: View of the second floor of the Cattle Boma and the unsupported timber columns ................87

Figure A 10: Eroded soil next to Cattle Boma foundations - Nyumbani Village, Kenya ..........................89

Figure A 11: One of the large water tanks with severe leaks seen in the walls - Nyumbani Village,

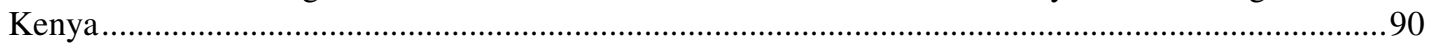

Figure A 12: Water tank repair work in process - Nyumbani Village, Kenya.......................................91

Figure A 13: Underground water tank - Nyumbani Village, Kenya ................................................91 


\subsection{PURPOSE}

\subsection{Overall Master's Project Purpose}

The purpose of this Master's project is to provide a focused set of recommendations and suggested guidelines for the design of buildings and other facilities in the arid and semi-arid regions of rural East Africa by using the actual project design of the Same (Sah-may) Polytechnic as an example. This report compiles a synopsis of the design considerations that significantly contributed to the design of the Same Polytechnic project and highlight the lessons learned from the process. The intent of this document is to serve as a reference resource for groups and organizations in the design and construction of buildings and other facilities required to support development efforts.

Many non-profit organizations support projects that try to improve the social and civil status of the population majority in East Africa. In many cases, these projects require the construction of facilities or buildings (i.e. schools, clinics). However, the personnel and financial supporters of these organizations usually have limited or no construction experience, as their expertise is focused on the services their projects intend to provide (i.e. medical care, child care, education), and they have limited financial resources to hire professional consultants. This leads to many groups encountering difficulties and setbacks during the design and construction process.

The challenges of construction for non-profit organizations in East Africa are amplified by the unique conditions for construction in the arid and semi-arid regions of rural East Africa. Locally manufactured building materials are inconsistent in quality and availability and conventional building material costs are inflated. There is no established 
system to regulate the quality of the work completed by building contractors nor are building codes enforced. It is common for buildings to be designed by local workmen who usually do not have practical background or education in building design. The workforce in rural areas does have substantial training in the execution of building trades but often lacks a solid grip on the principles of construction that ensure structural safety. These conditions often lead to inflated construction costs from inefficient use of materials, additional costs for repairs and sometimes a complete loss of the initial construction capital when the completed facilities are inadequate, unusable or unsafe.

Knowledge gained from past experiences on other projects in the region will be applied to the design process of the Same Polytechnic. The recommendations and guidelines provided in this report constitutes an inclusive summary of the challenges anticipated and encountered during the planning and design phase of the project, how they were addressed, and what information was considered when selecting the best course of action. The ultimate goal of this report is to serve as a resource for future projects by providing a list of considerations for use by non-governmental organizations operating in the East African region.

\subsection{Interdisciplinary Design Team}

The task of designing the Same Polytechnic was charged to an interdisciplinary team of students from the College of Architecture and Environmental Design at California Polytechnic State University, San Luis Obispo. The student team offered a focused and available work force that incurred no additional cost to the Same Polytechnic's developers. The students represented the degree programs of Architecture, 
Architectural Engineering, Construction Management, City and Regional Planning, and Landscape Architecture. All the disciplines were advised by faculty members during the design process.

After an initial site visit to Same, Tanzania by the design team leader, the whole team assembled to identify the goals and challenges each of the different disciplines needed to address in the design. Constant communication and open dialogue was required within the team because the design decisions of one discipline affected those of the others. The overall design team was organized into smaller sub-teams based on design discipline. Each discipline team researched information relevant to their field which was then used to develop initial designs that provided the basic physical form and appearance of the buildings. The initial building designs were mainly the priority of the Architecture team but were constantly reviewed by the other teams to ensure all the considerations were being addressed. Once the conceptual designs were agreed upon, the final design process began with the different teams working out the details of the design based on information obtained from the site visit and research that addressed the goals of the Same Polytechnic's developers. The final design produced building plans and drawings that graphically explain what was to be constructed.

\subsection{Scope of Work}

The scope of work of this report is the identification of major planning and design issues for the Same Polytechnic, and how a student led interdisciplinary team accomplished the design. The integration and coordination of multiple disciplines 
required to achieve a comprehensive design is also illustrated in the summary.

Discussion of topics regarding design considerations is narrowed to the disciplines of:

- Architecture

- Structural Engineering

- Landscape Architecture

- Water Systems

- Construction

Several important areas of the design process are covered in this document. The first is how the implementation of sustainable elements (i.e. passive environmental regulation systems) influenced the architectural form of the Same Polytechnic's facilities. Secondly, the issues pertaining to the identification, selection, and use of available building materials is addressed. It is very important to know what building materials are available when considering the structural design, safety and durability of the building. Additionally, the topic of building material selection has significant impact on the cost and constructability of the project, the third area of primary interest. The issue of constructability affects the feasibility of the project, which in turn is affected not only by the chosen materials but also the skill level of the local work force. Significant consideration was given to the abilities of the workforce as this variable has an impact on the structural and architectural designs. 


\subsection{BACKGROUND}

\subsection{Regional Description}

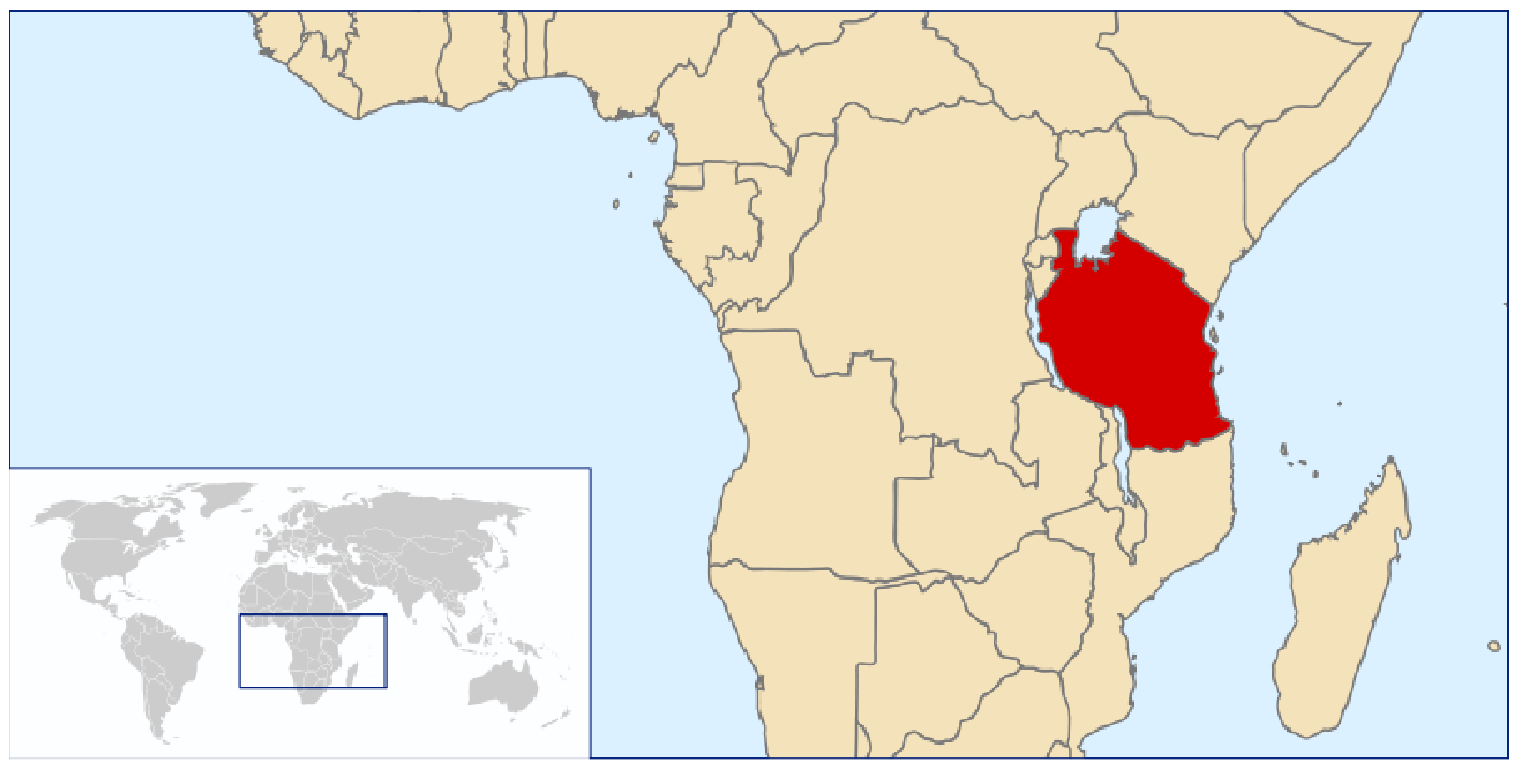

Figure 2 a: Enlarged map of sub-Saharan Africa identifying location of the United Republic of Tanzania

The United Republic of Tanzania is located in East Africa and is bordered by Kenya and Uganda to the north, Rwanda, Burundi and the Democratic Republic of the Congo to the west, Zambia, Malawi and Mozambique to the south with the Indian Ocean to the east (see Figure 2 a). According to the Tanzania 2002 Population and Housing Census, the country is home to approximately 34.5 million with $80 \%$ of the population classified as rural. Tanzania has an annual per capita income of US \$320 (Tanzania Census 2002). Agriculture constitutes $46.4 \%$ of the US $\$ 12.1$ billion gross domestic product and $80 \%$ of the work force (U.S. State Dept. 2007). In contrast to the economy's heavy dependence on agriculture, due to topographic and climactic conditions, only $4 \%$ of the country's nearly 900,000 sq km is arable land. The climate varies from tropical on 
the coast to temperate and arid in the interior highlands with the common natural hazards of flooding and drought (CIA 2008).

\subsection{Project Site Location \& Description}

Tanzania is divided into 26 regions with the project site for the Same Polytechnic located in the northern region of Kilimanjaro (see Figure $2 \mathrm{~b}$ ). Within the region, the project site is situated in the district of Same, one of six which subdivide the region and is one of the least developed in the country in terms of civil infrastructure (see Figure $2 \mathrm{c}$ ).

The district itself has a population of approximately 212,000 (Tanzania Census 2002) and has seen a shift in agriculture away from the traditional cash crop of coffee to the sustenance food crops of maize and rice (Maghimbi 2007).

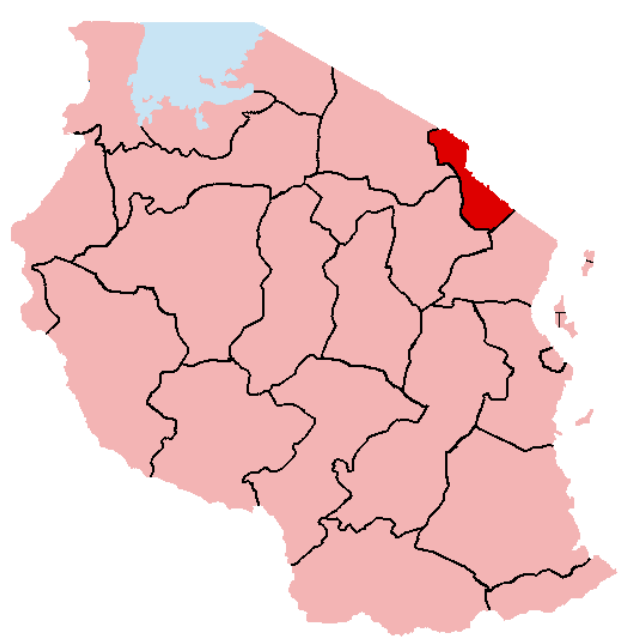

Figure 2 b: : Map of Tanzania showing regional borders with the Kilimanjaro Region highlighted in red

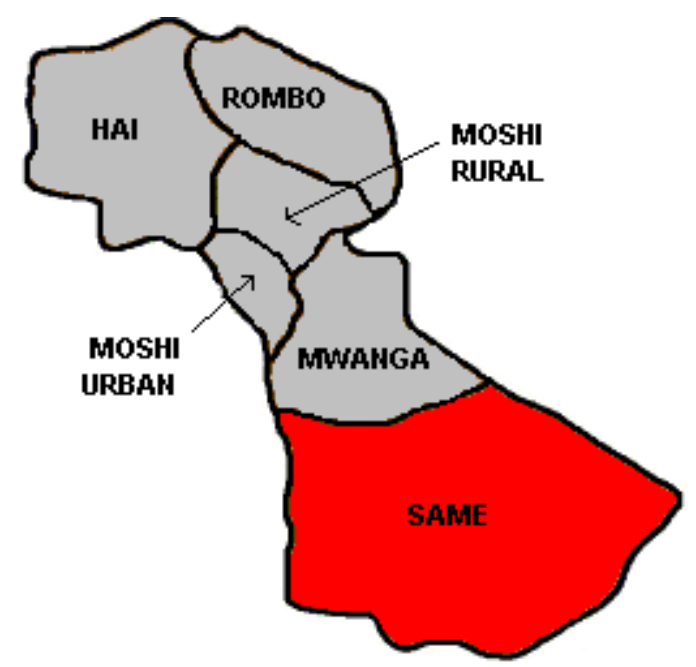

Figure 2 c: : Map of Kilimanjaro Region showing district borders with the District of Same highlighted in red 
The district also has access to the B1 highway, a major transportation route for the country which bisects the area and passes directly through the town of Same. The well maintained B1 highway runs from the regional capital of Moshi in the north to the city of Segera to the south and on to Dar es Salaam, Tanzania's largest city and economic center. The location of the project site in close proximity to the national road infrastructure offers the project excellent access to transportation and material goods which are not readily available within the region.

The site for the Polytechnic is approximately 100 acres in size and is situated just $5 \mathrm{~km}$ to the north of Same Town. With the B1 highway serving as one boundary line for the campus and offering direct road access, the opposite side of the site is bordered by the existing Vumari Forest Preserve which serves as a natural boundary continuing up into the South Pare (Pah-ray) Mountains. Running along a similar route to the B1 highway is the main power line leading into Same Town offering the site easy access to the established power grid (see Figure $2 \mathrm{~d}$ ). 


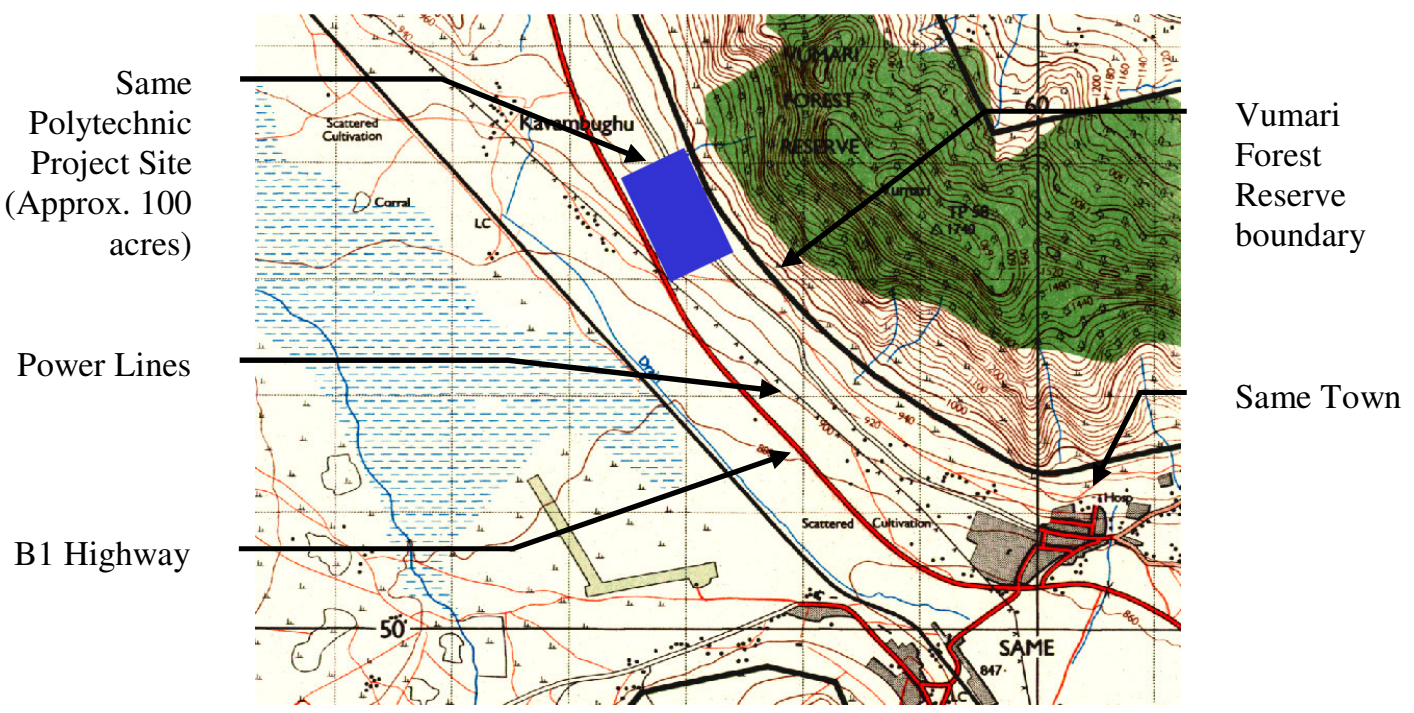

Figure 2 d: Enlarged map showing detailed project site location with topographic features

\subsection{SAME POLYTECHNIC PROJECT DESCRIPTION}

\subsection{Project Primary Goals}

The Same Polytechnic is a project proposed by the Catholic Diocese of Same.

The purpose of the Polytechnic is to provide vocational training for 250 and 500 students who have graduated from Tanzania's public secondary school system. Recent efforts by the Tanzanian government to improve the population's education level have included a mandate which requires all students to graduate from secondary school. Some students will continue on to the university level but a majority will not and will need to enter the work force, thus the impending need for a vocational school.

The primary and secondary school curriculums provide no training or programs for acquiring job skills which will limit opportunities and reduce the overall standard of living for the individuals not continuing on to a University. The Diocese's intent is to anticipate this need for vocational training by developing the school with the long term 
goal of dramatically increasing the skill level of the local workforce. It is hoped that the presence of a skilled work force will attract both federal and private group interest and which in turn may help attract funding for further social, civil, and economic development. Although the school will be administered by the Diocese, the Polytechnic will remain a secular institution and accept students regardless of religious background.

\subsection{Project Secondary Goals}

\subsubsection{Construction Standards}

In addition to providing vocational training, the Diocese has several secondary goals for the school. The first is for the actual school buildings, water systems and other facilities and infrastructure to serve as an example of improved construction methods and practices for the students and staff as well as the surrounding community. Due to the underdeveloped status and poor economic conditions in the area, much of the local population is left to build their own homes and places of business with most having little or no experience in construction. Compounded by the fact that the area does not enforce the country's building or safety codes, the district sees a high rate of building failures in a variety of forms. It is the Diocese's hope that the local population will use the faculty of the Same Polytechnic as a resource and view the facilities as prime examples for how to construct homes and other buildings.

\subsubsection{Energy Sustainability}

An additional goal of the Polytechnic pertains to sustainability. Energy utilities are very expensive in the region. Access to electricity is readily available but reliance on the power grid will incur regular expenses that will increase the operating costs of the 
school making it less financially sustainable for the Diocese. To reduce the amount of electricity required by the school facilities, the use of artificial lighting and electrically powered environmental control systems will be reduced. Solar panels to produce electricity are available but require a large amount of initial capital. This makes them unavailable to the local population and the Diocese would also like the systems used to reduce electrical consumption to be affordable to the local rural population.

\subsubsection{Water Sustainability}

Additionally, a very limited infrastructure for the distribution of water exists in the area. Only one pipeline supplies clean drinking water to the town of Same with one community access point. The water is collected using plastic containers by the local population and then transported to residences usually by bicycle. This method of providing clean drinking water is not feasible for operating the Polytechnic. Therefore, a borehole will need to be drilled in order to provide an adequate supply of drinking water to the school occupants. The borehole will require a pump system capable of providing a constant supply of water to the school. This means that a mechanical pump is required in order to provide the necessary volume of water.

Mechanical pumps are powered by electricity from either fuel consuming generators, the power grid, or expensive solar panels. Either option would bring additional costs so limiting the amount of water required to be pumped will help reduce operating costs. For this reason, the amount of water pumped from the borehole will be limited to that necessary for human consumption. To provide a water supply for other applications such as irrigation, laundry and other grey and black water uses, a rain water 
collection system will be designed for the site. The system will collect the rain water that falls on the school buildings and store it for the noted uses between rain seasons. 


\subsection{ARCHITECTURAL DESIGN}

The architectural considerations had the greatest influence on the physical size and appearance in the design of the Same Polytechnic's facilities. These considerations were based on the primary and secondary goals of the project. The architectural design of the Polytechnic provides all the necessary types of facilities such as residential, educational, administrative, and recreational, with enough programmed space to accommodate the faculty and students for the school to operate properly. At the same time, constant attention was given to the cost of construction of the final design. The Polytechnic design met the set goals while being cost efficient, which will enable the Diocese to fund the project.

In addition to meeting size and budget goals, the architectural design achieved the secondary project goals of environmental and financial sustainability. The considerations that contributed towards this success pertained to the internal temperature and lighting of the buildings. In more developed regions, modern buildings have air conditioning and heating systems and artificial lighting which require electricity. Use of electrical power incurs a regular cost and its generation can produce pollutants into the environment. Reducing or eliminating the Polytechnic's dependency on electrical power reduced the school's regular operating expenses and the adverse impact on the East African environment. 


\subsection{Required Facilities and Size}

The initial step in the architectural design process was developing a list of facilities required to support the various school functions and to provide the necessary accommodations for the student body. It is common in East Africa for students to leave home to continue their education after primary school. Therefore, the school needs to have residence and dining facilities in addition to classrooms and administration buildings.

Once this list was compiled by evaluating case studies of existing technical colleges in Tanzania, a required size was established for each building category. The size was determined from the requirements of the specific task the particular building needed to support and the number of individuals intended to use the building. This expanded list of buildings and corresponding sizes in terms of square footage was referred to as a space list (see Figure 4 a for a partial list \& Appendix B for the complete list). In addition to the students and faculty of the Polytechnic, the size of some buildings needed to have enough capacity to include the presence of the surrounding community. The Diocese expressed the intent for the Polytechnic to have open ties with the local population. The communal buildings of the Polytechnic were designed to consider a greater number of occupants beyond the 500 students at a single time in order to accommodate this intent. 


\begin{tabular}{|l|l|l|l|l|l|l|}
\hline Architectural Space List & & & & & & \\
\hline Project Name: Same Polytechnic & & & & & & \\
\hline \\
\hline
\end{tabular}

Figure 4 a: Partial architectural space list

A lack of information is to be expected when working in rural areas of under developed countries. This lack of information will lead to assumptions being made in order to progress. The main assumption made was with regard to the total number of students the Same Polytechnic would house. The Diocese gave an initial range of 250 to 500 students for the final capacity but was unclear as to when a decision would be made. The upper bound number of 500 students was selected for design purposes to ensure that the design could support any number given within the initial range. However, the larger student population resulted in larger facilities that require more initial capital to construct. This required the Diocese to raise more funding for the project which could have delayed the project. To prevent unnecessary construction delays, the Polytechnic's facilities are designed to be built in phases. Each phase includes all the necessary buildings to operate the school such that the Diocese was able to build what it could afford and have the 
school open. The alternative would have resulted in those buildings constructed first sitting idle until all the buildings were finished before the school could open. The phased design led to a repeatable and modular design of the Polytechnic's buildings. By this method, several buildings served the same purpose with their combined capacity meeting the size required of that type of building by the current number of students (see Figure 4 b). For example, instead of designing one dormitory building to house all 500 students, 7 dormitories were designed. Each dormitory unit had the same architectural plans and could house 72 students. If the Diocese can only afford to construct the number of facilities to support 200 students, they are not bound to a larger financial commitment, only those buildings required to house, instruct, and administer 200 students, faculty, and staff. This method is a common practice for large capacity projects. 

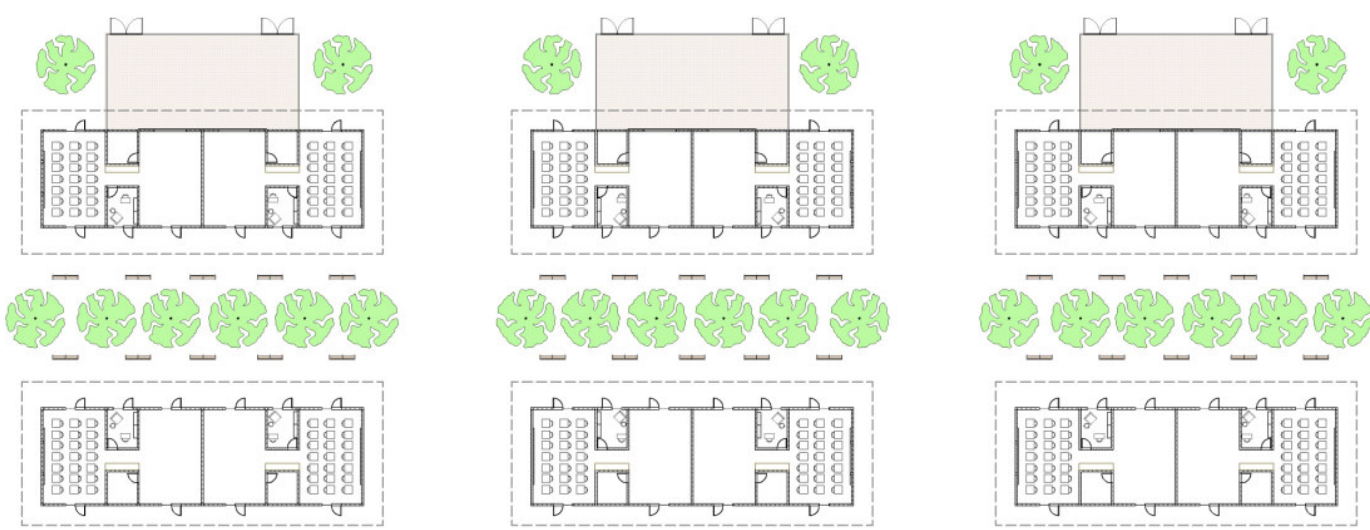

Figure 4 b: Classroom layout showing repetition of the same building plan

\subsection{Internal Temperature Considerations}

Room temperature control is particularly challenging for the design of the Same Polytechnic due to the extreme environmental conditions present in East Africa. Because of these extreme conditions, the environmental control systems for the project's buildings were considered in the early stages of architectural design.

Modern environmental control systems can be categorized into two groups, passive and active. Active systems use mechanical devices to regulate temperature, humidity, and air flow in a building. Typical systems include air conditioners, swamp coolers and fans. They are mounted on or near buildings and are operated by electrical power. Passive systems work through the shape and materials of the building regulating the amount of solar radiation that enters the building's interior space and regulating air movement. Buildings in colder climates are designed as solar collectors, capturing solar radiation through windows to raise the interior temperature by using the greenhouse 
effect. Buildings in hot climates reflect solar radiation to keep temperatures cool inside during the day. Heat can also be absorbed into the building walls and roof during the day which can heat a building interior if cooler temperatures are experienced at night. This heat absorption system requires that building materials chosen have a significant thermal mass such as concrete and masonry.

A passive system was selected in the design of the Polytechnic for its use of solar energy and because it reduced electricity consumption. Additionally, the system was good for the Polytechnic due to the project's location in East Africa which is positioned on the equator, exposing the region to a large amount of solar energy.

The District of Same sees narrow variations in temperature throughout the year. Average monthly highs range from $78^{\circ} \mathrm{F}$ to $91^{\circ} \mathrm{F}$ and average monthly lows from $60^{\circ} \mathrm{F}$ to $66^{\circ} \mathrm{F}$ (see Appendix B, Table B.3). The target temperature range for human comfort is $68^{\circ} \mathrm{F}$ to $75^{\circ} \mathrm{F}$ (Pohl 2007). Therefore, moderate cooling during the hot and dry months and minimal heating during the cooler months was required. This required regulation of temperatures was well within the capabilities of passive environmental control systems.

Humidity was also a concern for internal comfort. Relative humidity in the region ranges from $57 \%$ during the dry months to $77 \%$ during the rainy season (see Appendix B, Table B.3). The higher level of relative humidity mandated that it was necessary to provide ventilation during the warmer and wetter months. Air movement assists the body's cooling mechanism by accelerating the rate of evaporation of perspiration from the skin which is important for comfort in humid environments. The design of the 
buildings considered ways to achieve air movement naturally through appropriately placed openings.

Some buildings in East Africa have rudimentary forms of ventilation systems (see Figure $4 \mathrm{c}$ ). However, standard construction in the region allows too much heat and humidity to enter a building. The common corrugated metal roof systems are excellent conductors of heat and transmit much of the solar radiation striking the roof into the building which is not advantageous in East Africa. The heat energy is trapped within the building, elevating the internal temperature to the point of discomfort. The amount of heat energy transmitted and trapped internally usually proves too great for the common ventilation systems to exhaust and regulate the interior temperature. Therefore, a primary design consideration was to evaluate methods to reduce internal temperatures by incorporating ventilation systems and consider treating the metal roofs with a less conductive material. 


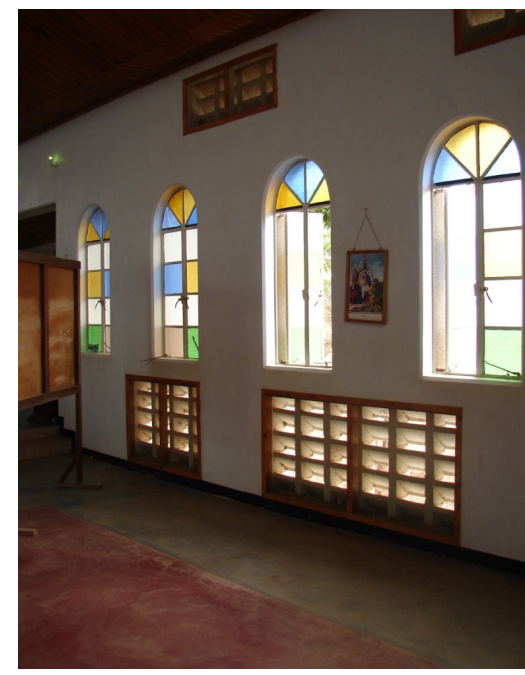

Figure 4 c: Air vents placed in the wall of a church - Makanya, Tanzania

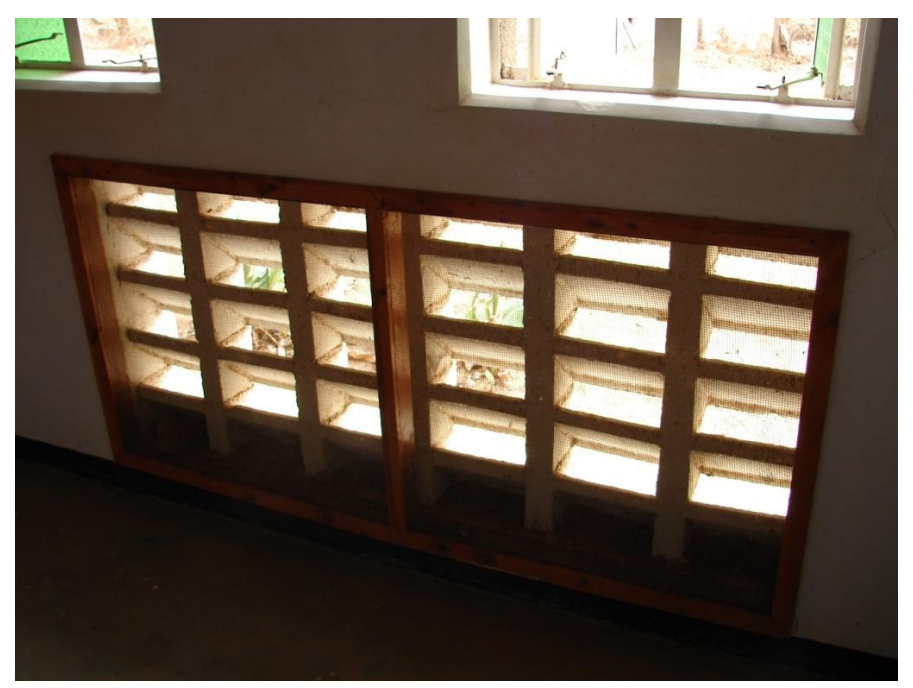

Figure $4 \mathrm{~d}$ : Detail of ventilation provided by pre-manufactured hollow masonry units - Makanya, Tanzania

\subsection{Passive Environmental System Design}

The main factor in the incorporation of a passive environmental system into the design of the Polytechnic's buildings was the need to keep as much direct solar radiation off of the building's surfaces. This condition was especially true for the building surfaces that had direct contact with the interior space (i.e. walls, roof) because of elevated solar radiation levels for buildings located near the equator and the unavailability of conventional insulation materials. Materials commonly employed in developed countries are not readily available and are very expensive, making them inapplicable for this project. The amount of solar radiation penetrating the Earth's atmosphere and reaching the surface is very high in East Africa from being situated on the equator. To reduce solar radiation effects on the internal temperatures of the Polytechnic's buildings, a double roof system was chosen (see Figure 4 e). 


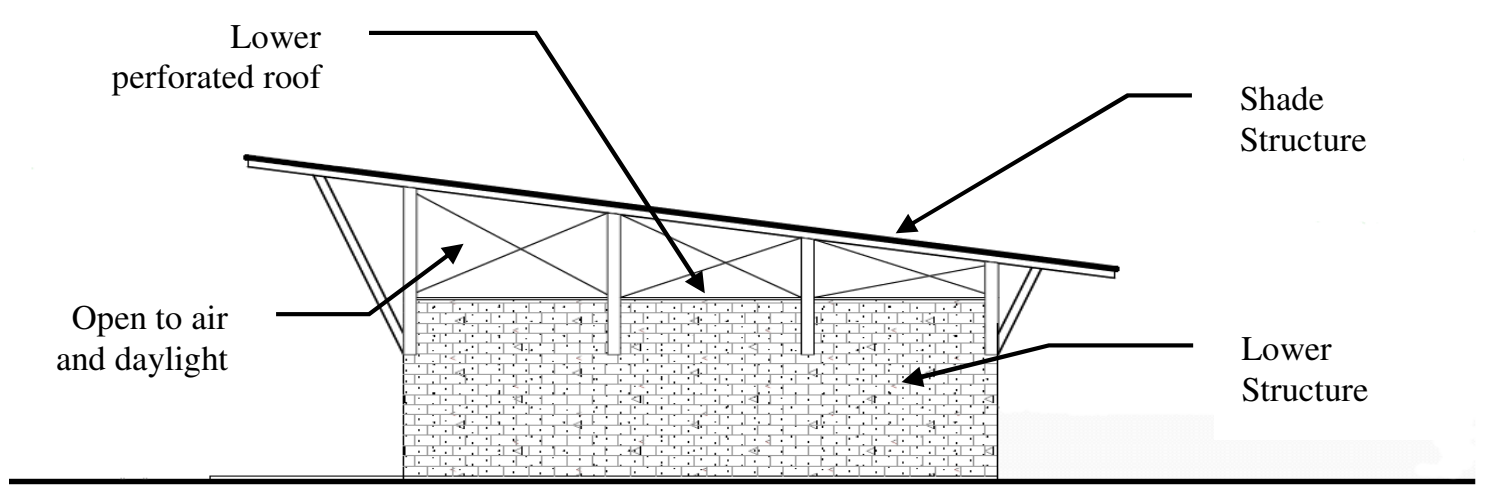

Figure 4 e: Elevation of typical building with double roof passive environmental control system

The overhanging roof was designed to keep as much solar radiation away from the internal space as possible. This outer roof effectively shaded the structure underneath from the effects of the sun by reflecting a portion of the solar radiation away from the building. The design of this system was still limited to the use of corrugated metal for the outer roof meaning that some of the solar heat energy would still be transmitted through the roof into the structure below (see Figure $4 \mathrm{f}$ ). To minimize the effects of the heat passing through, sufficient space and openings were provided between the outer shade structure and the main building to permit natural air movement which disperses the heat. Adding low heat conducting material to the roof was considered but the additional weight from the available materials resulted in additional demand on the structural system of the buildings increasing the danger to those inside should a structural failure of the roof occur. The addition of material to the roof was not selected for this reason. 


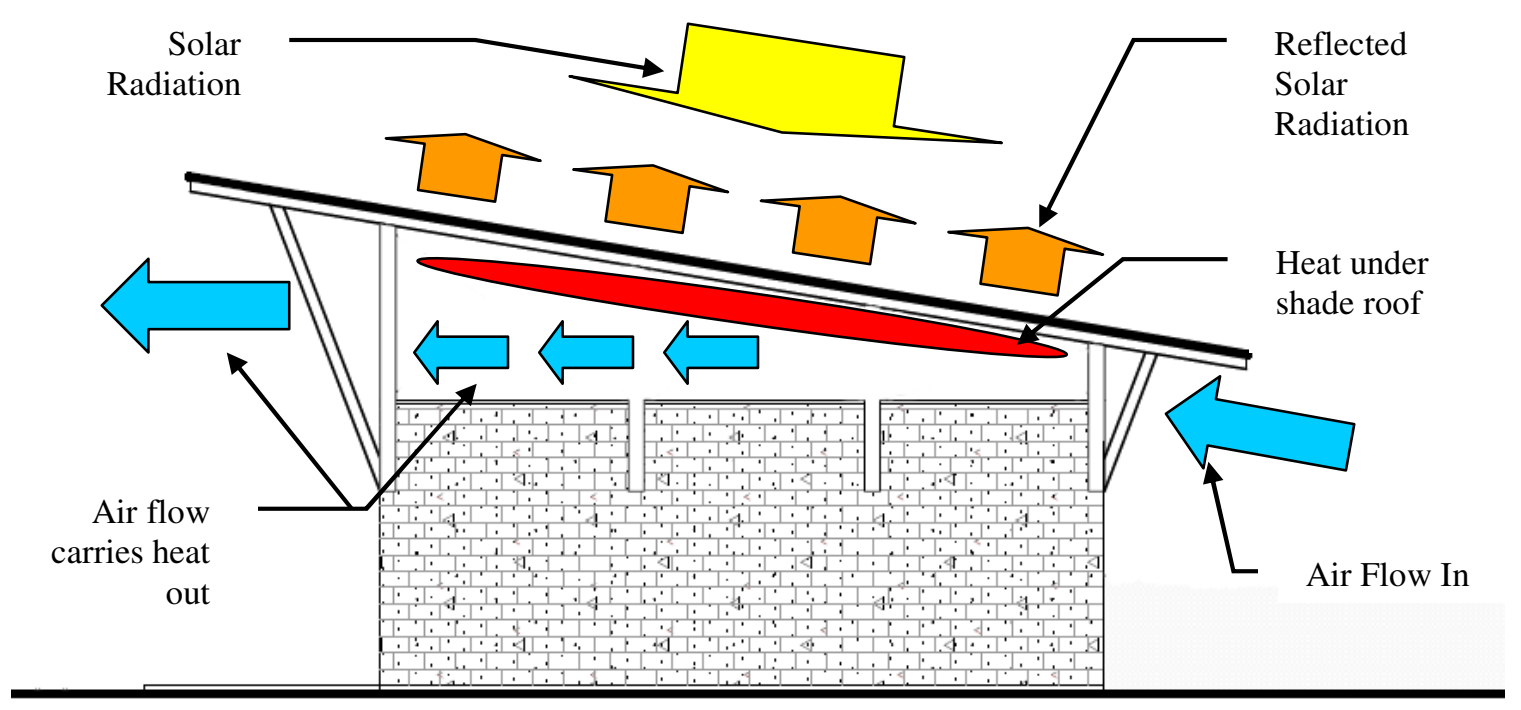

Figure $4 \mathrm{f}$ : Diagram illustrating the mechanism for the double roof environmental system

The shade structures were designed to be large enough to protect the inner building envelopes from the sun when the solar radiation levels are at their highest during the middle of the day and early afternoon. It was not reasonable to design the shade structures to block the solar radiation from the East and West when the sun is lower in the sky during the morning and evening. The structures would have become larger in order to shade every wall at all times of the day leading to more materials and cost. Therefore, the East and West facing walls of the lower structure will be built with dense materials. The increased density means that the walls can absorb a great amount of heat energy from direct sun light without increasing the internal temperature of the building. Since the East and West walls will not see direct sunlight during the middle of the day, this system is adequate and more cost efficient than extending the shade structures to shield the walls. However, because the East and West walls will be exposed to the direct sun in 
the morning and afternoon, they could not have large openings for windows. Direct sunlight entering the buildings from these exposures would have rapidly increased internal temperatures through the greenhouse effect and produced a significant amount of glare in the building.

The standard construction practices in the region provided several dense material options for use in the construction of the Polytechnic. Much of the buildings in the area are constructed using masonry for its durability against wind and rain as well as detritus feeding insects (i.e. termites). Masonry units can be made from a variety of materials but are mostly made from a base of clay soil. The local workforce is skilled in the use of masonry to varying degrees. Based on observations of past construction projects, it was assumed that a reasonable level of quality could be expected with masonry construction. This made masonry the best choice for the primary building material used in the design of the Polytechnic, however, the structural engineering of the buildings needed to be considered before a final masonry material could be selected for the walls.

Natural air movement through the interior spaces of the buildings was achieved by appropriately positioning air inlets and outlets in the building envelope. These openings were placed with respect to the building's orientation to the naturally occurring wind patterns on the project site (see Figure $4 \mathrm{~g}$ ). The air inlets were positioned at low elevations in the building by using special pre-manufactured hollow masonry units available in the area (see Figure $4 \mathrm{~d}$ ). These inlets were placed under windows because the hollow masonry units had less strength than solid units. This required the hollow 
masonry units to support less weight above them and reduced the possibility of cracks forming or a partial wall failure from occurring.

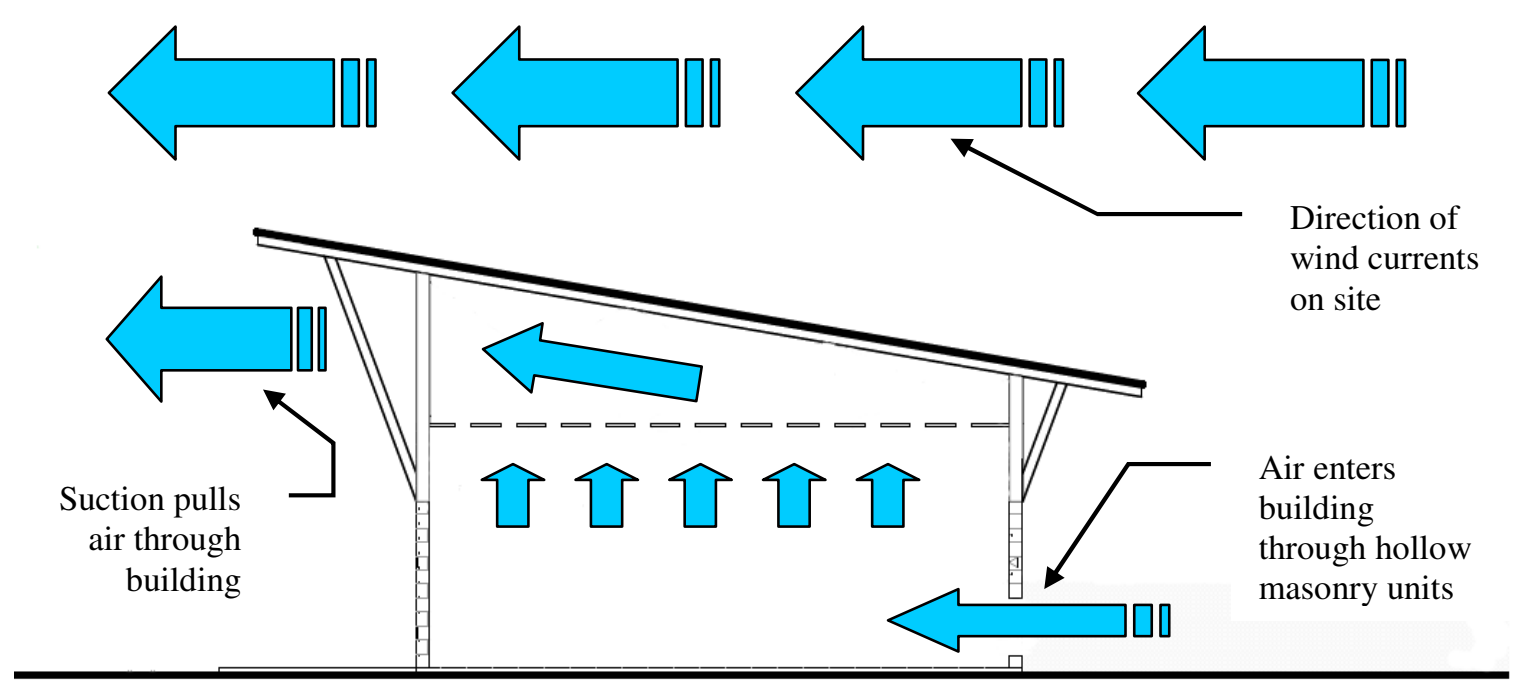

Figure 4 g: Diagram illustrating the mechanism for providing natural air ventilation

The outlets for air movement were placed higher up in the building envelope to draw air up and out of the building. This movement was driven by the outlets placement on the low pressure sides of the building. When air currents move over and around a building, high pressures form on the windward side and low pressures on the leeward side. The low pressure zones pull the air out of the interior of the building. As the air is pulled out of the building from the outlets at the top, air is pulled into the building from the inlets below creating natural air movement (see Figure $4 \mathrm{~g}$ ). All the openings are operable so that they can be shut during the cooler months when ventilation is not required. 


\subsection{Internal Lighting Considerations}

Providing adequate internal lighting was an essential concern for the design of the Polytechnic's buildings. Many existing school buildings in the region rely on large windows for both lighting and ventilation. Electric lighting is too expensive for most schools to employ so they are limited to the use of natural daylight. Natural daylight is a viable method for illuminating interior spaces and is used with artificial electric light as a supplement. The large windows allow direct and indirect sunlight to enter the building which increases internal temperatures. Additionally, direct sunlight leads to a significant amount of glare. Human eyes register different levels of light and extreme differences in relative lighting levels is called glare which can lead to discomfort and impair sight.

Glare is amplified by dark surfaces in the interior of buildings which is typically the case for buildings in East Africa. These dark surfaces also limit the reflection of light throughout the space which then requires more light to adequately illuminate the entire building.

\subsection{Internal Lighting Design}

The internal lighting system was designed in accordance with the Diocese's goal for the buildings of the Polytechnic to serve as an example of improved building standards. Since the local population is limited in the use of electricity, the Polytechnic utilizes natural daylight for the majority of the interior lighting during the daytime hours. The limited use of electricity will also reduce the Polytechnic's operational costs and reduce the school's impact on the environment. The design task of utilizing daylight was 
assisted by the high levels of daylight East Africa experiences throughout the year. Even during the rainy seasons cloud cover blocks the sun only intermittently during the day.

Direct sunlight is not used in natural daylight systems because it may cause unwanted heat gains and glare. The sun is the primary source of daylight but the Earth's atmosphere diffuses its light resulting in the whole sky serving as a secondary source of light (Pohl 2007). This diffused light is what is referred to as daylight. The intent of natural daylight systems is to permit as much daylight into the building without letting direct sunlight to enter as well. This is achieved by positioning openings in the Polytechnic's buildings with respect to the individual building's orientation to the path of the sun across the sky.

The variable height of the sun in the sky was also considered in designing for lighting. As the Earth swivels on its axis throughout the year, the apparent height of the sun changes in the sky. With the Polytechnic located just south of the equator, the sun is almost directly overhead from March to September and then lowers slightly to the north from October to February. This meant that the design of the buildings did not have to address the condition of the sun being at a low angle for much of the year and that the shade structures protected much of the upper building surfaces from the sun throughout the year. 


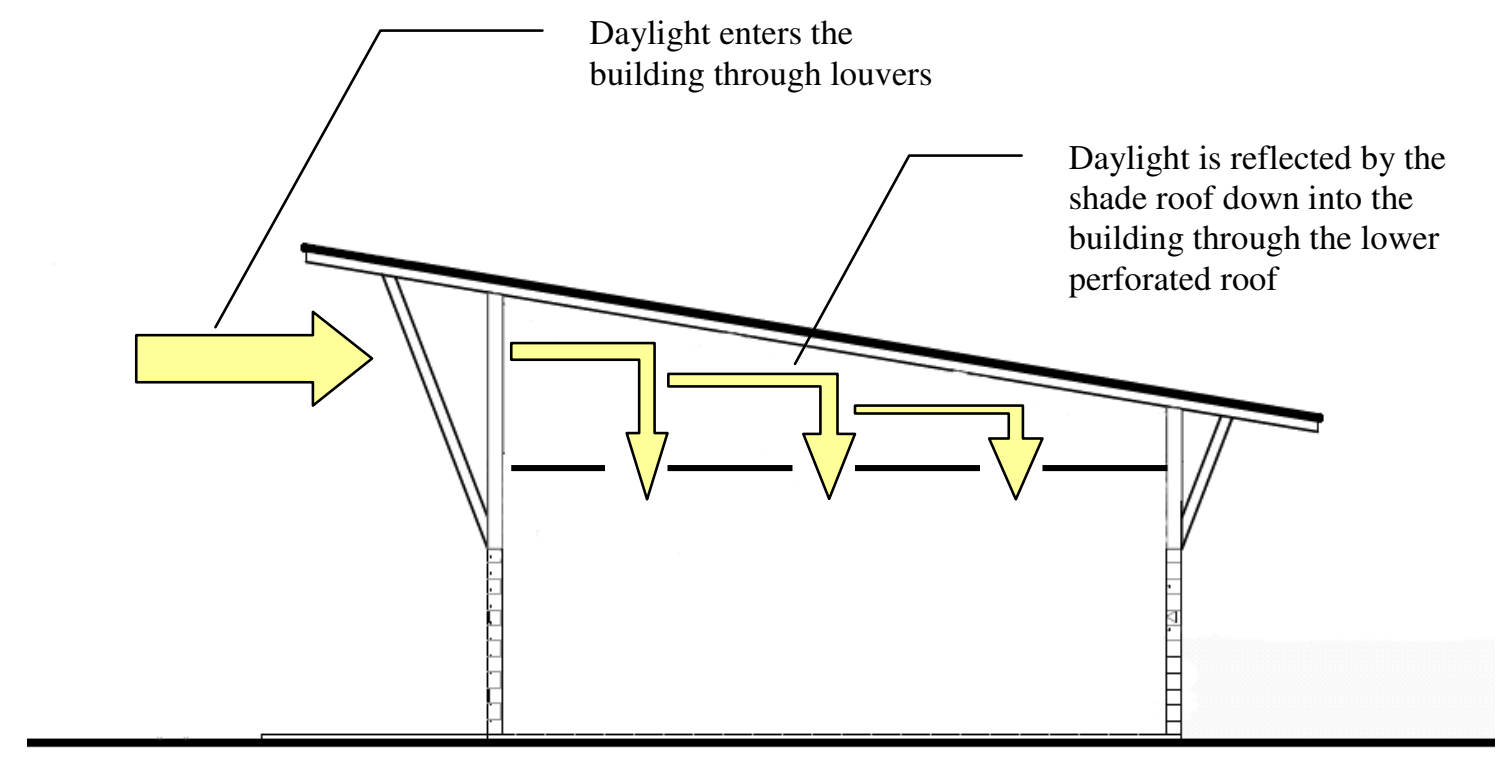

Figure 4 h: Diagram illustrating the mechanism for using natural daylight for interior lighting
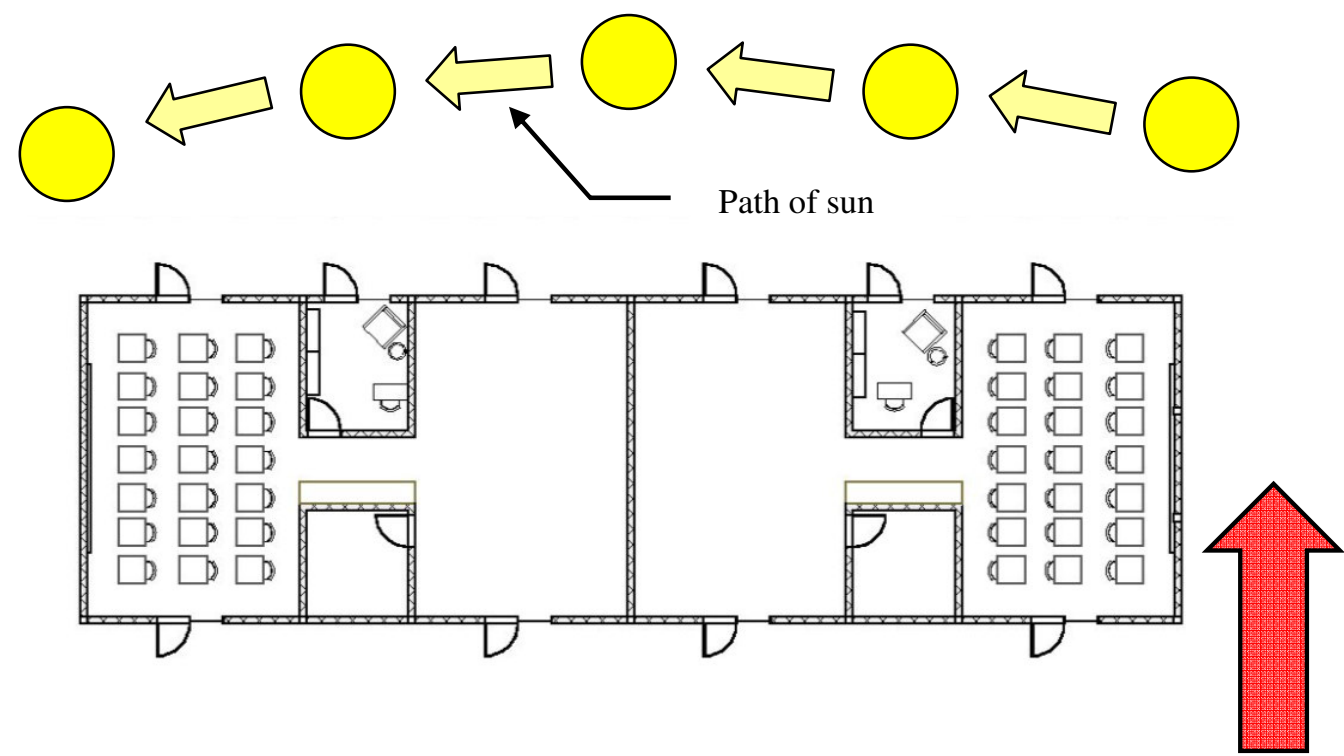

NORTH

Figure 4 i: Diagram showing the appropriate orientation of the building plan to the path of the sun 
The design of the Polytechnic's daylight system utilized the space between the higher side of the shade structure and the lower building to permit daylight to enter. This part of the building was well protected from direct sunlight due to its position directly below the shade structure. This location utilized the underside of the sloped shade structure, painted white, to reflect the daylight down into the building's interior (see Figure $4 \mathrm{~h}$ ). Horizontal louvers were installed at the openings to ensure that rain could not enter the building. To give this main opening under the high side of the shade structure better and more constant exposure to daylight, it was placed facing either South or North (see Figure 4 i). This arrangement gives more of the building's interior spaces direct exposure to daylight which results in less electric light required. Because the shade structure, combined with the louvers, provided enough protection to keep direct sunlight from entering the building, similar but smaller openings underneath the shade structure were placed on the East and West sides of the buildings. Windows were provided on the northern and southern exposures but were elevated to keep direct sunlight out that fell on the lower surfaces of the buildings (see Figure $4 \mathrm{j}$ ). The top of the windows ended directly underneath the structural bond beam (see Section 5.2) and extended down but did not go past the half-height point of the wall. 


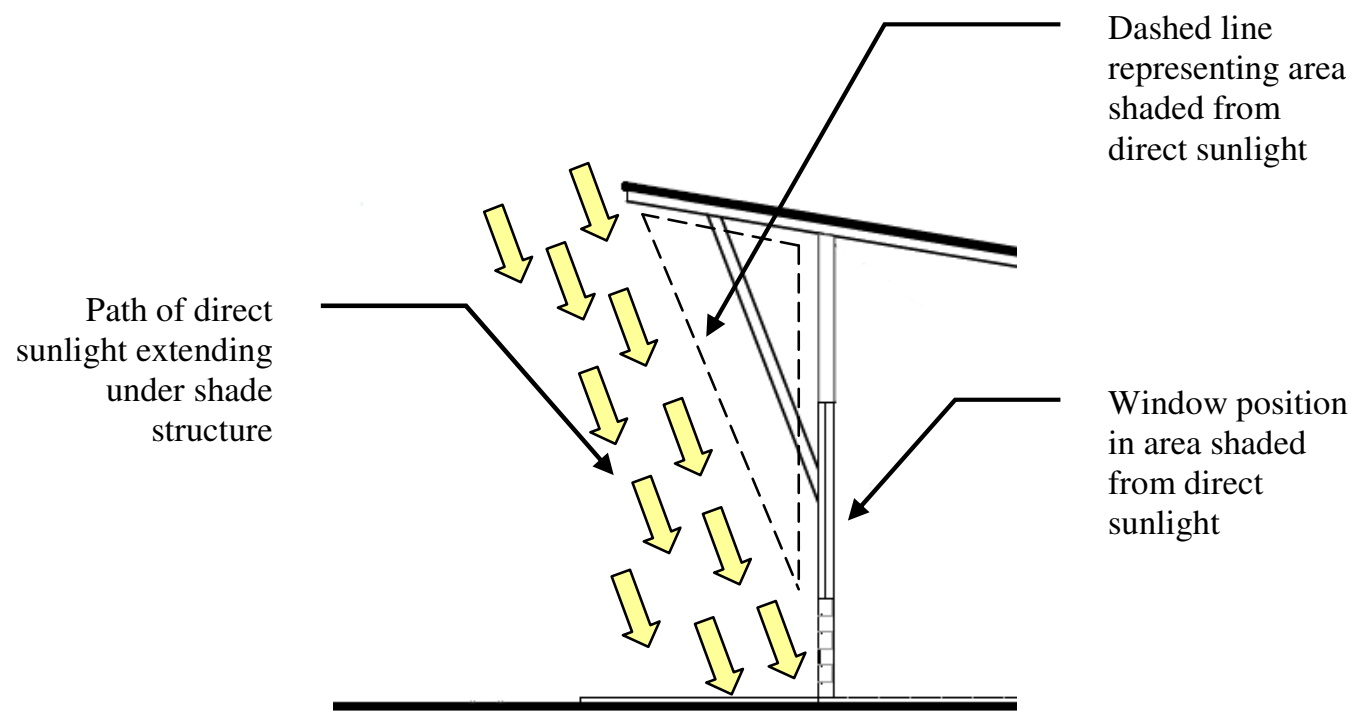

Figure 4 j: Illustration showing appropriate placement of windows in building walls

Electric light was provided in all the buildings to varying degrees based on the use of the buildings. The classroom and administration buildings see most of their use during the day so electric light was installed in limited locations. These limited locations included store rooms, closets and deeply recessed spaces in the buildings. The dormitories, kitchen $\&$ dining, and library will all have more electric lighting because greater use was expected during the evening and night.

\subsection{Cultural Considerations \& Design}

In addition to the functionality and desired performance of the Polytechnic's buildings with regards to internal environment and lighting; elements of the indigenous culture needed to be considered in design. A design that ignored the culture of the local population could expose the Polytechnic to adverse ramifications. These ramifications 
could include a resistance to attending the school by prospective students and a lack of support from the local community. This scenario would impede the success of the Polytechnic. Considering the local culture resulted in a design that produced a more comfortable social environment for the students. The issues that affected the design were identified through meetings with the Diocese and local tribal representatives.

The proximity of the living accommodations for male and female students in relation to one another is a cultural issue. While it is common for young men and women to attend the same educational institutions after graduating from secondary school, there are religious and cultural expectations of how the Polytechnic students should live in proximity to each other. Social intermingling is acceptable during the day, but gender separation is mandatory during the evening and night hours. Therefore, the student dormitories are segregated into single-sex clusters (see Figure $4 \mathrm{k}$ ) and positioned on the site with sufficient distance between them.

To provide a communal living environment for the resident students, the design of the dormitories incorporated an element common to family group living found in many different cultural groups in the East Africa region. Many family group compounds are arranged in a circular format with central facing entries. This was done to provide the family and their livestock safety from predators during the night. This centralized, inward design was adopted in the design of the individual dormitory modules. Each module is laid out in a rectangular cluster with the entrances to the individual student rooms opening to an inner courtyard (see Figure $4 \mathrm{k}$ ). The courtyard also contains a central study and social building for the students to gather in outside of their rooms. 

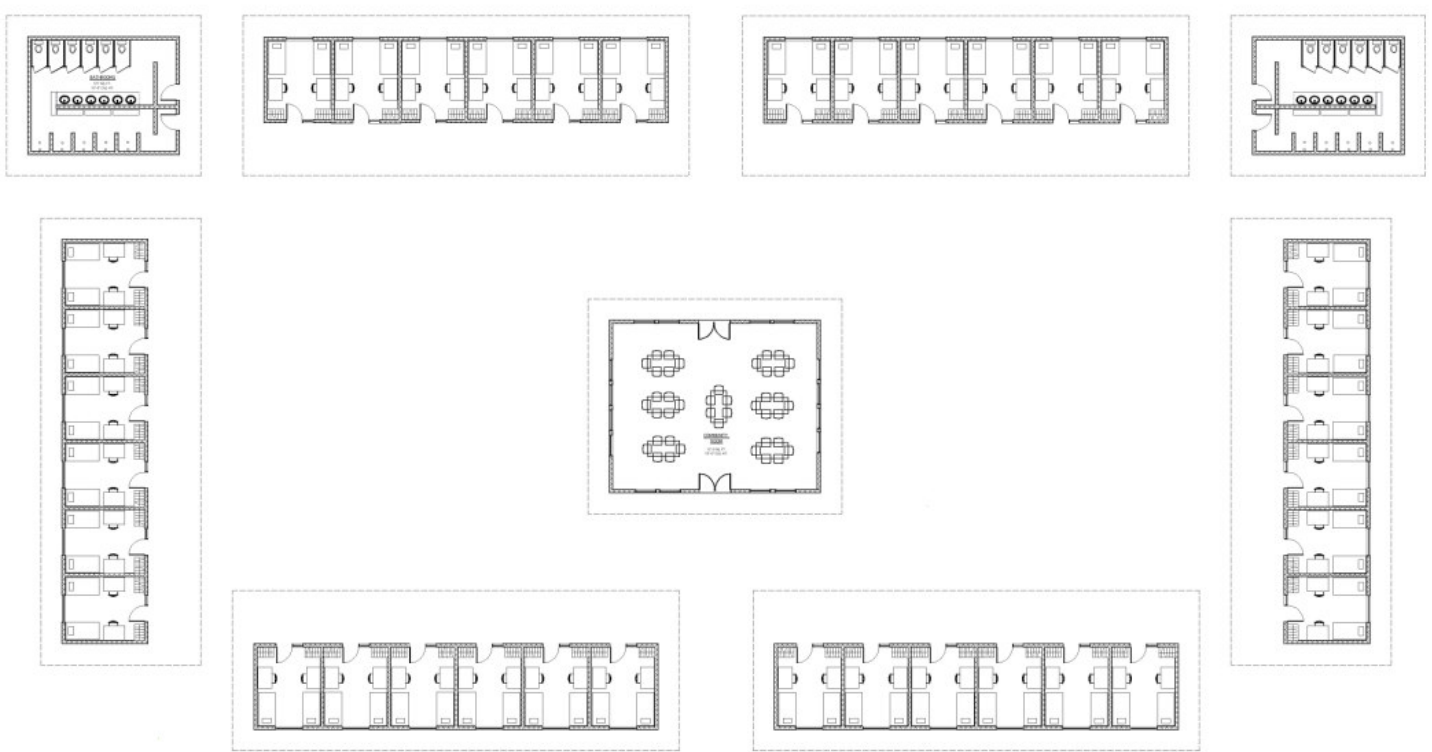

Figure 4 k: Layout plan of a single sex dormitory cluster 


\subsection{Structural design}

\subsection{Life Safety}

The primary concern of structural engineering is to provide a structural design for a building that makes it safe for human occupancy; this is known as life safety.

Engineers design buildings to meet certain minimum standards set forth by a building code applicable to the project location. Meeting these standards permits a reasonable expectation of safety against the forces of earthquakes, wind, and the self weight of the building for the building's occupants and owners. The immediate question for this project from the structural engineering standpoint was what building code should be used in the design of the Polytechnic's facilities.

Tanzania uses the British Standards Codes of Practice as its governing building code. This stems from Tanzania's relationship with Great Britain as a former colony. It is often the case that developing countries adopt the building codes of their former colonial rulers. However, this building code is not heavily enforced in rural regions of Tanzania. The only required design review is by the local office of the Ministry of Education to ensure that the classrooms provided enough space for the intended number of students. Past construction projects managed by the Diocese did not involve a structural review for the buildings so it was assumed that this would also be the case for the Polytechnic. The lack of review did not alleviate the design from adherence to code but did offer the opportunity to use a different code which the design team was more experienced with. 
The members of the structural design team for this project were unfamiliar with the British code. It would have been possible for the team to design using this code but would have required a significantly larger amount of time. The US Military building code TI-809 was selected for the design of the Polytechnic instead. The US Military code was chosen for several reasons. First, it is very similar to many building codes in the United States requiring the structural design team to make very few adjustments and shortening design time compared to having to learn a completely new code. Secondly, the US Military code is the governing code for military and US State Department installations and is intended to be used throughout the world. This gave its use in Tanzania more credibility as opposed to using the California building code. Additionally, the US Military code contained site specific information for design structures in East Africa.

\subsection{Economical Design}

The second primary concern for structural engineering is to produce an economical or cost effective design. In addition to the structure of a building needing to be safe, it must also be financially feasible to build. To achieve this, engineers determine the vertical and lateral loads that the building will need to support and resist. This is referred to as the structural demand of a building. The building is then designed using just enough material to safely withstand this structural demand. This optimizes the design so that the building does not use an excessive amount of materials. This reduction of material is especially important to reduce construction costs in East Africa since the 
expense of building materials makes up the majority of the entire construction price. The reduced amount of materials also reduces the amount of labor required for construction.

\subsection{Structural Demand}

The structural demand imposed on the Polytechnic's buildings was determined through building code approximations using information about the project's location in East Africa. The buildings needed to resist both vertical loads from the effects of gravity as well as lateral or horizontal loads caused by both wind and earthquakes.

\subsubsection{Design for Gravity Loads}

Gravity loads are the forces imposed on a building which must be resisted in the vertical direction. Each element of a building must be able to support the weight of the building above it. Gravity loads are broken up into two categories, live load and dead load. Dead load is the weight of the building structure and anything attached to it. The live load category encompasses all the additional load or weight applied to a building structure but is not physically attached to it. This includes the weight of the human occupants, furniture, equipment, rain, and snow. The taller a building is or the more floor levels in a building results in increasingly larger gravity loads at the lower floor levels. The greater load requires greater strength of the structure which results in more building material and greater cost.

Increased building height also requires greater structural complexity increasing not only material costs but labor costs as well. This greater structural complexity also results in an increased chance for instabilities to form making the building unsafe. The 
risk of instabilities forming is greater in rural East Africa where past experiences have observed misunderstandings by the local workforce in the basic principles of structural load flow (see Appendix A). To reduce construction costs and limit the risks of some of the Polytechnic's buildings being unstable and unsafe, all of the Polytechnic's buildings were limited to one story. This means that the majority of the live load from the occupants, furniture and equipment is transferred directly to the earth underneath the slab. Consequently, the walls are only required to support their own weight and the weight of the roof above resulting in a more reliably safe design.

\subsubsection{Lateral Load Considerations}

Lateral loads from wind pressures were a concern in the structural design because of the form of the shade structures. The wind or air movement required for the ventilation system may cause uplift on the shade structures. The connections used to anchor the shade structures to the lower building were designed to resist these forces and keep the roof structure from lifting off of the building below.

East Africa is a seismically active region which dictated that the lateral forces caused by earthquakes needed to be accounted for in the structural design. East Africa is home to the Great Rift Valley which serves as visible evidence of the ongoing tectonic plate activity occurring beneath the Earth's crust. The African Plate is splitting and pulling apart underneath East Africa forming the Great Rift Valley as well as other significant geologic features including Lake Victoria, Mt. Kilimanjaro and Mt. Kenya, two dormant volcanoes (see Figure 5 a). 


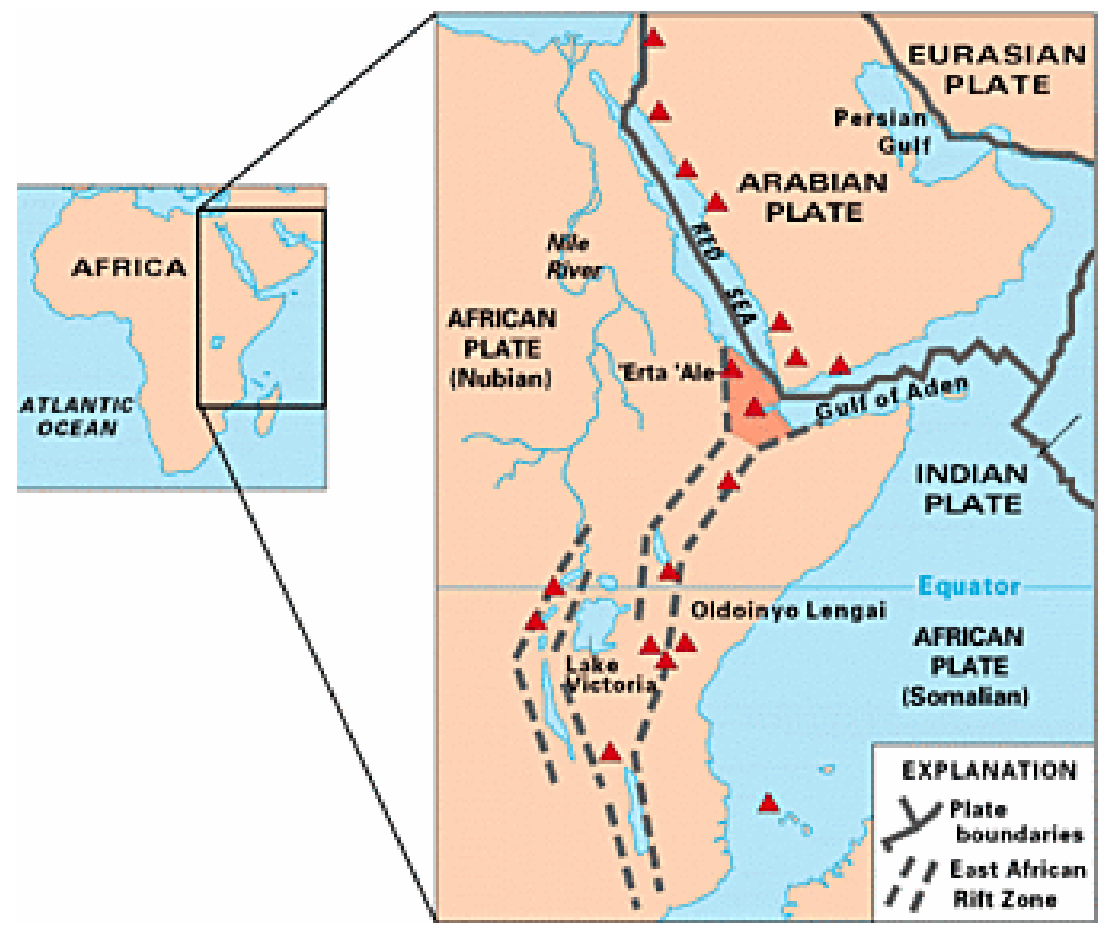

Figure 5 a: Detail of tectonic activity in East Africa

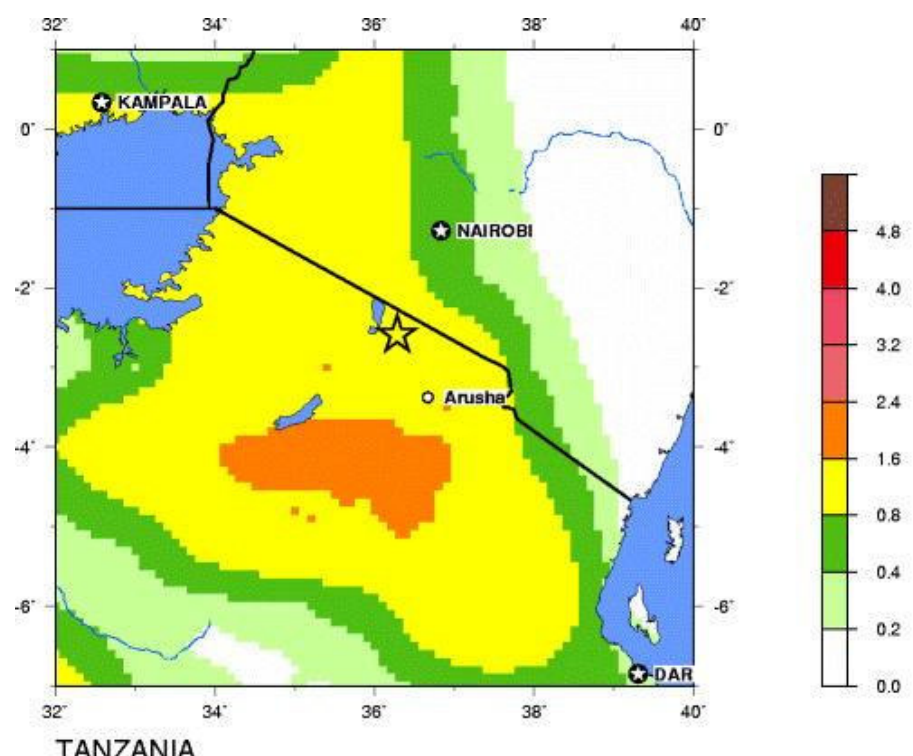

20070717 14:10:42 UTC 2.59S 36.28E Depth: 8.0 km, Magnitude: 5.9

Peak Ground Acceleration $\left(\mathrm{m} / \mathrm{s}^{2}\right)$ with $10 \%$ Probability of Exceedance in 50 Years

Figure 5 b: Seismic hazard map of northern Tanzania (USGS 2007) 
Seismic hazard information was available through the US Military TI-809 document but additional information was obtained from the United States Geologic Survey (see Figure $5 \mathrm{~b}$ ). The information was essential in the determination of the strength of seismic events likely to occur in the region and the subsequent approximation of lateral forces on the buildings. The forces are directly related to the weight of the buildings. When the ground accelerates during an earthquake, heavier buildings experience greater forces applied to them than lighter buildings. Insufficiently designed buildings have resulted in significant losses of life through catastrophic building collapses in developing regions including East Africa. Therefore, the structural design to resist seismic forces received considerable attention and improvements to current structural systems were considered for the Polytechnic's facilities and are described in the following sections.

\subsection{Building Material Selection Criteria}

The main criteria in selecting building materials to be used in the construction of the Polytechnic were availability and cost. These two considerations are often directly related. The unit price of a particular product may be inexpensive in a major metropolitan area but the cost to transport this material to a rural job site might eliminate its financial advantage over another higher priced material located closer to the job site. Locally available or locally manufactured materials were advantageous for their cost benefit and their selection benefited the local economy by supporting local tradesmen. Donated materials were available from outside the country but if the Polytechnic relied on these for construction then the institution would not have served as an example for the 
local community on how to improve their own construction practices since the donated materials would not be available to the community

The strength and performance of the different material options was considered as well. A particular building material may be inexpensive but if it could not resist the forces it would be subjected to then the cost benefit of using the material was eliminated. Also, a material may be affordable and strong enough but not selected because of its inability to withstand the environmental conditions present.

A unique consideration to building in East Africa was accounting for the materials the local workforce was experienced in using. It may be possible to find inexpensive materials or to have received donations but if it is a material the local workforce is not familiar with, then quality control issues will arise. Even if the building was properly designed using alternative materials, the workforce could misuse or improperly implement them compromising the structural integrity and overall safety of the building. The only remedy for this was to ensure constant supervision by a trained manager but this could not be guaranteed.

Additionally, the architectural requirements were considered in the structural design of the building. Incorporating the types of materials required by the architectural design of the environmental systems affected the selection of building materials. Combining the structural and architectural requirements to be addressed by the same material resulted in a more efficient design. 


\subsubsection{Masonry Construction}

The primary building system chosen for the construction of the Polytechnic was masonry because it is a common material in the area. Timber framing is not used because of the presence of large colonies of detritus feeding insects (i.e. termites) which can cause wide spread damage to timber framed construction. Reinforced concrete and structural steel are used on a limited scale because they are expensive and limited in availability. The local workforce is well experienced in the use of masonry and a reasonable level of quality could be expected in construction. Masonry also met the requirements put forth in Section 4.3 for the passive environmental system implemented into the architectural design.

Individual masonry units can be made from a variety of materials. The most common masonry material in rural East Africa is fired clay brick (see Figures $5 \mathrm{c} \& \mathrm{~d}$ ). Chunks of clay are harvested from beneath the top soil. These chunks are shaped or formed into bricks and allowed to dry. The clay bricks are then stacked in mounds above chambers where wood fires are started. Once the fires are lit, the whole mound is covered with mud and left to bake for a month during which time the clay is hardened by the heat of the fire. The mud cover is removed and the adobe bricks are ready for use. It is typical for this process to take place on a construction site such that the bricks do not need to be transported. 


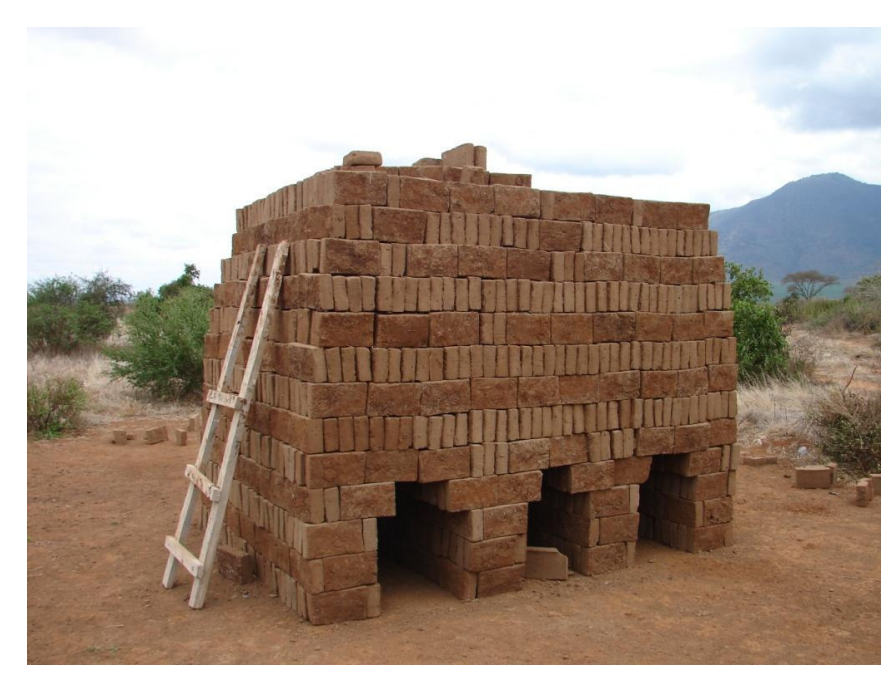

Figure 5 c: Clay bricks prepared for firing - Makanya, Tanzania

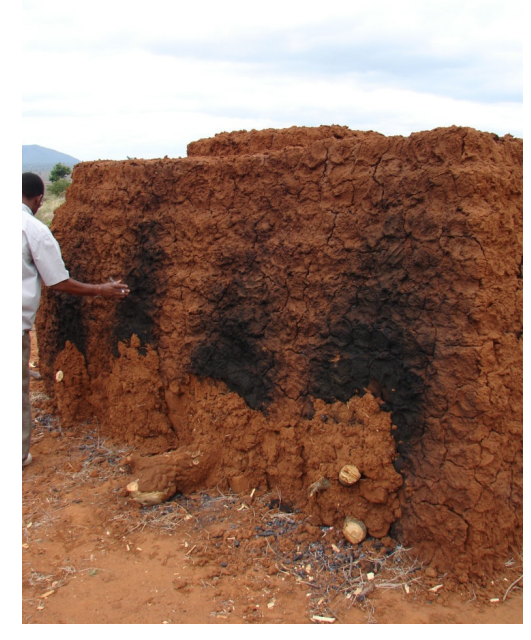

Figure 5 d: Clay bricks in the process of firing - Makanya, Tanzania

Another option for masonry units is cement stabilized soil blocks (CSSB) (see

Figure 5 e). Sand, clay and cement are mixed together with just enough water to start the chemical reaction of the cement. This loose wet mixture is then placed into a press which compresses the mixture into the shape of a brick. The bricks are then set aside while the cement sets, solidifying the brick (see Figures $5 \mathrm{f}, \mathrm{g}, \mathrm{h}$ ). During this period, the bricks need to be moistened regularly to prevent too much water from evaporating. If there is not enough water present in the brick then the cement will not set and the strength of the brick will be compromised. A lack of water can result from not enough being added to the initial soil mix or from high temperatures that result in the evaporation of the water in the mix. Once the bricks have cured for a month's time, they are ready for use in construction. 


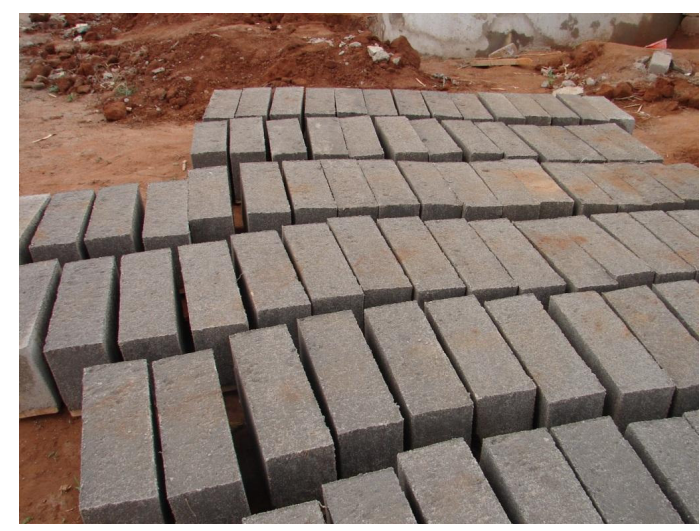

Figure 5 e: CSSB - Same, Tanzania

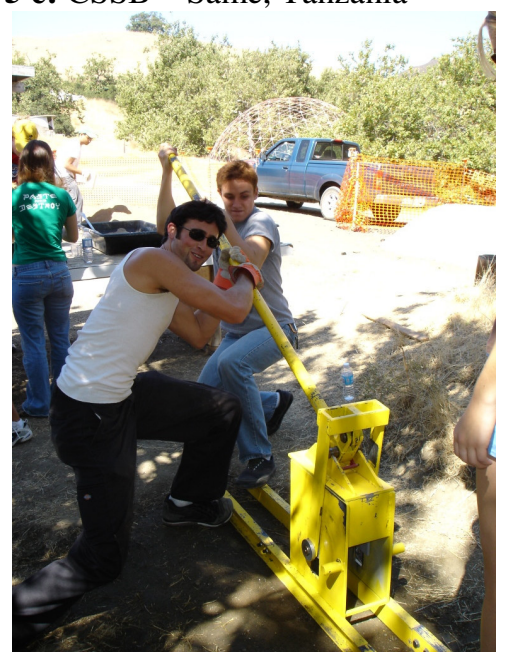

Figure 5 g: Wet mix compressed to form CSSB

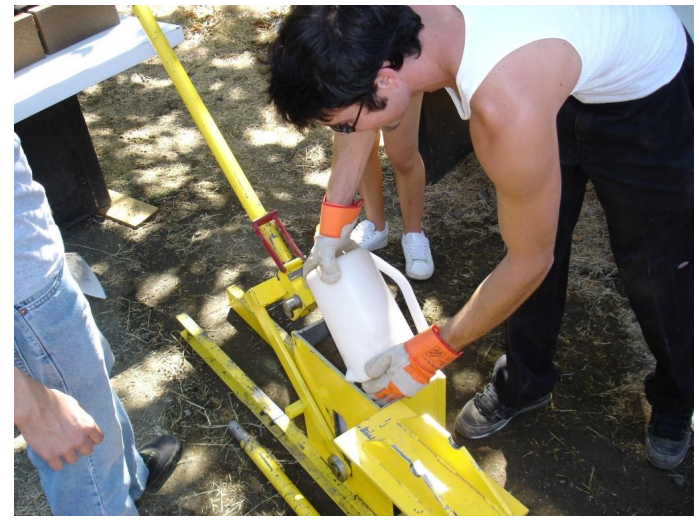

Figure 5 f: Wet mix poured into brick press

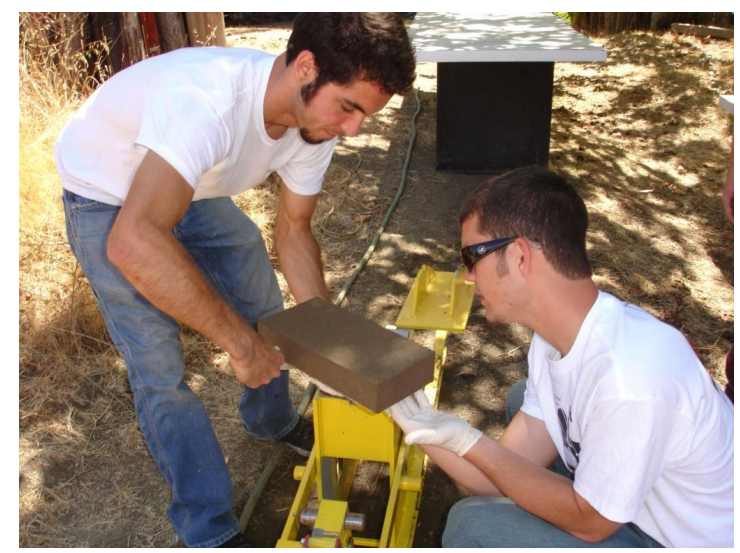

Figure 5 h: Fresh CSSB removed from press chamber and placed for curing

The third option for masonry units in rural East Africa is quarried stone. Quarried stone bricks are cut from bedrock and offer the greatest strength out of all the options (see Figures $5 \mathrm{i} \& \mathrm{j}$ ). The disadvantage is that quarried stone blocks can only be produced in certain areas where there is access to the right type of bedrock but both adobe bricks and CSSBs can be produced on site. Therefore, in addition to the unit cost of the stone bricks themselves, the cost of transportation needs to be factored into the decision. 


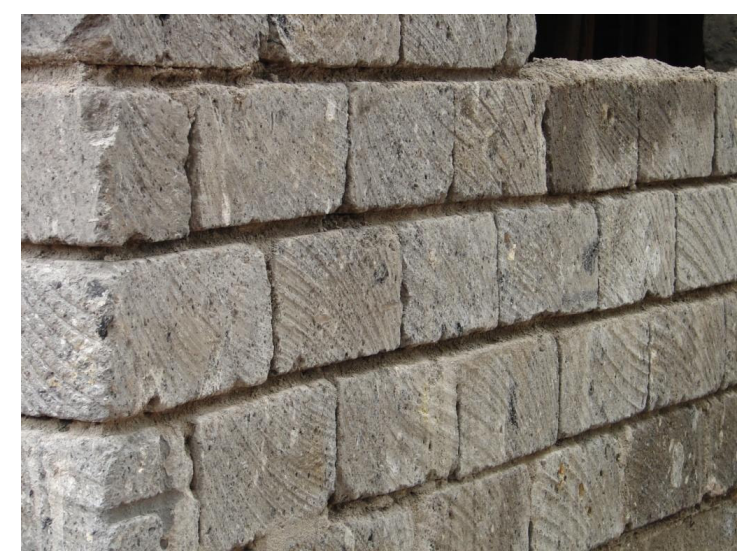

Figure 5 i: Stone masonry construction Nairobi, Kenya

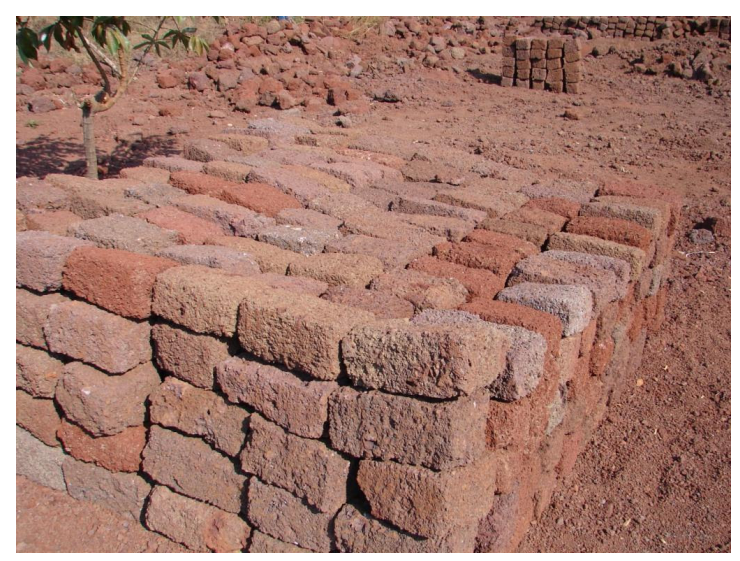

Figure 5 j: Volcanic stone bricks prepared and ready for transport to construction site - Moshi, Tanzania

Of the three masonry unit options, cement stabilized soil blocks (CSSB) were selected for the design of the Polytechnic. The CSSB option was chosen for its improved performance and durability over fired clay adobe, for its cost benefit over stone masonry, and its ability to be manufactured on site. CSSBs consist of a mix of approximately $60 \%$ sand, $30 \%$ clay, and $10 \%$ cement. The sand provides the majority of the CSSB's compressive strength while the cement binds the clay and sand together. This binding increases the compressive strength of CSSBs over adobe and reduces the weakening effects of moisture experienced in plain adobe. Additionally, the use of mainly earthen material and only $10 \%$ cement made this an environmentally friendly option that did not require the burning of trees, as the manufacturing process for adobe does, in a region fighting deforestation.

Adobe bricks perform well under load but can be compromised by moisture. When adobe comes in contact with water, the clay absorbs the water and expands. This 
expansion leads to cracking in the adobe and an eventual failure in the form of a partial or total wall collapse (see Figure $5 \mathrm{k}$ ). The cracking can happen after one occurrence of wetting and will worsen over repeated cycles. This type of failure results in extensive repair costs or the building becoming unusable altogether. Adobe is an appropriate building material in the arid regions of East Africa, however, the tropical monsoon rains deposit a great deal of water and small imperfections in the construction of a building could expose the adobe to the rainwater.

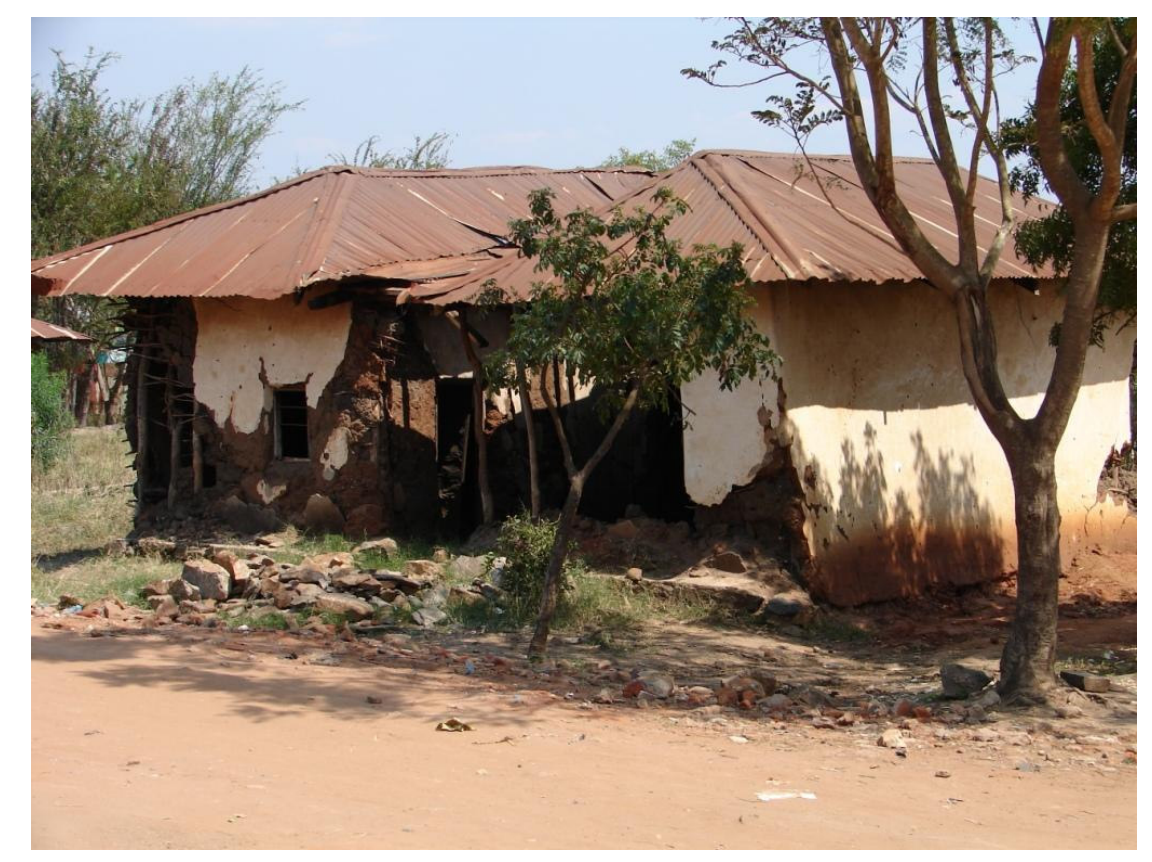

Figure 5 k: Partial building collapse due to saturation of adobe masonry Same, Tanzania

\subsubsection{Reinforced Concrete Construction}

While masonry was employed for a majority of the structure of the Polytechnic's facilities, it was decided that the use of reinforced concrete was beneficial for strengthening the buildings to resist earthquakes. Masonry and concrete are typically 
reinforced with steel bars called rebar. Rebar is very expensive but readily available throughout East Africa (see Figure 5 1). Un-reinforced masonry is very effective in resisting gravity loads in compression but is considered structurally unsafe when subjected to lateral loads that produce both tensile and compressive stresses, especially in the case of earthquakes. Combined with its heavy weight, this deficiency has led to unreinforced masonry being declared unsafe in areas of high seismic activity and it is a construction practice no longer allowed in the State of California. Unfortunately, it proved too costly for the Diocese's budget to reinforce all the masonry throughout the Polytechnic's buildings. However, eliminating steel reinforcement altogether would have reduced the strength and performance of the buildings to an unacceptably dangerous level considering the seismic activity levels in the Kilimanjaro Region.

To improve the strength and performance of the masonry structures during an earthquake, a system of reinforced concrete columns and beams was designed into the structures to form a system called confined masonry (WHE 2005). The columns are placed at regular intervals throughout the masonry walls. The columns are connected at the base to the foundation and at the top by the continuous reinforced concrete bond beam which rests directly on top of the masonry wall (see Figures $5 \mathrm{~m}, \mathrm{n}, \mathrm{o}$ ). The bond beam is not designed to support gravity loads but loads applied perpendicular to the face of the walls. This type of loading is referred to as out-of-plane loading and is the usual cause of failure in un-reinforced masonry. This loading is caused by the ground accelerating in a direction perpendicular to the wall. The mode of failure for out-of-plane loading is the separation of the top of the masonry wall from the rest of the structure 
during an earthquake. The separated masonry then falls to the ground which can cause serious injury or death to people in the immediate vicinity. The reinforced concrete bond beam provides a support at the top of the masonry wall to prevent this type of failure.

This system is not uncommon in East Africa but does not entirely eliminate the risk posed by un-reinforced masonry.

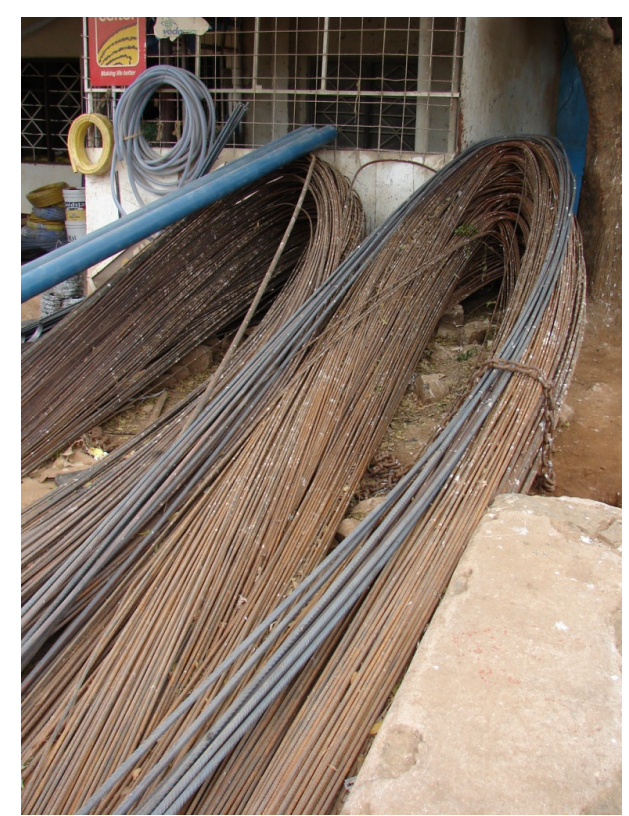

Figure 5 l: Steel reinforcing bars for sale - Same, Tanzania

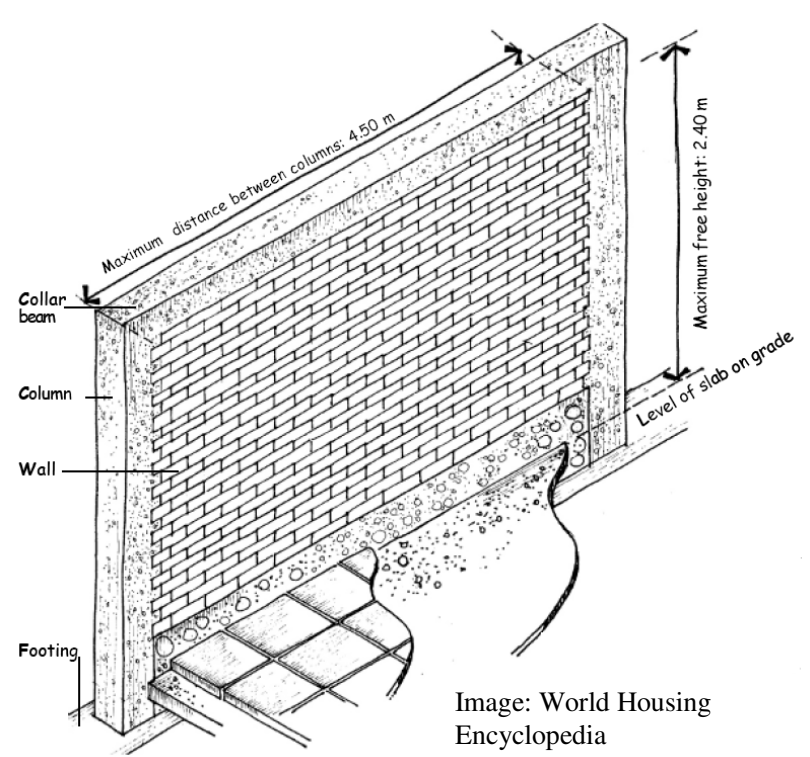

Figure $5 \mathrm{~m}$ : Illustration of reinforced concrete columns and bond beam structural system 


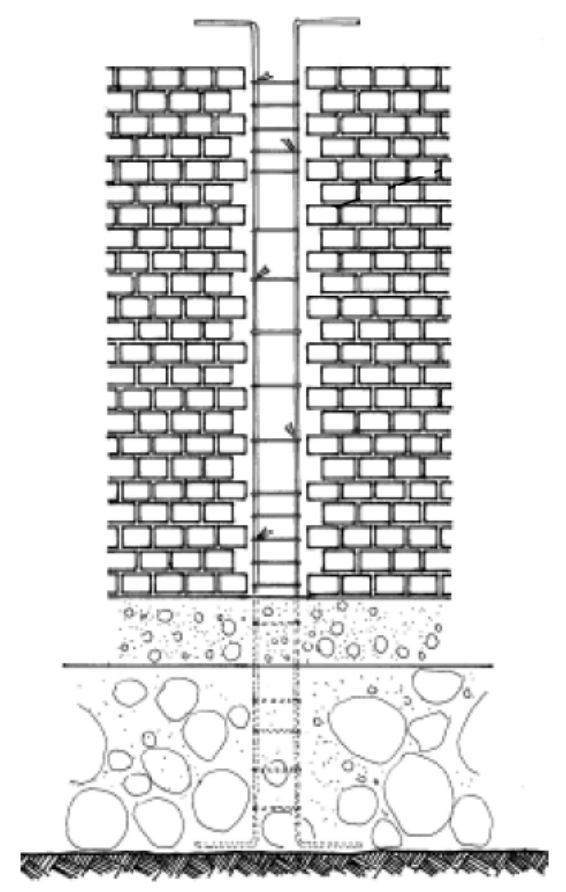

Image: World Housing Encyclopedia

Figure 5 n: Side view illustration of a reinforced concrete column embedded in an unreinforced masonry wall

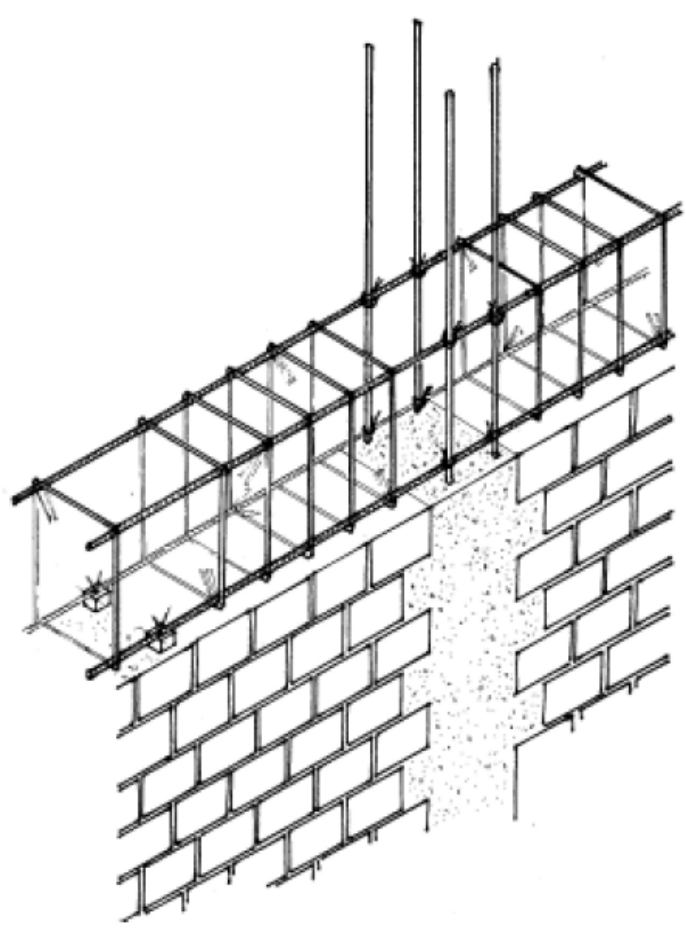

Image: World Housing Encyclopedia

Figure 5 o: Detail illustration of a reinforced concrete bond beam connected to a reinforced concrete column and resting on top of an unreinforced masonry wall

To improve the safety of the un-reinforced masonry, an additional reinforcing element was designed into the walls of the Polytechnic's facilities. A layer of steel wire mesh reinforcement was designed to further confine the masonry units to prevent a partial collapse of the wall. Different types of wire mesh are readily available throughout the region and are often used in agricultural purposes (see Figure 5 q). This wire reinforcement is anchored into the exterior side building's foundation. The wall is then erected to its full height and the wire mesh is run up the side of the wall and through the reinforcing of the bond beam. The bond beam is then cast with concrete and the wire mesh is run down the interior face of the wall and anchored into the floor slab. The faces 
of the walls and the wire mesh are then plastered over (see Figure 5 p). During an earthquake, the wire mesh provides additional confinement for the unreinforced masonry by restraining individual masonry units or wall segments from falling even if cracking and separation occurs.

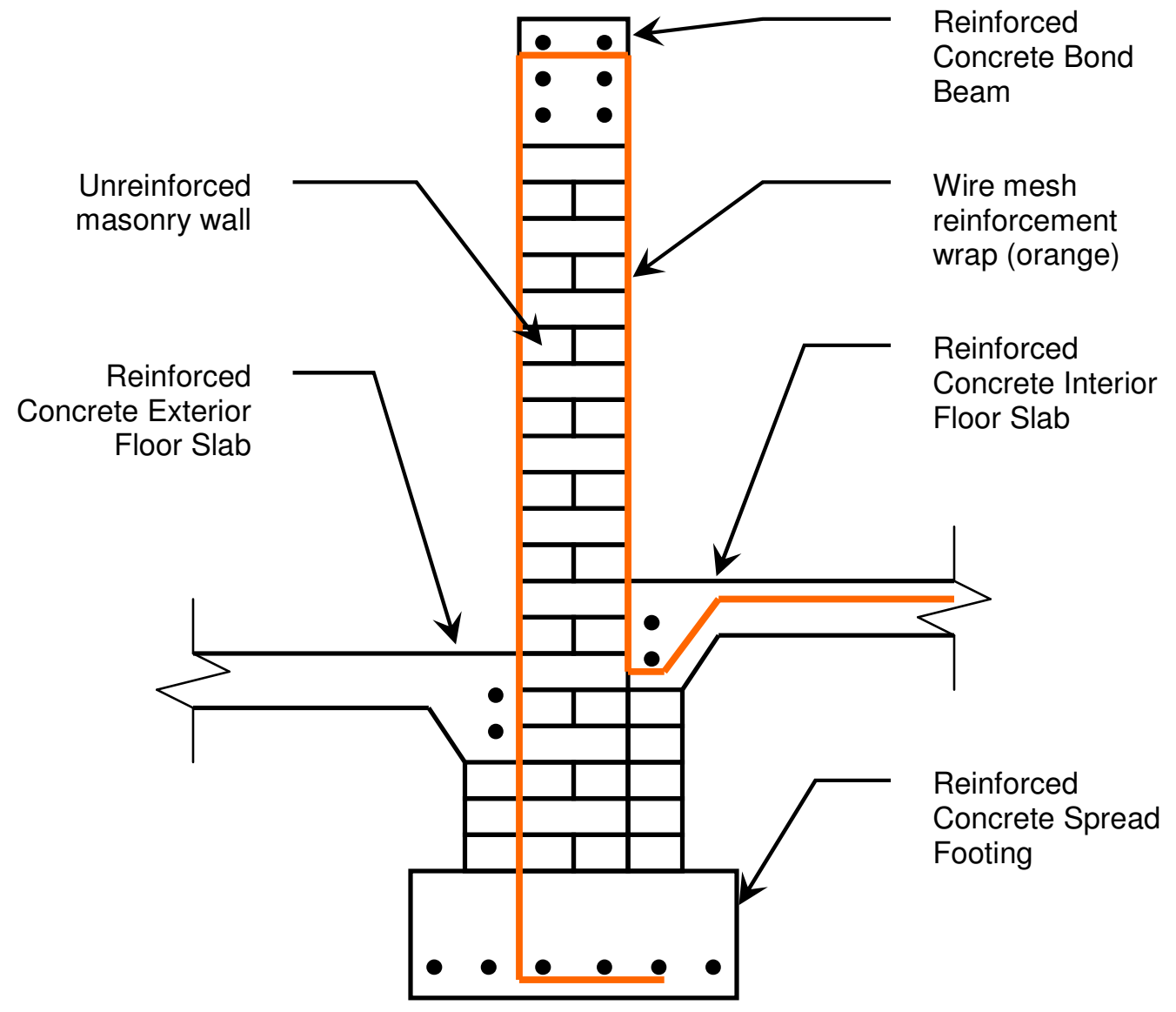

Figure 5 p: Section view of a typical masonry wall with steel wire mesh reinforcement

The practice of plastering masonry walls is very common in East Africa, especially with adobe construction. Plaster is applied to protect the masonry walls from moisture during the rainy season and other environmental elements. The wire mesh then 
serves two purposes: it provides minimal reinforcement to the walls against out-of-plane loads, and also serves as temperature reinforcement for the plaster. All materials are subject to volumetric expansion and contraction due to temperature variations. The wire mesh resists the stresses imposed by the expansion and contraction of the plaster as it is subjected to direct solar radiation throughout the day and cooling during the night.

Without this reinforcement, the plaster will crack and spawl off the building exposing the masonry to the elements which leads to erosion of the wall (see Figure $5 \mathrm{r}$ ).

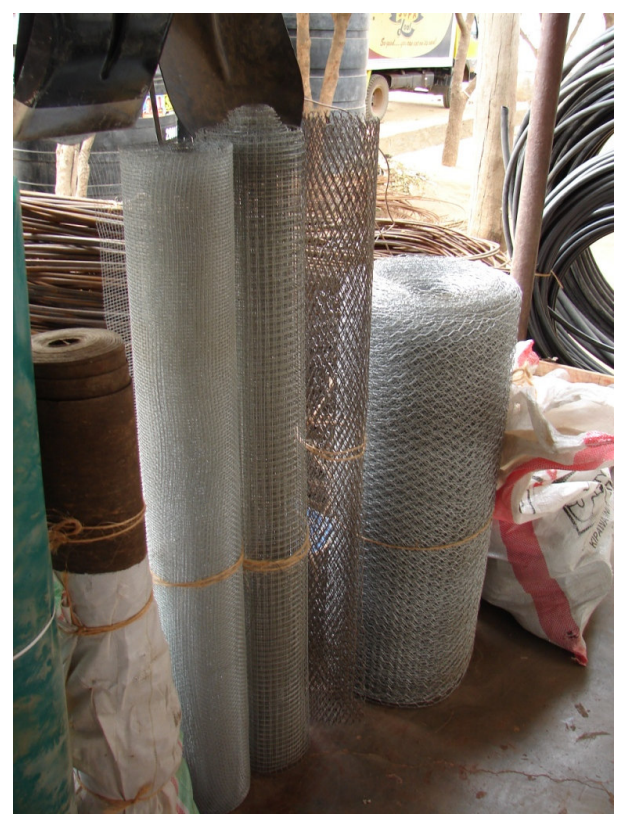

Figure 5 q: Steel wire mesh for sale - Same, Tanzania

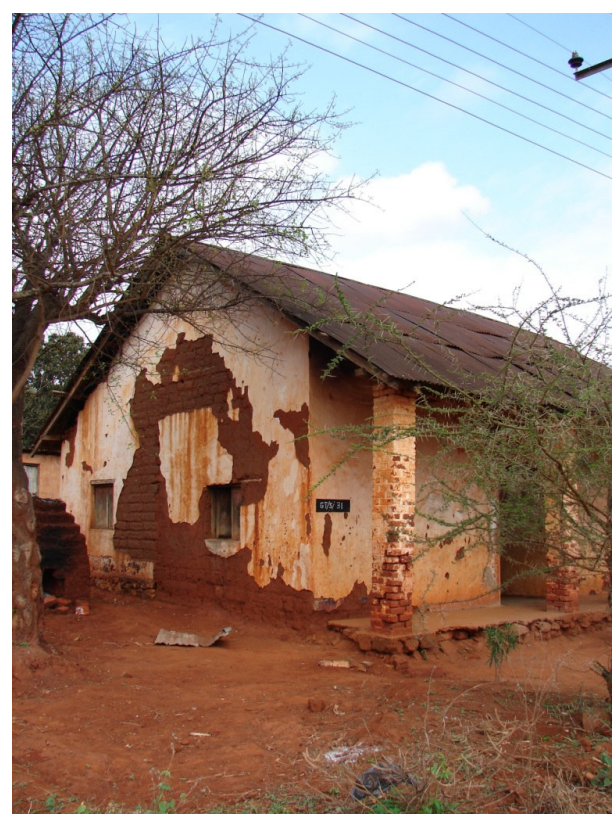

Figure 5 r: Spawling of plaster off of an unreinforced adobe masonry building - Same, Tanzania

Reinforced concrete was also selected for use in the foundation systems of the Polytechnic's buildings. Reinforced concrete spread footings are one of the most common foundation systems in East Africa and perform well with one story buildings. To construct the foundation system, the building footprint is laid out on the site. 
Trenches are then dug where the spread footings will be placed underneath the walls of the buildings (see Figure $5 \mathrm{~s}$ ). The trenches need to reach an acceptable depth such that the soil can support the structure above. The appropriate depth is determined by the degree of compaction of the soil and should be evaluated by an experienced builder or engineer. The trenches are leveled out with a layer of slurry composed of a wet mixture of soil and cement.

A continuous reinforced concrete footing is then poured on top and allowed to set (see Figure $5 \mathrm{t}$ ). After the footing has sufficiently cured, masonry stem walls are erected on top of the footing to the height of the floor slab. The inner area created by the stem walls is then filled with coarse rock, sand, and clay in a mix called murram (see Figures $5 \mathrm{u} \& \mathrm{v})$. This earthen pad is then compacted down by hand in preparation for the pouring of the reinforced concrete slab above. 


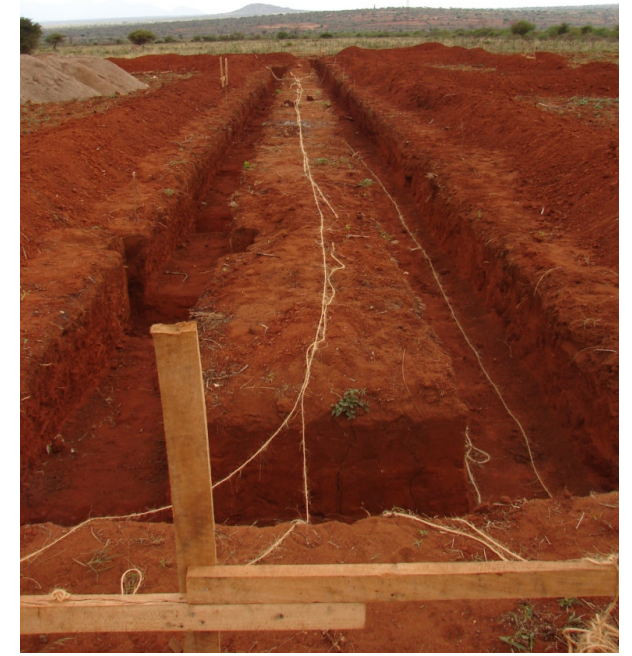

Figure 5 s: Trenches dug for foundations - Same, Tanzania

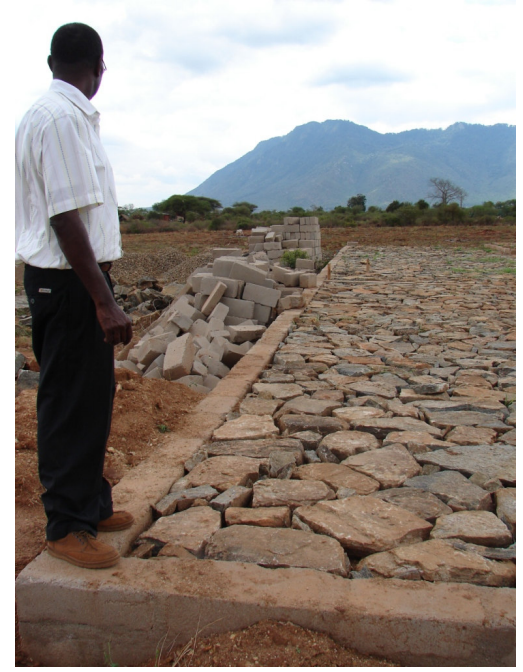

Figure 5 u: Foundation prepared with coarse stone - Same, Tanzania

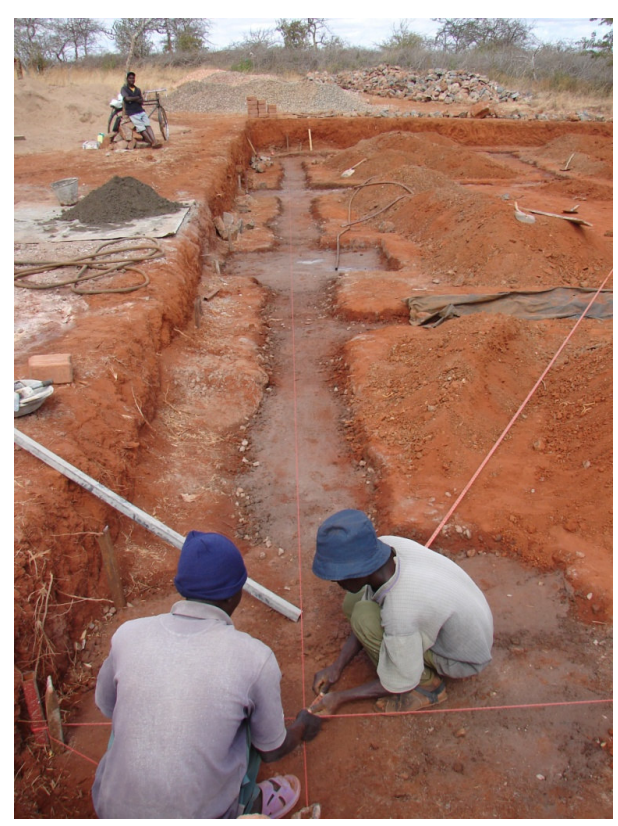

Figure 5 t: Foundation trenches filled with reinforced concrete spread footings - Nyumbani Village, Kenya

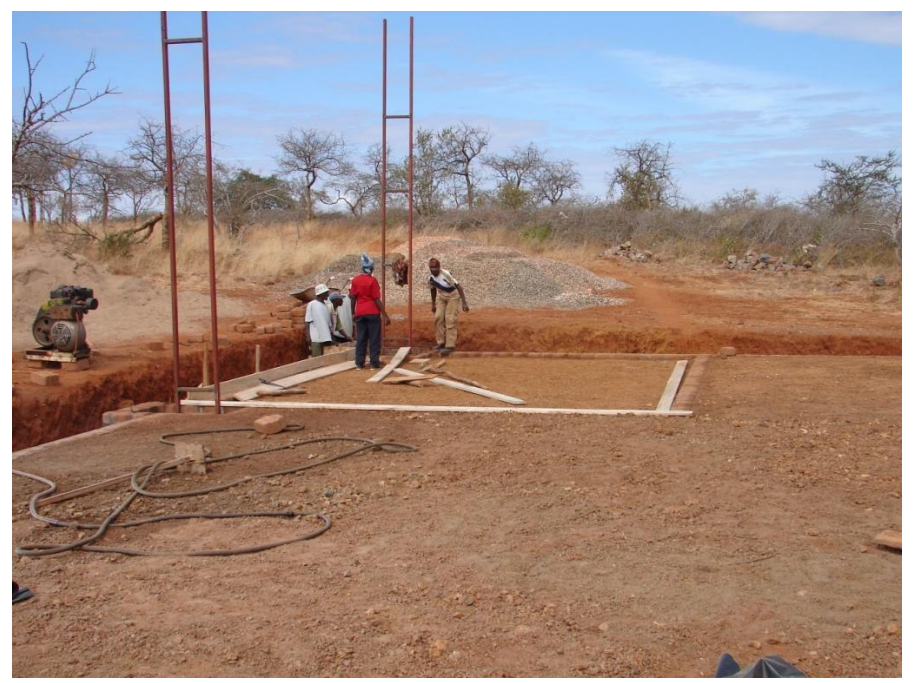

Figure 5 v: Foundation prepared with stone and compacted murram Nyumbani Village, Kenya 


\subsubsection{Structural Steel Construction}

Structural steel was chosen for use in the fabrication of roof trusses and other framing elements. Roof trusses are required to support the upper shade structures while allowing air movement over the lower buildings. The ability of steel to support gravity loads with minimal self weight makes it the appropriate choice for use on top of the masonry walls. It was also selected over timber due to timber's susceptibility to termites, weather, and water. Steel is also vulnerable to contact with water but basic treatment options are available in East Africa to prevent rusting.

Steel also offers a more durable connection to concrete and masonry than timber. Timber must be insulated from direct contact with both masonry and concrete due to these materials' tendency to retain moisture. Exposing timber to moisture will result in dry rot which will undermine the strength of the timber. Steel can be placed in direct contact with masonry and timber and can also be cast into these materials if required. However, care must be taken where steel is cast into concrete and masonry as both of these materials are prone to shrinkage. Shrinkage can result in cracks developing around steel pieces that have been partially cast into either material. These cracks allow water to penetrate deeper into the concrete and masonry possibly resulting in the rusting of the steel reinforcement.

Structural steel elements are also very versatile in the ability to be assembled into a variety of geometric arrangements. Structural steel is widely available in East Africa in a variety of sizes and shapes and welding is a common practice with varying levels of skill and competency (see Figures $5 \mathrm{w} \& \mathrm{x}$ ). The variance in skill level and critical 
nature of welded connections require that any welds used are designed to be robust enough to accommodate losses in strength from poor workmanship. Welders should be evaluated based on previous work prior to hiring.

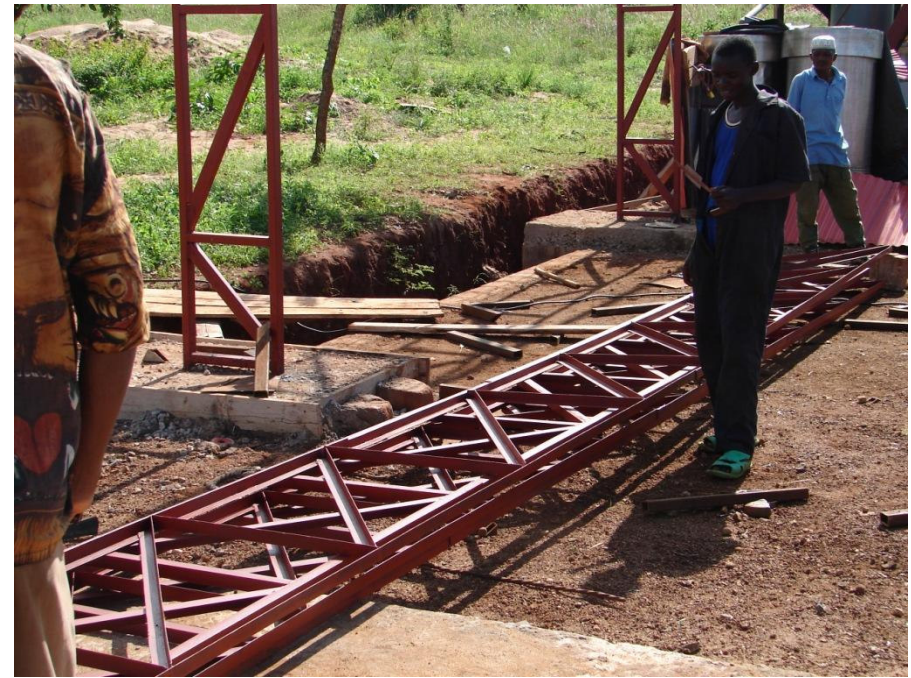

Figure 5 w: Welded steel trusses prepared for construction Nyumbani Village, Kenya

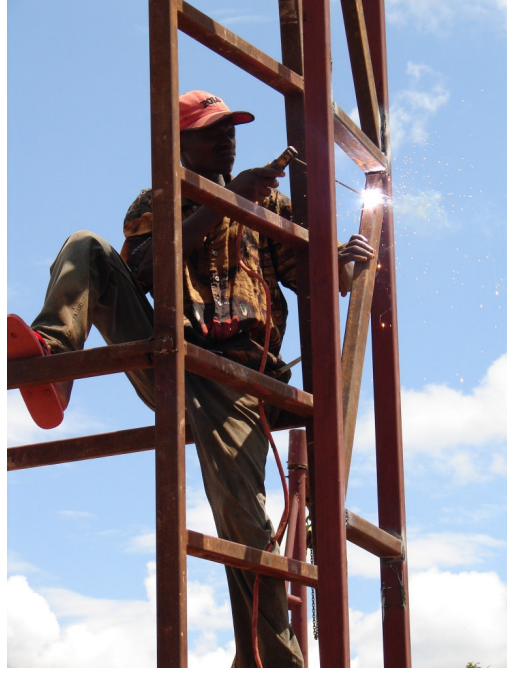

Figure 5 x: Structural welding during construction - Nyumbani Village, Kenya 


\subsection{LANDSCAPE DESIGN}

\subsection{Plant Selection}

There are two main criteria for the selection of plant species that are included in the landscaping of the Polytechnic's grounds. The first requirement is the plants either had to be indigenous to East Africa or already existed in the ecosystem. It is preferable to select species native to the region but some pre-established species were selected as well because of their compatibility with the climate. Secondly, the plants need to be able to survive in the semi-arid climate of this part of East Africa. The climates range from tropical to desert in East Africa, so although some species may be indigenous, tropical plants requiring large amounts of water would not be viable options. Plants accustomed to more temperate and tropical climates would require too much water in a region where water is scarce. A list of all the identified plants that meet these criteria was compiled for better evaluation and the most appropriate selections were made based on the landscape design requirements (see Appendix D).

The Diocese requested that fruit orchards be included in the design of the landscaping of the site. It was difficult to identify fruit bearing plants that fit the main two criteria but passion fruit, mango, and papaya plants are acceptable options that are already present in the District as food crops (see Figures 6 a \& b). Additionally, the Diocese also requested that giant bamboo was included in the landscaping for several reasons. Giant bamboo grows rapidly and needs little care. It can serve as a natural barrier and can be harvested for fencing and construction purposes. Native species of 
giant bamboo exist in East Africa but have been over harvested in northern Tanzania so the Diocese intends to begin a reforestation program with giant bamboo in the area.

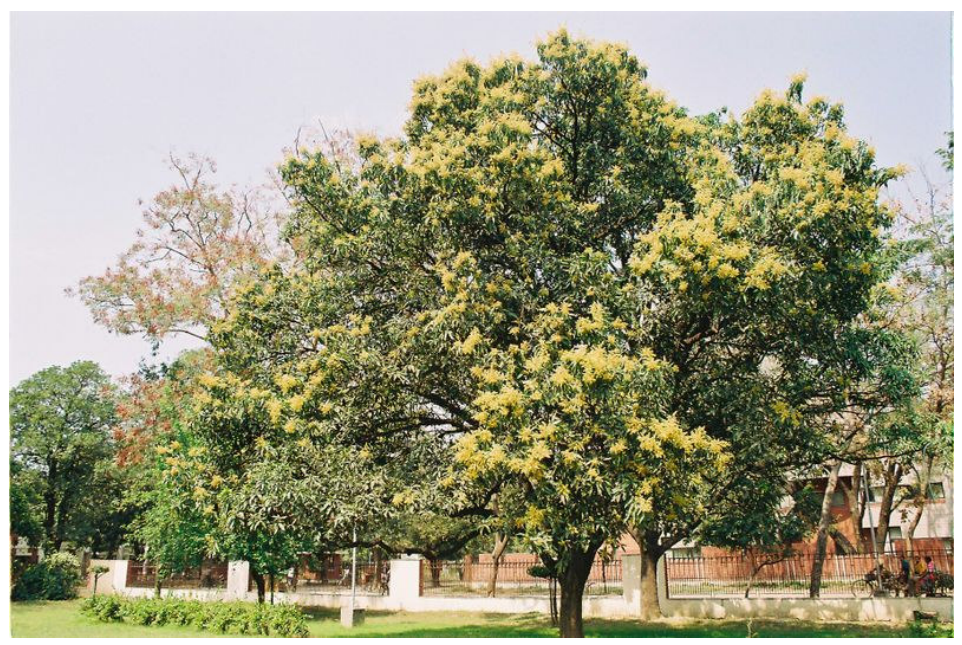

Figure 6 a: Mango tree

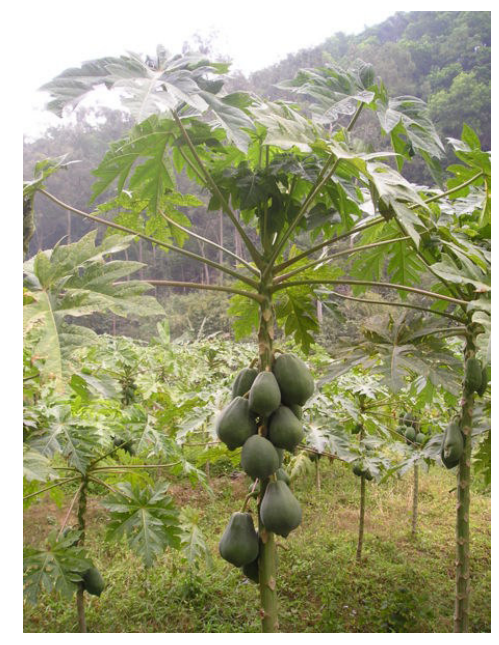

Figure 6 b: Papaya tree

\subsection{Environmental Shading}

The landscaping of the Polytechnic was intended to be both ornamental and functional as well. The landscaping design employed trees with extended canopies to support the passive environmental systems designed into the architectural form of the buildings. The shade trees were placed to help keep direct solar radiation off of the buildings. However, the trees could not be too close or too tall as they would block the natural wind currents and hinder the ventilation systems of the buildings. It was also important to ensure that the trees did not block too much daylight from entering the buildings. Trees also had to be planted far enough away from buildings so that the roots of the trees did not cause structural damage. Tree roots are capable of penetrating 
masonry and concrete in the pursuit of water. Once established in a crack, the growing root can widen and inflict considerable damage requiring extensive repairs.

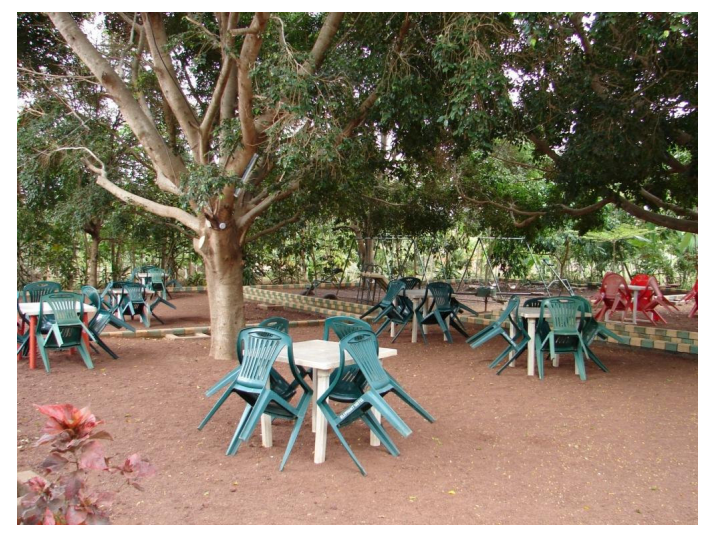

Figure 6 c: Shaded outdoor dining area Elephant Motel, Same, Tanzania

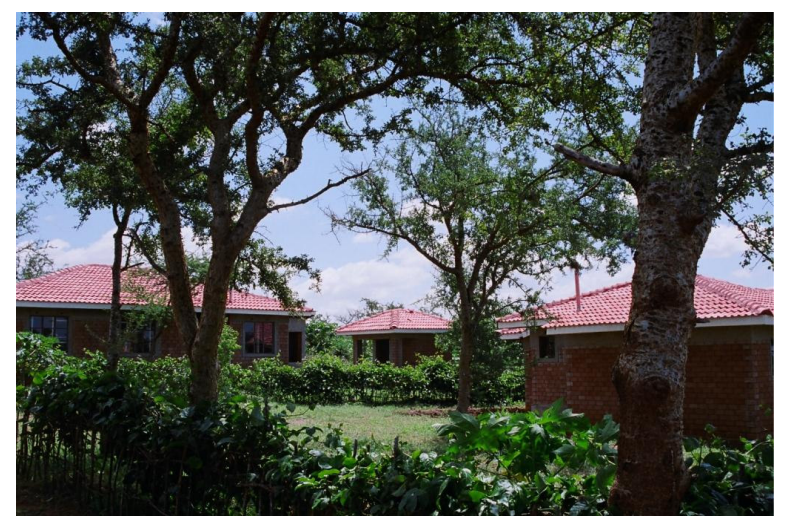

Figure 6 d: Shaded outdoor area - Nyumbani Village, Kenya

In addition to shading buildings, trees were employed to create shaded exterior spaces around the site. These spaces provided gathering points for social and school activities (see Figures $6 \mathrm{c} \& \mathrm{~d}$ ). The Diocese wanted the exterior environment surrounding the buildings of the Polytechnic to be just as comfortable as the interior of the buildings for the students and faculty to enjoy. The shade trees and other foliage also help to retain more water from rainfall on the Polytechnic's site by reducing the rate of evaporation.

\subsection{Space Definition \& Maintenance Plan}

The landscaping was also used to define space within the site. The boundaries surrounding buildings, courtyards and social centers were defined using landscaping. Various recreational fields were included in the site and the fruit orchards were laid out around the recreational fields to separate them from each other and the rest of the 
compound. The giant bamboo was used as a noise barrier against the main highway running along the south-west property line (see Figure $6 \mathrm{f}$ ). The flow of pedestrian traffic was directed to pathways and access points using manicured plants, trees and walls (see Figure 6 e).

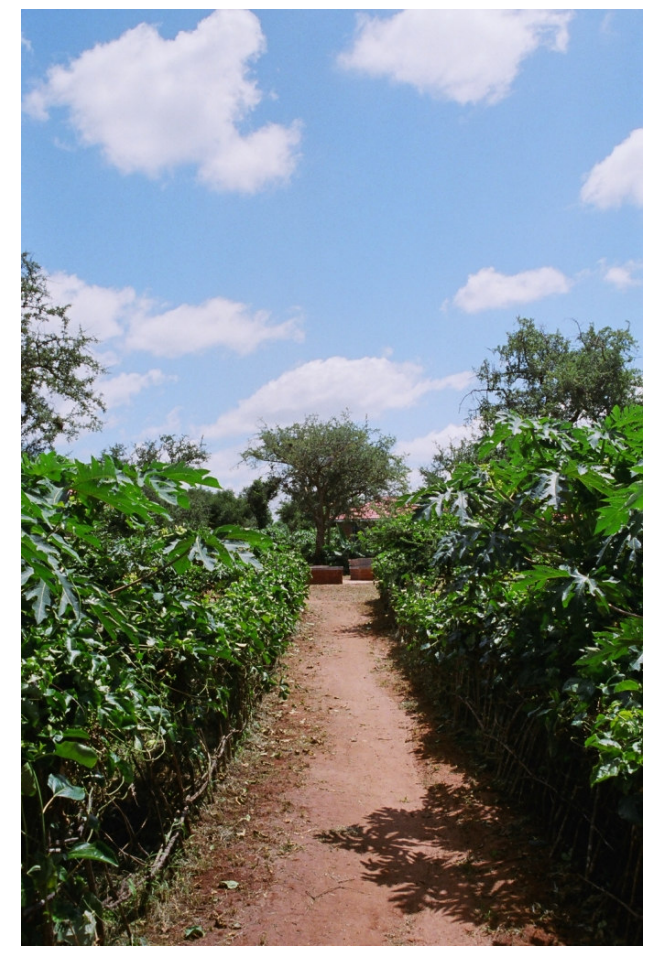

Figure 6 e: Landscaping utilized to define footpaths - Nyumbani Village, Kenya

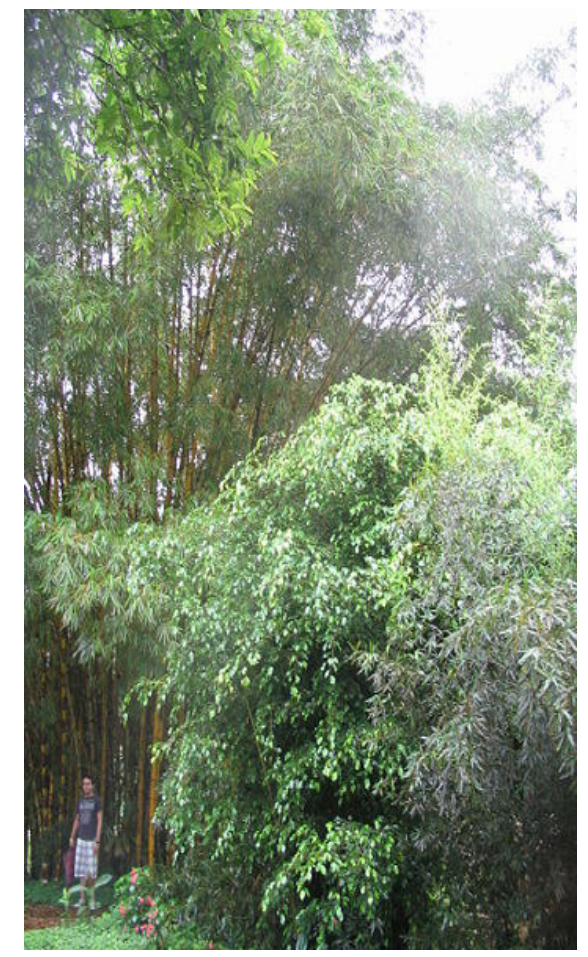

Figure 6 f: Giant Bamboo

A maintenance plan was developed for the site after the landscaping had been completed. The plan details the care and watering requirements for the entire site. This information helped the Diocese formulate a work plan for the care of the Polytechnic grounds. The information also provided requirements for the design of the Polytechnic water system by determining how much water was required in different areas and how much water storage capacity was required for the rainwater collection system. 


\subsection{WATER SYSTEM DESIGN}

\subsection{Water System Considerations}

A comprehensive water system was a necessity for the Polytechnic. Access to clean water from a well drilled into the water table needed to be provided for the Polytechnic to have continued access to clean water for human consumption and sanitation. The only other publicly available water source is a single access point to piped water from the national water system that served the entire community. If the Polytechnic relies on this source, water must be collected in plastic canisters and transported back. This method was not feasible to support a student population of 500 students so a bore hole is required. Additionally, waste water needed to be removed in an environmentally sustainable and sanitary manner and water for irrigation and landscaping also needed to be available.

In addition to these primary needs, a rain water collection system was incorporated into the Polytechnic plan at the request of the Diocese as previously mentioned in Section 3. Water pumped from the water table would be constantly available but pumps consume electrical or fossil fuel energy which is costly and the size of the Polytechnic meant that a large amount of water would need to be pumped for everyday consumption. This would put a great deal of demand on the bore hole and require almost constant pumping increasing operation costs. The rainwater collection system is intended to alleviate this demand on the bore hole and limit energy costs from the pump. 


\subsection{Water System Design}

The first task in the design of the water system was to identify what materials and products were available in the region. Water is a vital resource everywhere in the world and the effects of its absence are frequently seen in much of Africa. Due to its vital importance, there are several companies in the region that specifically deal with materials for the storage and distribution of water. Simba Plastics is one of the largest such companies and is located throughout East Africa with its products available for purchase in rural locations (see Figures 7 a $\&$ b). These products include water pipes, pipe junctions, valves and storage tanks all coming in a variety of sizes.

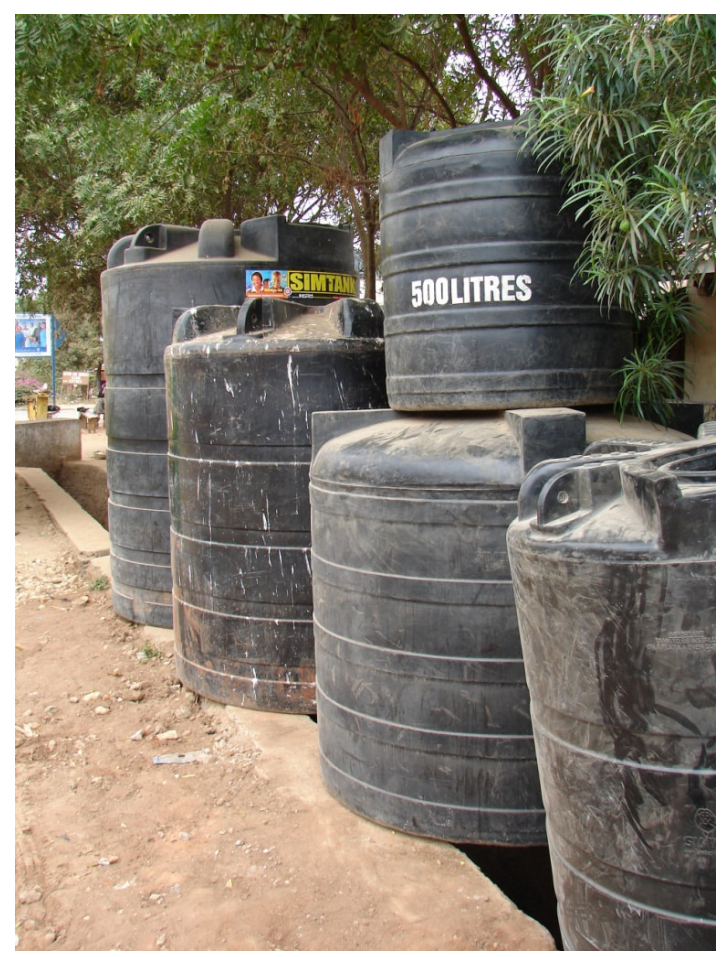

Figure 7 a: Simba Plastics plastic water tanks for sale - Same, Tanzania

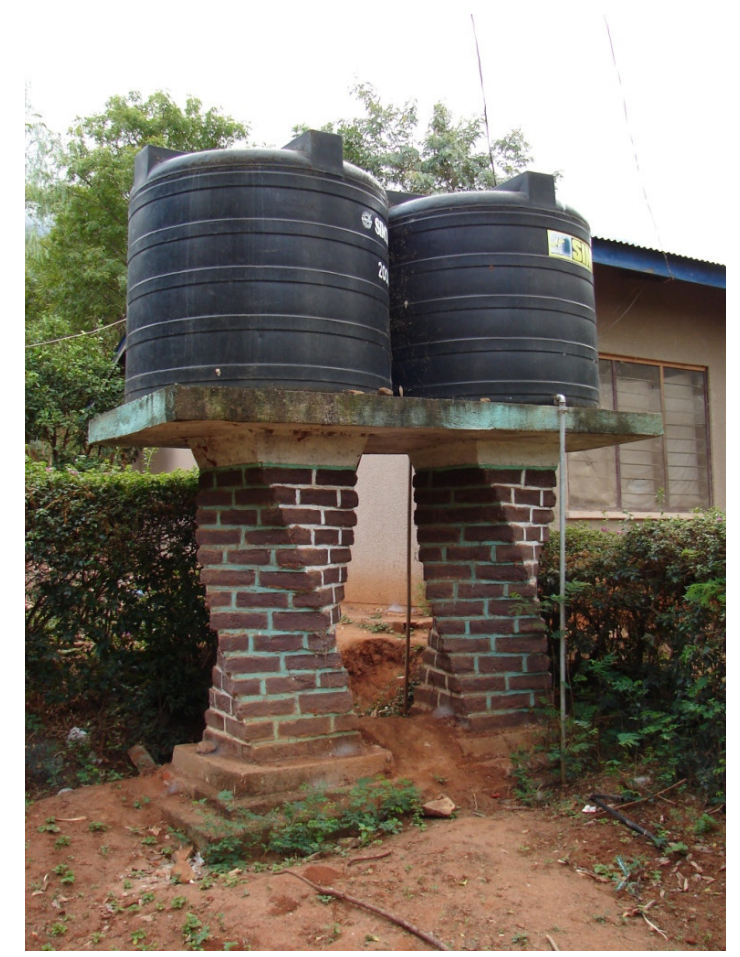

Figure 7 b: Plastic tanks used for storage Same, Tanzania 
It was decided to use the plastic water tanks for storage purposes. The alternative was to construct water tanks out of reinforced masonry but past experience in the region has shown these tanks were not well made and developed severe leaks (see Appendix A). Masonry tanks require extensive repairs and extended operation of pumps to replace lost water. The plastic tanks offered better expected performance, reliability, and easy installation.

The main water storage tanks were placed at the highest point possible on the site. This would allow gravity to perform the work necessary to distribute water to access points below and provide an adequate level of water pressure to operate sinks, showers, toilets and hoses. It is necessary to estimate the amount of water use expected at the different points of access so that the distribution pipes are large enough to meet the flow demand. Separate water tanks are provided for the water pumped from the bore hole and collected rainwater to prevent cross contamination since the rainwater is not safe for drinking. The well water source is more reliable so the water pumped from it had to be available for all the applications: drinking, cooking, sinks, showers, toilets, and irrigation. When rainwater is available, it will be used for non-drinking applications including toilets and irrigation. Therefore, the two sources are integrated into one piped distribution system so that rainwater and well water can be interchanged at these locations.

Waste water from sinks, showers and toilets is removed from the buildings. Gravity is again utilized to pull the waste water to a combined system of septic tanks and sand filters (see Figures $7 \mathrm{c} \& \mathrm{~d}$ ). This dual system is designed to separate the solid 
particulate material out of the waste water after it leaves the buildings. Once the water passes through the sand filter, it is safe enough to be used for irrigating non-food crops. The expertise and direction of Lifewater International was employed for the design of the septic tank and sand filter system. Lifewater International is one of several non-profit groups which specialize in the design, installment, and distribution of information on water system applications in developing regions. 


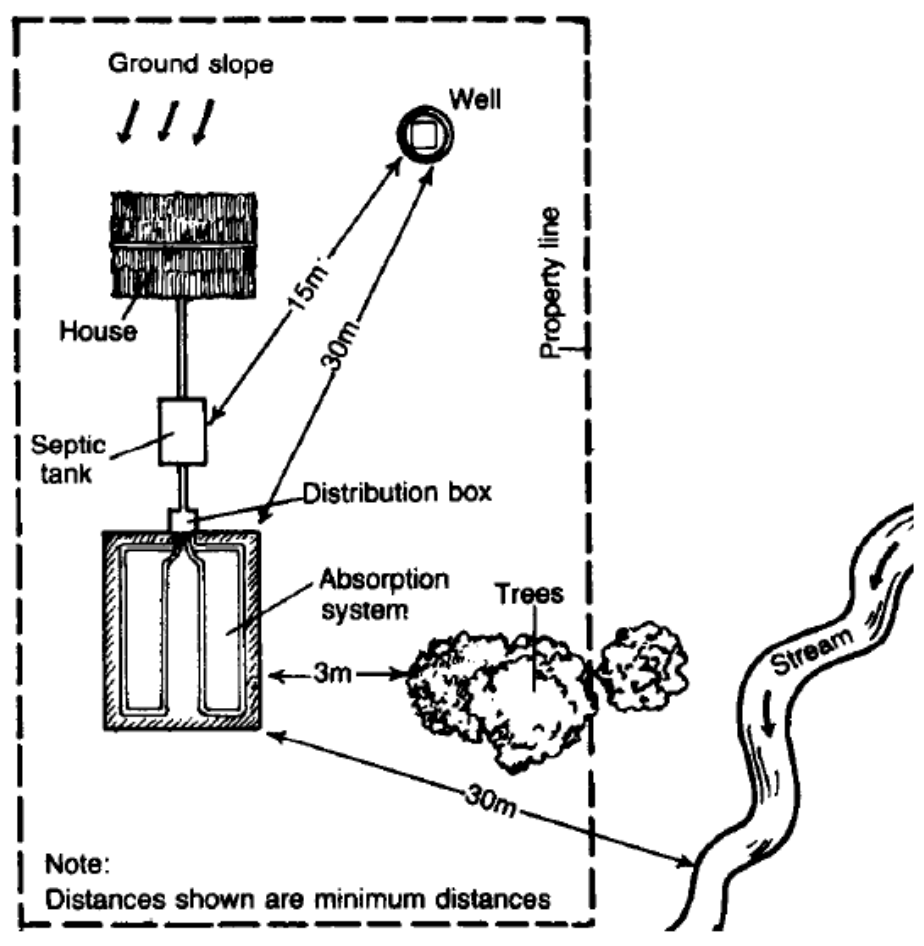

Figure 7 c: Plan view illustration of water system layout showing positioning and required distances between the different elements of the water system

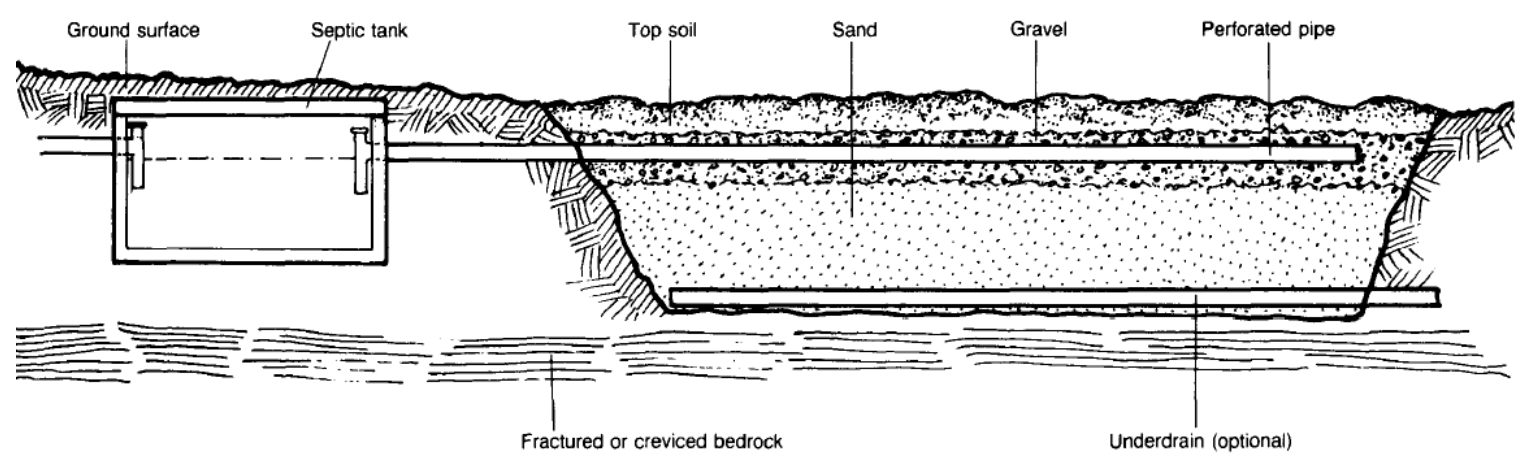

Figure $7 \mathbf{d}$ : Side view diagram of septic tank and sand filter system

The rainwater collection system was given considerable attention due to the Diocese's intent for it to serve as an example to the local population. Its design is based on collection surface area and desired storage capacity. The roofs of all the buildings 
serve as collection points with gutters funneling the water into drain pipes which then

flow downhill to storage tanks (see Figures 7 e $\&$ f). The storage tanks are then able to distribute the collected rainwater for irrigation purposes below or the water can be pumped to a higher elevation for use in toilets and irrigation higher up. The storage capacity was designed on the surface area of the buildings, how much rainfall the area received and how much water is needed for irrigation purposes between rain seasons. Average monthly rainfall figures were used due to estimate variations in annual rainfall from year to year. Enough storage capacity needed to be provided to harvest enough rainwater for the Polytechnic during a year with below average rainfall.

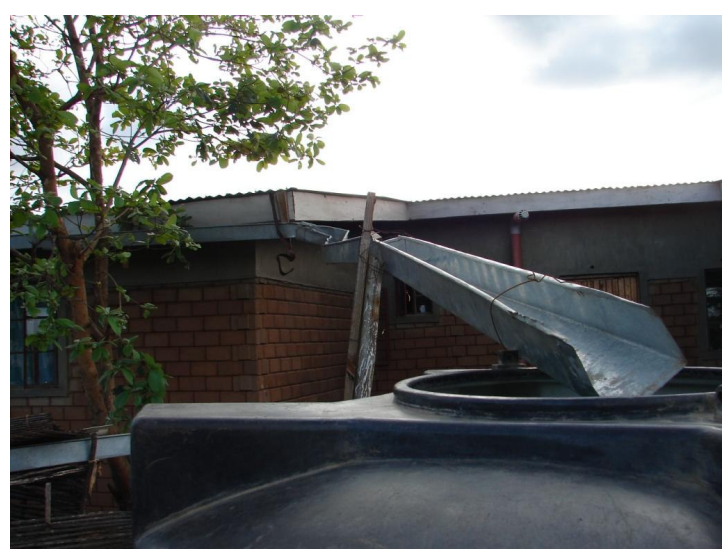

Figure 7 e: Rainwater collection gutter from building to water tank - Nyumbani Village, Kenya

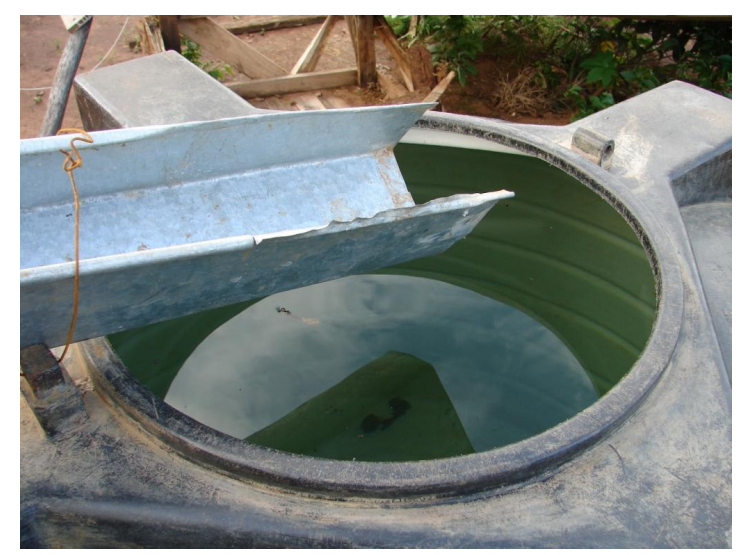

Figure 7 f: Water tank filled with water from rainwater collection - Nymbani Village, Kenya 


\subsection{CONSTRUCTION MANAGEMENT}

\subsection{Construction Phases}

The modular design of the Polytechnic's facilities permitted the entire campus to be constructed in phases. The different phases can be constructed at the same time or over a period of time depending on the availability of funding. It is necessary to include a portion of all the different types of facilities in each of the phases. This ensures that as each phase is built, the Polytechnic will have all the necessary facilities to support the student population regardless of the phase. Additionally, if some facilities are built well in advance of when they are needed, they will sit unused for some time. Uninhabited buildings need continuous upkeep and maintenance to prevent them from falling into disrepair resulting in an unnecessary cost. The designation of phases should prevent this from occurring. Some of the central buildings (i.e. administration, kitchen \& dining, multi-faith) are required in full capacity in the first stage because of their central use in the daily operations of the school. The classroom and dormitory buildings make up a majority of the later phases since these buildings correspond with the growth of the school's population.

The modular design of the facilities also enabled the use of focused rotating construction teams. With the construction of similar buildings taking place at the same time, teams of laborers can be formed that performed a singular task in the construction of the buildings. For example, one team of laborers starts construction on the foundation of the first building. After the foundation team has completed construction of the first foundation, the team then moves on to start the foundation of the second building. A 
second construction team, the walling team, then starts to build the walls of the first building. The foundation team finishes the foundations of the second building and moves on to the third building. The walling team then moves on to the second building to begin the walls and a third roofing team starts to erect the roof on the first building. This rotating team of builders continues until all the buildings of a phase are completed. This process results in faster construction time by eliminating the lag time experienced when workers switch construction tasks. The rotating process also improves the quality of the construction work by the employment of dedicated teams that become proficient at a single task as opposed to having to perform several on one job.

Quality control is more easily managed by allowing supervisors to focus their attention to solve the shortcomings of one team directly without having to first identify the source of the problem. However, for this method to be efficient, enough buildings must be included in the construction phase to support multiple teams. Trying to use this method for just a few buildings would not result in the same time saving benefits and would result a disproportionate number of workers to be hired in relation to the amount of construction work required.

\subsection{Excavation Minimization}

While the architectural design considerations has a strong influence in the placement and arrangement of the Polytechnic buildings on the site, the amount of building site preparation and excavation was also considered. The site of the Polytechnic is located on the lower slopes of the South Pare Mountains. Although it is not a severe slope the project site is not level. Before construction could begin, the building pads 
need to be leveled out. This requires excavation in some areas and placement of soil in others, commonly referred to as cut and fill.

Heavy earth moving equipment and tractors are available for hire at a daily rate including the time of a trained driver and the cost of fuel. The alternative is to excavate using manual labor. While the hiring of heavy equipment will allow for the work to be completed faster, the cost could outweigh the benefit. Labor is inexpensive but moving large quantities of soil is time consuming when only using hand tools. Regardless of which method is used, the buildings are situated in a manner that limits the amount of cut and fill required without interfering with the passive environmental systems of the buildings. This was achieved by placing the buildings on the site so that the longer dimension of the buildings ran along the slope of the hill and not into it (see Figures 8 a \& b). 


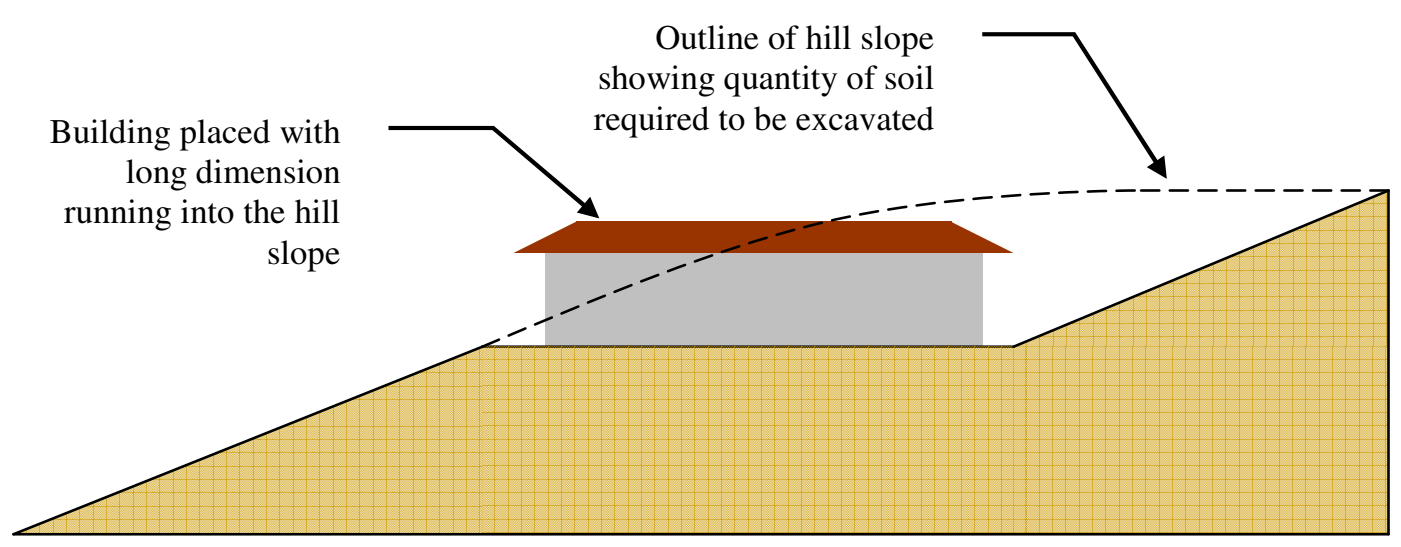

Figure 8 a: Illustration of increased excavation required to prepare site for buildings running into hill slope

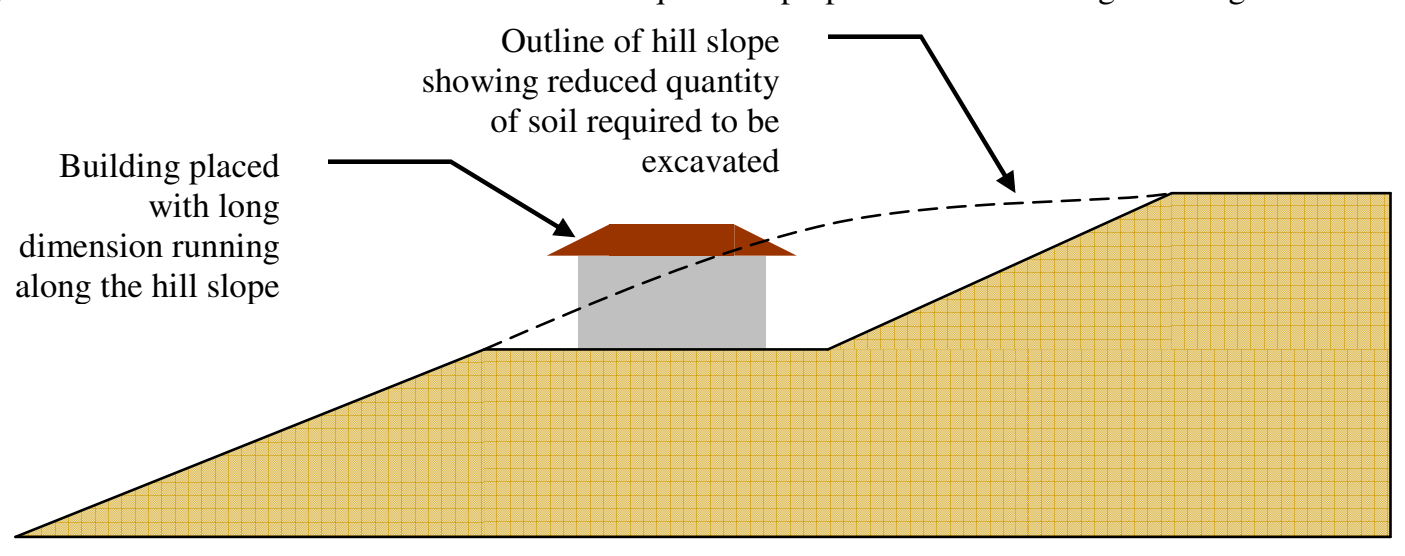

Figure 8 b: Illustration of decreased excavation required to prepare site for buildings running along hill slope

\subsection{Masonry Wall Construction Sequence}

The unique wire reinforced masonry wall system described in Section 5.4.2 posed a unique challenge to build. During the design of the wall system, close collaboration between the structural and construction disciplines was required to ensure that the final design could be built. The wire mesh could not be cut up into small pieces for the ease of construction as that would have reduced the integrity of the system but running a single piece up and over the wall would be difficult in the field. A construction sequence was 
developed by both the structural and construction disciplines to ensure that the walls had the proper strength and were not too difficult to erect (see Figure 5 p).

\subsection{Material Quantity and Labor Cost Estimation}

Once design work was completed, material quantity and labor estimates for the construction of the Polytechnic were developed. The estimates provide a comprehensive construction cost estimate for the entire project. Additionally, the estimates provide a safety check for the Diocese during the hiring process of construction teams. This check is necessary due to the construction process in rural East Africa. Construction projects are put out to bid to teams of builders led by the most experienced individual of the group referred to as "fundi" which roughly translates into artist. The fundis evaluate the project and submit a work proposal. The proposal contains the fundi's estimate for the cost of labor and does not address the cost or amount of materials required. A fundi is then selected based on this bid. Once a fundi is selected, he submits a request for materials to begin construction. It is the responsibility of the owner or developer to purchase the materials and transport them to the job site. The material and labor estimates serve as a cross check for the Diocese to protect itself against cost inflation by the fundi. This is a common risk for construction endeavors in rural East Africa, especially for well known and high profile groups known to have funding available for construction, such as the Catholic Church (see Appendix A). 


\subsection{DESIGN RECOMMENDATIONS}

The following recommendations are intended to assist development groups in the design and construction of facilities in East Africa and are primarily based on the design experience gained from the Same Polytechnic, Tanzania project as well as the Nyumbani Village, Kenya project (see Appendix A). The recommendations represent a summary of the lessons learned and information gathered from the noted projects and serve as a starting point for future projects. However, while these recommendations address some of the most critical considerations, they do not constitute a complete list of all the factors that need to be considered in the design of future projects nor do they serve as a replacement for the involvement of experienced individuals in a design team.

\subsection{Engagement of University Resources}

Universities can offer valuable resources, information, and services to development organizations in the design and construction of facilities in rural East Africa. The design of buildings and other facilities is a complicated and intricate process that involves the participation of experienced individuals from several professions. The involvement of such individuals in development projects similar to the Same Polytechnic is usually on a volunteer basis which means that sometimes it is not possible to assemble an interdisciplinary design team with all the necessary professions represented. Certain Universities have degree programs in most or all of the building design professions and engaging the administration and faculty of these Universities can lead to a better balanced design team consisting of supervised students studying in the various programs. 
There are organizations of volunteer professionals that focus on assisting development projects in East Africa and other regions of the world. However, the members of each of these groups usually come from one design profession and the groups operate independently from each other leaving the project developer to contact and engage each one separately. If a complete design team is formed from these types of organizations, the management and coordination of the different groups and their work will most likely be the responsibility of the developer. This could prove very difficult for inexperienced developers if the groups are located in different areas and if the volunteers are occupied with their professional obligations.

The localized campuses of most Universities means that the different disciplines of a faculty supervised student design team would be able to work in close proximity to one another resulting in improved communication and coordination. Additionally, it could be possible to include the student design work into the University's curriculum increasing the amount of time and effort the students and faculty are able to commit to the project design. If the right University is found then this option for assembling a design team could be easier than trying to engage volunteer professional organizations independently.

Finding specific information for facility design and construction for underdeveloped and remote regions of rural East Africa is difficult. This required information can vary from the strength of steel needed in structural engineering, to climate information for architectural design to the price of cement for cost estimation. While this information is readily available in East Africa, there are no known platforms 
(i.e. websites) that provide direct access to it for individuals or groups located outside the region. Contacting local Universities in East Africa can provide a connection to appropriate faculty members with access to or prior knowledge of this information. The Same Polytechnic design team contacted faculty at the University of Dar es Salaam who willingly provided the necessary information which allowed the team to make better informed decisions in the design process. East African Universities can be identified and contacted through their websites which most of the major educational institutions maintain.

\subsection{Involvement of Volunteer Professional Organizations}

The involvement of volunteer professional organizations is recommended even if a complete design team is formed through other means (i.e. Universities) because of the valuable knowledge some of these groups posses from past involvement in projects in East Africa. These groups can be identified through internet searches and the following is a list of the professional groups that assisted in the design of the Same Polytechnic.

\subsubsection{Engineers Without Borders}

Engineers Without Borders (EWB) is a well developed organization with representatives in many East African countries. Their experience and contacts can provide a multitude of useful information pertinent to design and construction in rural communities in the region. EWB focuses on the design and construction of civil infrastructure projects (i.e. water \& sanitation systems) drawing on knowledge of the most current technology and applications. However, the organization's willingness to 
participate as a member of a larger team is questionable although individual members may be willing to contribute.

\subsubsection{Lifewater International}

Lifewater International is a Christian based non-profit organization focused on providing developing communities with safe drinking water, adequate sanitation, and hygiene through partnerships with other organizations. Lifewater assists in the design of water and sanitation systems, provides information and technical documents on how to design these systems, and offers information and training in the proper construction of these water and sanitation systems.

\subsubsection{World Housing Encyclopedia}

The World Housing Encyclopedia (WHE) is a joint project by the Earthquake Engineering Research Institute (EERI) and the International Association for Earthquake Engineering to provide a resource of housing and construction types in seismically active regions of the world. The WHE offers reports on types of construction used in particular regions, resources on basic earthquake information and tutorials on recommended construction methods.

\subsection{Site Visit}

A visit to the local region of the project location will provide valuable information that would not be available by any other means. There is very little information readily available pertaining to the availability and cost of construction materials in East Africa. It is difficult even to find information on the cost of cement which is a major industry in 
the region. Some larger international suppliers have websites that provide a list of their products that are available in the region but these products are usually more expensive and are available only in major metropolitan areas making applications in rural locations difficult. A site visit will also clarify access to and the condition of any civil infrastructure in the area which includes roads, electricity, and piped water. Knowing the status of these utilities can have a significant effect on the design of a project.

A site visit to a rural project location will allow for the compilation of a list of materials available from hardware stores located nearby (see Appendix C). In addition, a survey of the local tradesmen can identify the types of building materials that can be manufactured locally (i.e. fired adobe, cement stabilized soil blocks). While there is a limited range of building materials available throughout East Africa, some areas do have access to some specialized materials. For example, a unique type of stone brick but from sedimentary rock formed by volcanic deposits from past eruptions of Mt. Kilimanjaro is available in the District of Moshi to the north of Same (see Figure 9 a). The brick is durable, strong, and inexpensive and is used in a vast majority of construction projects in the District. The District of Same holds large deposits of gypsum under the top soil. Gypsum has many applications but is most commonly used in the production of cement and most of the domestic manufactures harvest gypsum from the area around Same. The local construction teams have begun experimenting with gypsum as an additive in the production of CSSBs to determine if there are any benefits (see Figure $9 \mathrm{~b}$ ). A site visit is the only way to identify similar options in other rural areas where access to information is limited. 


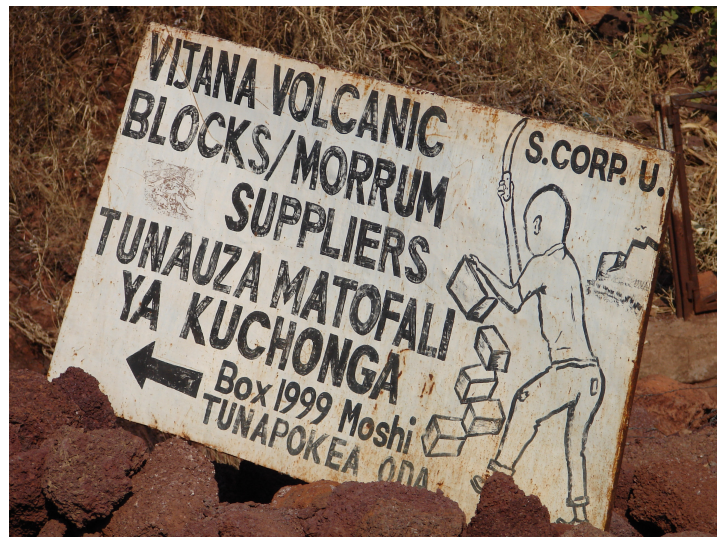

Figure 9 a: Volcanic stone brick manufacturer Moshi, Tanzania

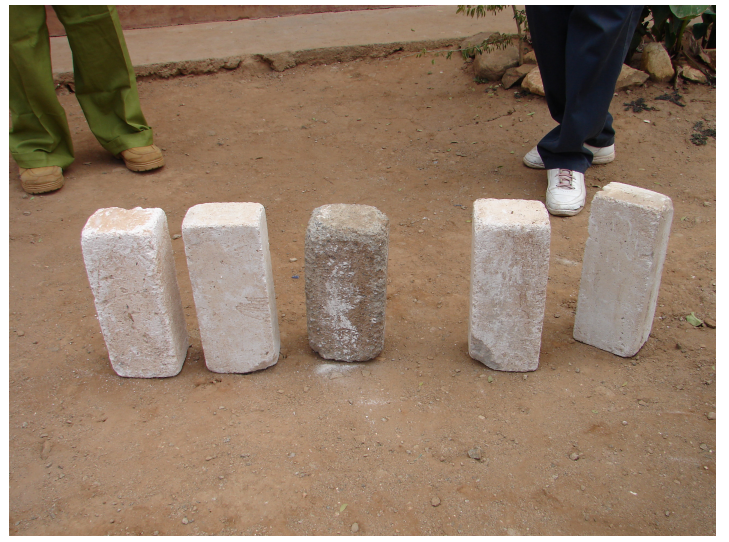

Figure 9 b: Experimental gypsum bricks Makanya, Tanzania

\subsection{Recommendations for Architectural Design}

The hot and arid climate of East Africa needs to be a primary consideration in the architectural design of buildings and facilities to be constructed in the region in order to provide a more comfortable indoor environment over current norms. Powered mechanical environmental control systems are very expensive and maintenance in rural areas is difficult which leads to the recommendation of implementing passive environmental systems.

Passive environmental systems affect building design based on the surrounding climate. There are many resources available on the different types of passive systems and selecting based on the surrounding environment and most architects are knowledgeable in the selection process. The implementation needs to take place early in the design process because these systems influence not only the form of the building but placement and orientation on the site and the selection of building materials as well. Passive systems may impact the initial cost of construction for a project but can 
drastically reduce the long term operating costs associated with buildings (i.e. energy costs). This makes them highly recommended for non-profit development projects since it allows for more funding to be directed towards the goals and activities of the project. The climate conditions of East Africa also include a large amount of daylight which can be utilized in natural daylight systems to illuminate the interior of buildings. The use of natural daylight reduces the amount of electric lighting needed during the daytime hours which will subsequently reduce operating costs from electricity use. Natural daylight systems influence the placement of windows and other openings in a building as well as its architectural form requiring that they be considered concurrently with passive environmental systems should the both be employed in the design of a project. In addition to the financial benefits, natural daylight is a more pleasant lighting option for humans over electric lighting.

The culture of the local population also needs to be a design consideration for building in rural East Africa (see Figure $9 \mathrm{c}$ ). Religion and other ethnic or cultural issues are very sensitive and, therefore, must be considered if a community development project is to succeed with the support of the local population. To understand the issues and how they pertain to building design, the local culture and history and population need to be researched. For certain populations and cultures in remote areas, this research may require a site visit to obtain enough information for design purposes and the design team should be aware of this early on. 


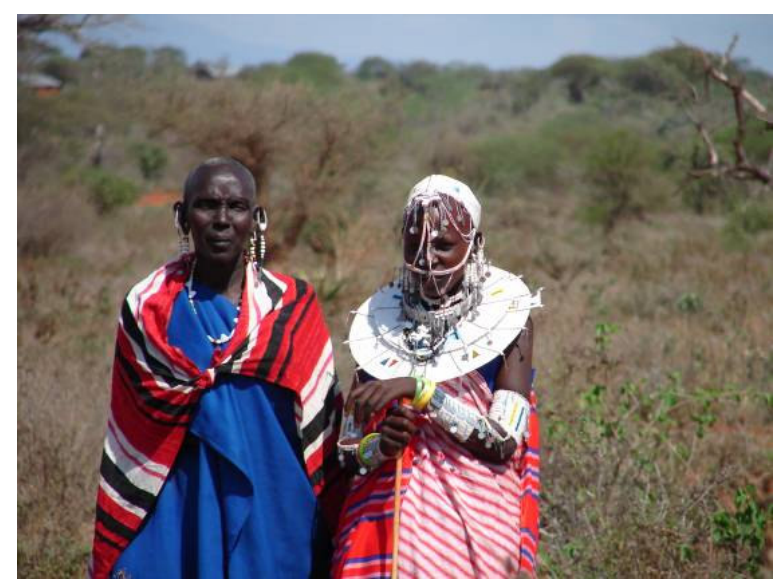

Figure 9 c: Masai women - Same, Tanzania

\subsection{Recommendations for Structural Design}

Consultation with structural engineers and experienced builders is highly recommended for any construction project in rural East Africa. The region is seismically active making the common un-reinforced masonry buildings potentially unsafe during an earthquake but structural engineers are able to provide improved safety using the locally available materials. Recommendations and tutorial resources on building using masonry and reinforced concrete in developing regions are available from the World Housing Encyclopedia and should be reviewed. These documents provide a good overview of the safety concerns, improved structural systems, and construction methods that can be employed. However, using this information does not substitute the contributions of engineers.

The structural design of buildings should incorporate the skill level of the workforce involved. The shape and structure of buildings should not be overly complicated in order to reduce the possibility of problems arising from varying degrees 
of proficiency in the various building trades (i.e. masonry, welding). This concern may be lessened by the presence of an experienced supervisor who is an experienced and trusted local or a foreign volunteer experienced in construction allowing for more freedom in the design of the facilities.

The use of adobe should be avoided if financially possible. While affordable and durable in dry environments, the tropical rains of East Africa pose a threat to adobe buildings. A properly designed and constructed adobe building may not have any problems with rain but flooding is not an uncommon occurrence in the region. During floods, the lower portions of walls become saturated and if the water remains long enough then the entire building could collapse under its own weight. For this reason, building with adobe in river and lake valleys or flood planes should be avoided but its use may still be considered on sloping sites, unless funding permits the use of cement stabilized soil blocks or stone masonry.

\subsection{Recommendations for Water Systems}

It is highly recommended that experienced water system designers and builders are consulted for any project in East Africa because of the severe consequences possible from a poorly designed and/or implemented water system. Access to clean water is critical for human health, hygiene and sanitation. A poorly designed water and sanitation system can promote disease and other ailments possibly resulting in death. Adequate distance and barriers must be put in place to protect clean water sources from refuse and other contaminates. Proper storage must also be provided to prevent the spread of disease and bacteria. 
The dry conditions present throughout most of East Africa and the absence of an extended civil water distribution system in rural areas increase the necessity for an adequate water system. These conditions dictate that a bore hole or well is required for more regular on site access to clean water. Rain water systems should be considered in support of bore holes to help offset the cost of running the pumps necessary to pull water up to the surface. Rain water collection systems also reduce the demand on the underground water table from which the bore hole draws water from, decreasing effects on the local environment already deprived of water. Collected rain water can be used for irrigation, in toilets, and for washing; however, it is not initially safe for human consumption but can be treated if required.

\subsection{Landscape Architecture}

Landscaping is an important element in the design of a comfortable and pleasant internal and external environment for humans. Landscaping can offer protection from wind and noise while improving the visual aesthetics of the building and the surrounding area. Trees and plants help keep buildings and environments cool by complimenting passive environmental systems. Trees and foliage should be carefully arranged around buildings to provide shade but not interfere with ventilation and interior lighting and protect the building's foundations from damage caused by roots. Landscaping can also provide sound and visual barriers to add privacy, help define spaces, and direct pedestrian traffic.

Landscaping and agriculture should only include native and previously established non-invasive plants. This is to ensure that new species are not introduced that 
could threaten native plants in a region where many are already endangered. These native species will also perform better in the East African climate and require less maintenance and water.

\subsection{Construction Management}

It is very important to estimate what quantities of the different building materials will be required to build a project before construction starts because in East Africa, the responsibility of purchasing materials is the responsibility of the developer. The materials are purchased in quantities requested by the construction teams or hired contractors. Previously developed material quantity estimates will provide a check to ensure that excessive amounts of materials are not being ordered which would consume more funding and possibly put the project in danger of not being completed. If prices of materials are available then material quantity estimates will make cost estimation for the project much easier and more accurate.

If possible, it is highly recommended to have representation of the development group present on site to supervise construction. This individual or group of individuals should have construction or building industry experience to be effective in speeding up the construction process. To speed up the construction process, the method of construction needs to be thought out in advance. Pre-determining the order of construction and how facilities will be built will allow the developer's representative to organize construction teams and properly schedule the purchasing and delivery of building materials on site. It will also be possible to better estimate how long construction will take, how much labor is required, and at what cost. The representative 
will also be able to observe the construction and ensure the quality of work and materials are adequate to reduce the need for repairs from faulty work (see Figure 9 d).

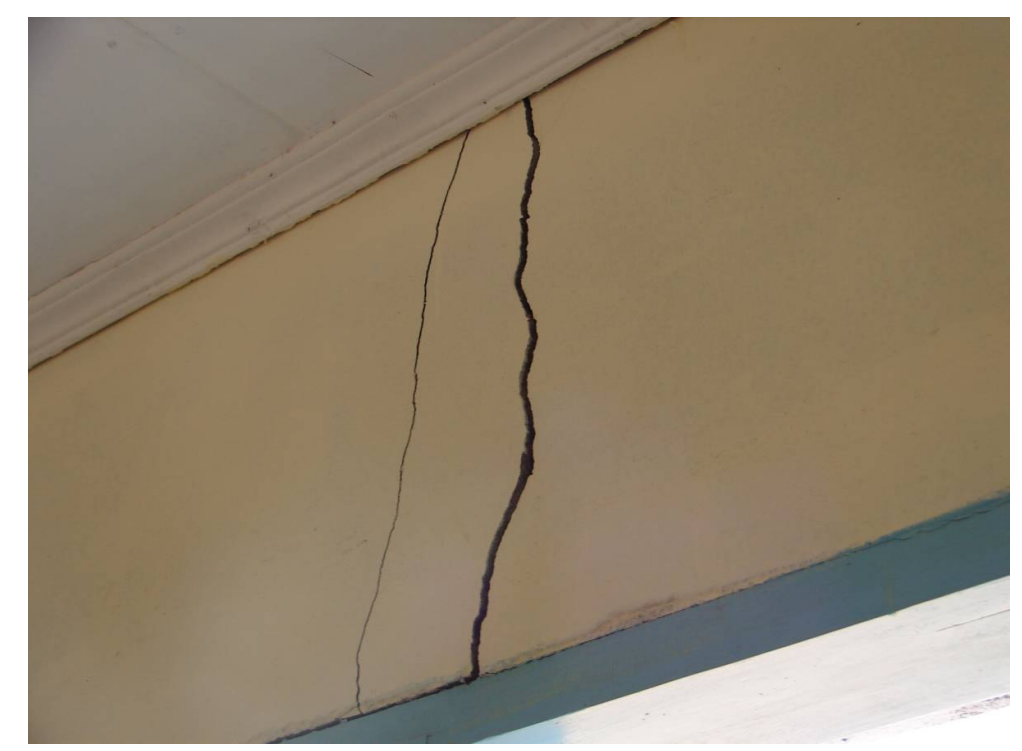

Figure 9 d: Severe cracking in the masonry of a newly constructed clinic - Makanya, Tanzania 


\subsection{INFORMATION RESOURCE LIST}

The following is a list of information resources that proved useful during the design of the Same Polytechnic:

- Topographic Information \& Maps

○ East View Cartographic - http://www.cartographic.com

- Climate Information

○ WeatherReports.com - http://www.weatherreports.com

- Seismic Hazard Information

- United States Geologic Survey http://earthquake.usgs.gov/regional/world/index.php?region=Africa

○ TI 809-04, Seismic Design for Buildings http://www.hnd.usace.army.mil/techinfo/ti/809-04/ti80904.htm

- Structural Material Properties

○ University of Dar es Salaam, College of Engineering and Technology http://www.coet.udsm.ac.tz

- Structural Systems \& Construction Methods

○ World Housing Encyclopedia - http://www.world-housing.net

- Water \& Sanitation Systems

○ Lifewater International - http://www.lifewater.org

- Water System Materials

○ Simba Plastics - http://www.simbaplastics.com 


\subsection{CONCLUSION}

The comprehensive design of buildings or any facilities is a complicated process involving multiple parties each requiring specific information to evaluate the many factors involved to provide a successful design. For development projects in East Africa, the complexity and difficulty of this process is amplified by the unique conditions which must be considered in addition to the project goals for a design to be successful and buildable. The challenge for constructing development projects in the region is again amplified by the lack of design and construction experience of those initiating the projects. Therefore, these important projects that seek to improve the quality of life of rural communities in East Africa are severely challenged; and there are no support networks or resources readily available. Even the more prominent institutions like the United Nations and the United States Agency for International Development do not offer support or advice to groups seeking to build facilities in the East African region in support of their development efforts.

This document and recommendations serve as the starting point for a resource of guidelines which will continually be built upon by the experiences and lessons learned from future projects in the region. With each new project, more knowledge will be gained which can be applied towards improved designs. The long term goal for this body of information is to help protect development groups and their efforts from being hindered or halted by the financial consequences of poorly designed and/or built support facilities and to support them in their goals of improving the lives of the people of East Africa. 


\subsection{BIBLIOGRAPHY}

(CIA 2008) United States Central Intelligence Agency. The World Factbook. Langley, VA: CIA, $2008<$ https://www.odci.gov/library/publications/the-worldfactbook/geos/tz.html> (accessed March 1, 2008).

(Lifewater 2008a) Lifewater International. Methods of Combined Washwater and Excreta Disposal: Technical Note No. SAN. 2.M. San Luis Obispo, CA: Lifewater International, $2007<$ http://lifewater.org $>$.

(Lifewater 2008b) Lifewater International. Designing Septic Tanks: Technical Note No. SAN. 2.D.3. San Luis Obispo, CA: Lifewater International, 2007 $<$ http://lifewater.org $>$.

(Maghimbi 2007) Maghimbi, Sam. "Recent Changes in Crop Patterns in the Kilimanjaro Region of Tanzania: The Decline of Coffee and the Rise of Maize and Rice." African Study Monographs. Suppl. 35. 73-83, March 2007, Kyoto University, Kyoto, Japan.

(Pohl 2007) Pohl Ph.D., Jens. The Emergence of Building Science: Historical Roots, Concepts, and Application. Collaborative Agent Design Research Center, California Polytechnic State University, San Luis Obispo, CA 2007.

(Tanzania Census 2002) United Republic of Tanzania National Bureau of Statistics. 2002 Population and Housing Census. Dar es Salaam, Tanzania: N.B.S., 2002 $<$ http://www.tanzania.go.tz/census> (accessed March 1, 2008).

(USGS 2007) United States Geologic Survey. “Africa Seismic Hazard Map," USGS Science for a Changing World.

$<$ http://earthquake.usgs.gov/regional/world/africa/gshap.php> (accessed August 1, 2007)

(U.S. State Dept. 2007) United States Department of State, Bureau of African Affairs. Background Note: Tanzania. Washington D.C.: US Dept. of State, 2008 $<$ http://www.state.gov/r/pa/ei/bgn/2843.htm> (accessed March 1, 2008).

(WHE 2005) World Housing Encyclopedia. Construction and Maintenance of Masonry Houses: For Masons and Craftsmen. Ed. Marcial Blondet. Pontificia Universidad Católica del Peru, Lima, Peru 2005. 


\section{APPENDIX A: NYUMBANI VILLAGE}

\section{A.1 Introduction}

The following is a compilation of field observations of design and construction considerations made during July 2006 and January 2007 at the Nyumbani Village Project in the Eastern Province of the Republic of Kenya (see Figures A $1 \& 2$ ). The particular construction projects of the Village detailed in this Appendix were chosen for their illustration of construction quality issues and the resulting design considerations applied to the Same Polytechnic

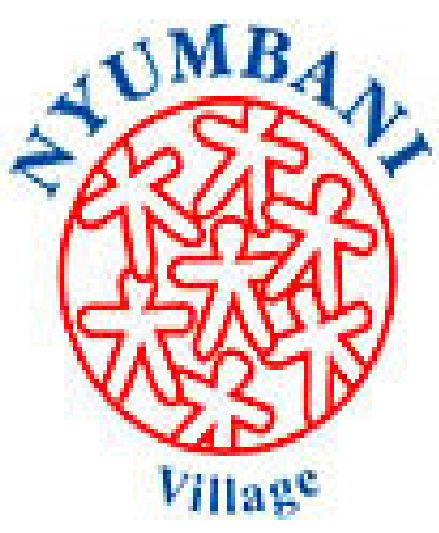

Figure A 1: Nyumbani Village Project Logo Project.

\section{A.2 Nyumbani Village Project Description}

The Nyumbani Village is the fourth project in the Nyumbani family of AIDS relief measures. All of the Nyumbani projects have been implemented and are supported by the Children of God Relief Institute founded by Fr. Angelo D'Agostino. The Nyumbani Village in Kenya will be a self-sustaining community to serve orphans and elders who have been left behind by the "lost generation" of the AIDS pandemic. Through group homes and community institutions, the Village will harness the energy of youth and the maturity of elders to create new blended families that foster healing, hope and opportunity. The goal is to provide compassion and service to all affected by AIDS, so that they will rise up to lead productive, safe and comfortable lives. 
The Village provides a family-like setting for orphaned children under the stewardship of elderly adults and ensures that the community-based clients and Village residents will receive love, sustenance, health-care and education, aiming at their physical and spiritual development. With an ample area of tillable land, the occupants will sustain themselves through agriculture, poultry, dairy projects as well as handicrafts and external services. The adolescents will benefit from the knowledge of the elderly occupants, who in turn will benefit from the support of the younger population. Vocational opportunity in the form of training, tools, and start up financing for trades, cottage industry and agricultural endeavors will be provided with the goal of self-sustaining independence, financial security and stability for residents, particularly maturing young people (Nyumbani 2008).

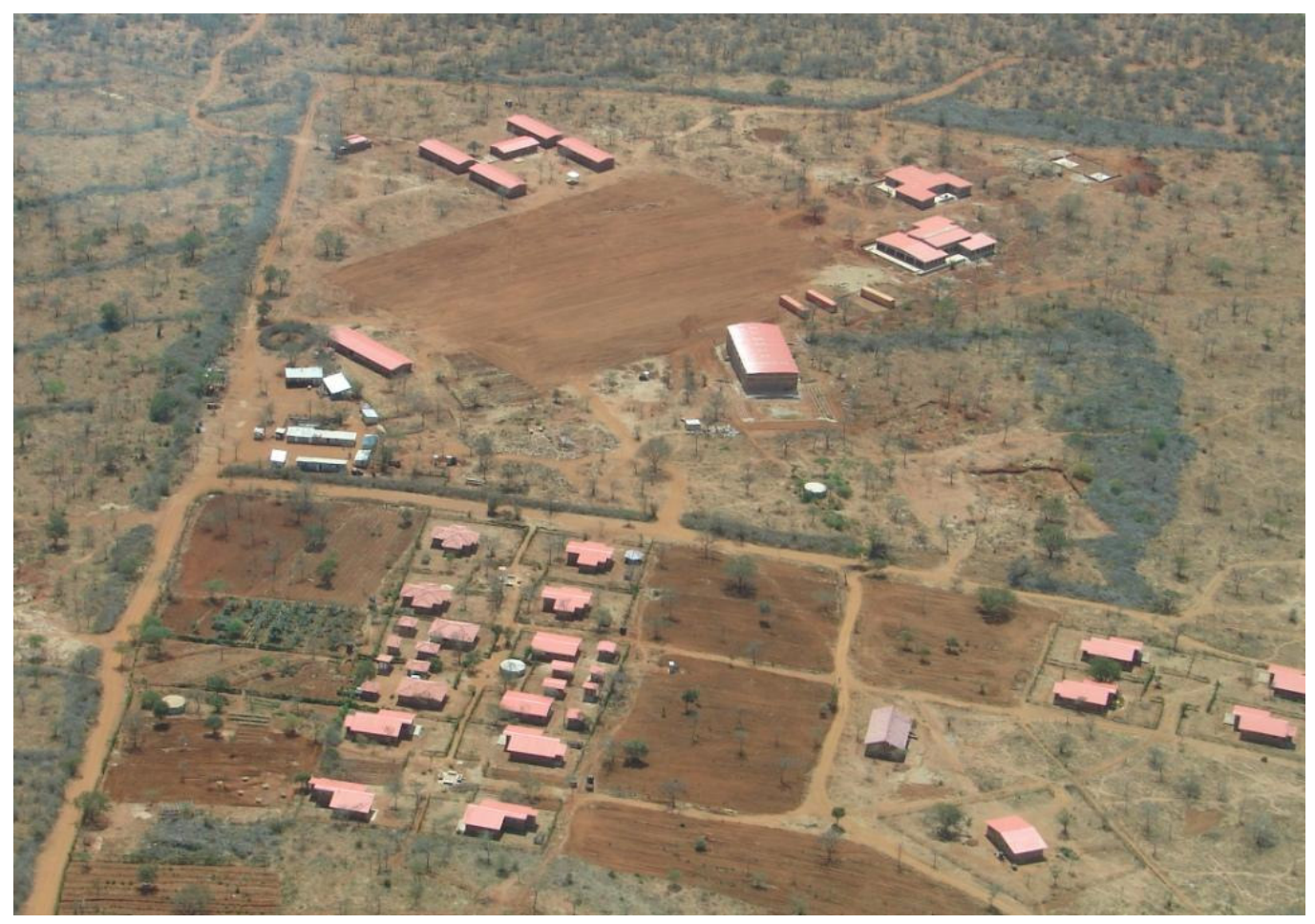

Figure A 2: Partial aerial view of Nyumbani Village 


\section{A.3 Cattle Boma Case Study}

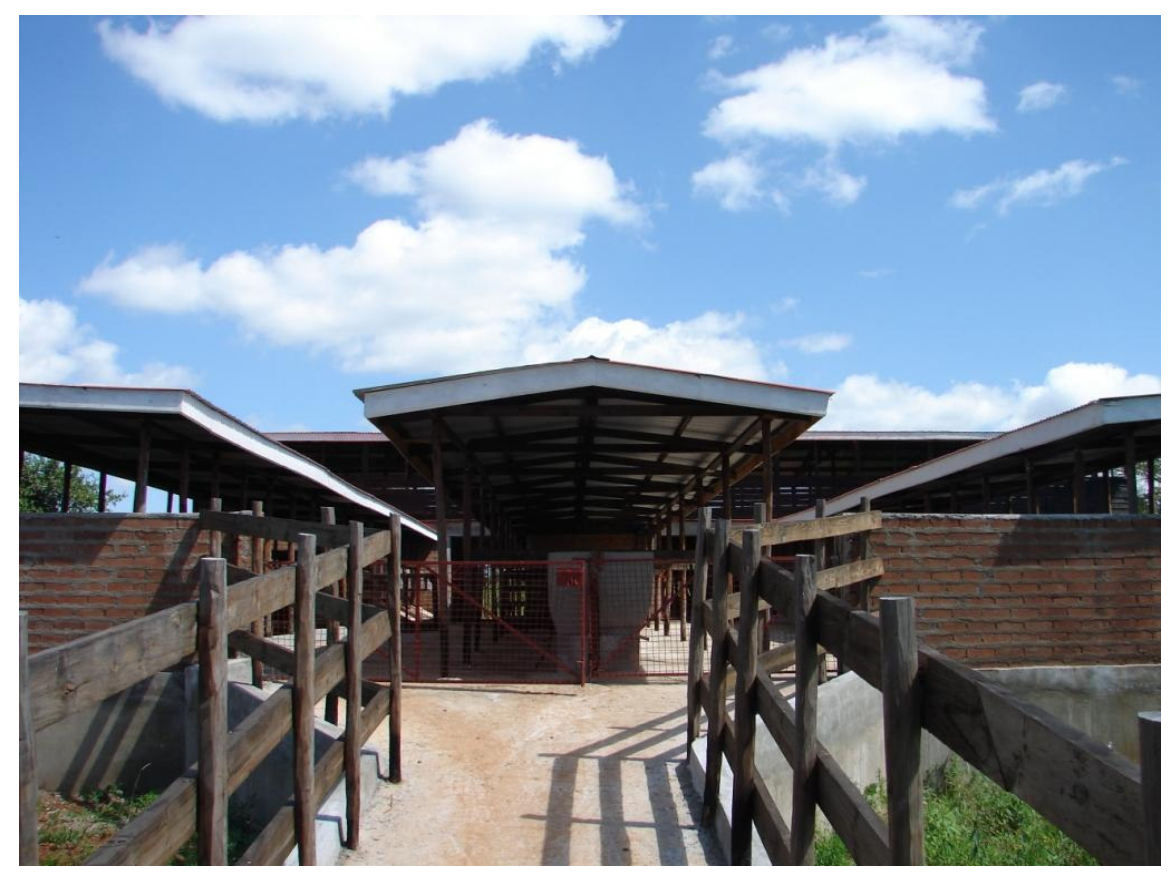

Figure A 3: Cattle Boma - Nyumbani Village, Kenya

The cattle boma or cattle barn is one of the primary agricultural facilities serving the Village's Sustainability Program (see Figure A 3). Its construction highlighted several critical challenges for building in East Africa. As is the case with many construction projects, only architectural drawings were provided when construction was started. The structural system design was left to the local construction team without any official review. The building was constructed with fully mortared masonry bearing walls on the first floor partially supporting timber floor framing for the second floor above. The bearing walls sat on top of reinforced concrete spread footings and masonry stem walls with a concrete slab for the interior floor. Away from the walls on the first floor, 
the second floor was supported by timber poles cast directly into the concrete slab. The walls of the second floor were made of timber siding and wire mesh for ventilation. The second floor was intended to store hay feed for the cattle. The corrugated steel roof was framed using timber trusses supported by timber poles at the exterior walls and along the interior span.

The masonry joints were not properly mortared. The mortar in between the individual masonry units increases the strength of the overall structure. During construction, wet mortar is applied to masonry units which are then placed in rows to form walls. As the wet mortar sets, a bond forms between the mortar and masonry. This bond adds strength to the whole wall. The masonry walls of the boma were not fully mortared with spaces and gaps present between the masonry bricks (see Figure A 4). These gaps reduced the strength of the wall in addition to the improper preparation of the mortar.

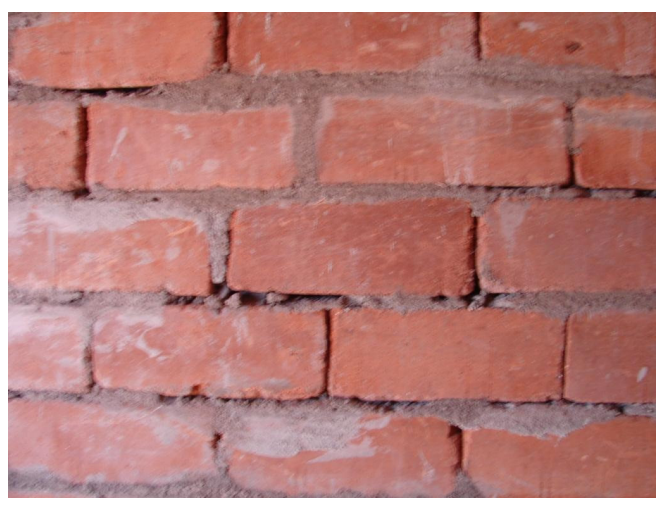

Figure A 4: Poorly mortared joints of the Cattle Boma masonry walls - Nyumbani Village, Kenya

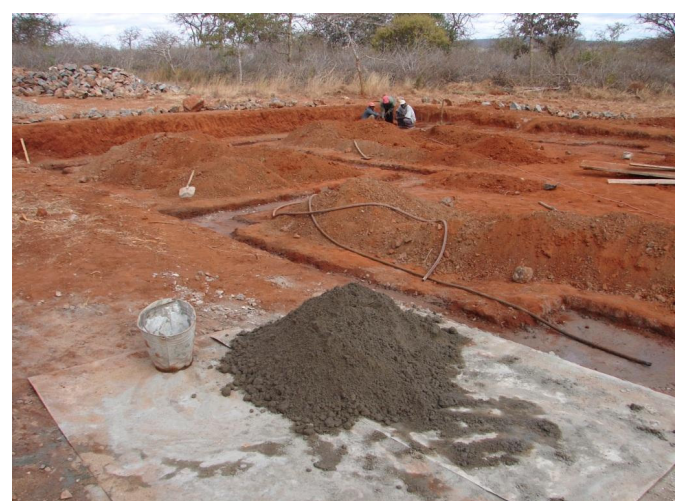

Figure A 5: Very dry mortar mixed in a pile on the ground in the morning and left exposed to the environment - Nyumbani Village, Kenya 
In order for a proper bond to form between the masonry and mortar, enough water needs to be added to the sand and cement to produce a mortar that is thick and sticky but not runny. If not enough water is added, then the mortar will not properly bond to the masonry. The mortar used in the construction of the boma was too dry and an adequate bond did not form. Fresh mortar was not used either. Mortar for the entire day's work was mixed in the morning and left out in the sun for the entire course of the day (see Figure A 5). During this time, the cement is undergoing the chemical reaction that gives the mortar its strength. Using this single source reduces the effectiveness of the bond further. Two weeks after the half-height masonry walls of the cattle stalls were laid, the top rows of bricks could be picked off the wall illustrating the weakened state of the bond.

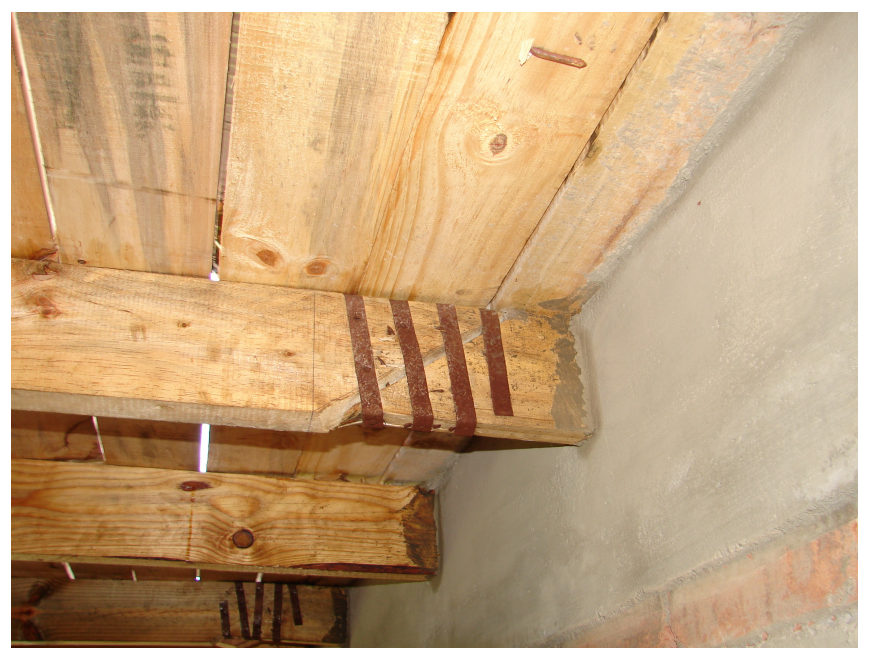

Figure A 6: Timber beams cast directly into concrete

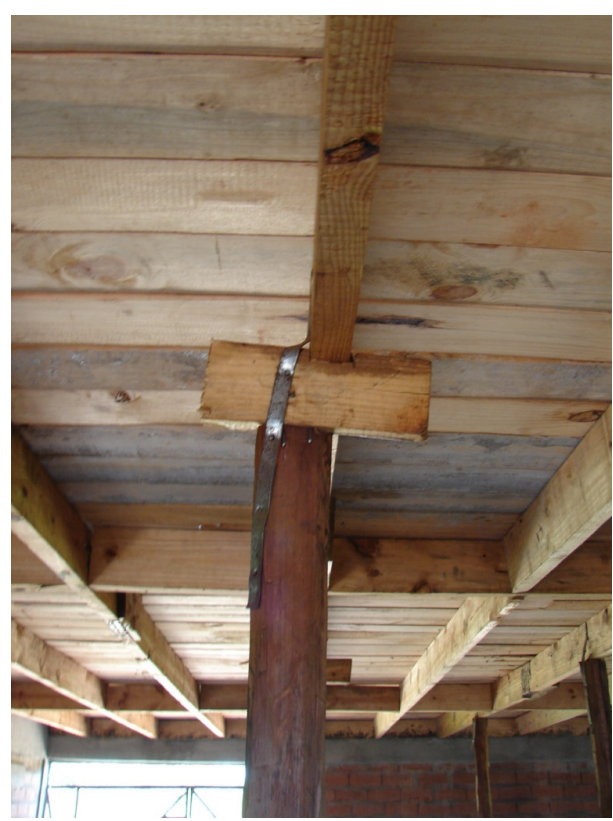

Figure A 7: Poorly assembled connection between timber beam and pole 
The timber beams supporting the floor boards were not properly connected to the walls and the timber poles supporting them. The timber beams were cast directly into concrete without any kind of preservative treatment (see Figure A 6). This increased the chance of the timber rotting in the future. Some of the connections of the beams to the columns were assembled with smaller pieces of wood filling in the gap between the beam and pole when the pole had been cut too short (see Figure A 7). This was a dangerous solution and increased the risk of the second floor collapsing once hay-fodder was stored above.

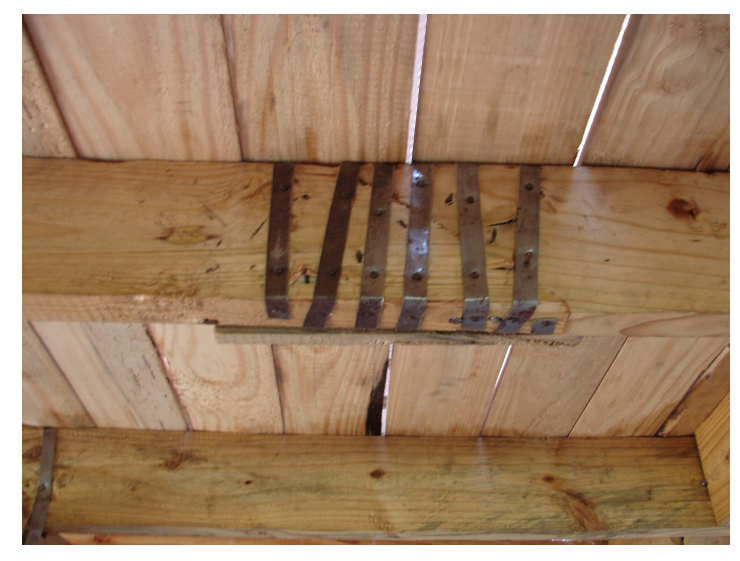

Figure A 8: Two pieces of timber spliced together to serve as a single beam supporting the second floor of the Cattle Boma - Nyumbani Village, Kenya

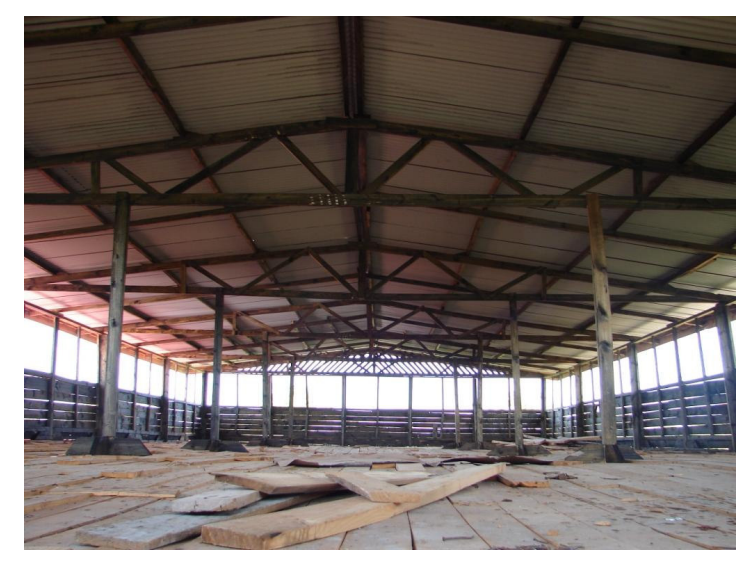

Figure A 9: View of the second floor of the Cattle Boma and the unsupported timber columns

In some areas of the second floor framing, the pieces of timber were too short to span the necessary distance. Instead of purchasing timber pieces that were long enough, two shorter pieces were connected or spliced together to span the distance. This resulted in an unsafe floor structure due to the internal forces acting on beams that support floors. The timber poles on the second floor supporting the timber roof trusses were not 
adequately supported either. The concentrated forces at the base of columns typically require direct support from columns underneath. However, the timber poles on the first floor were not placed directly underneath the columns on the second floor. The distance between the bearing point of the upper columns and the support point of the lower columns is around 2 feet with the second floor poles supported only by the thin floor boards. This is very unsafe and could result in the timber poles punching through the floor leading to a partial collapse of the floor.

Drainage for rainwater was not provided for the cattle stalls which were not fully covered by the roof. During the rainy season, water accumulated in the stall area and flooded the interior of the building. At the other end of the stall area, the water was directed down a ramp by curbs until the ramp ended in a grazing field. Due to the large amounts of water that fell on the building during the tropical rains, the concentrated runoff eroded the soil around and under the foundations of the building which required repairs to prevent a partial collapse of the foundation (see Figure A 10). 


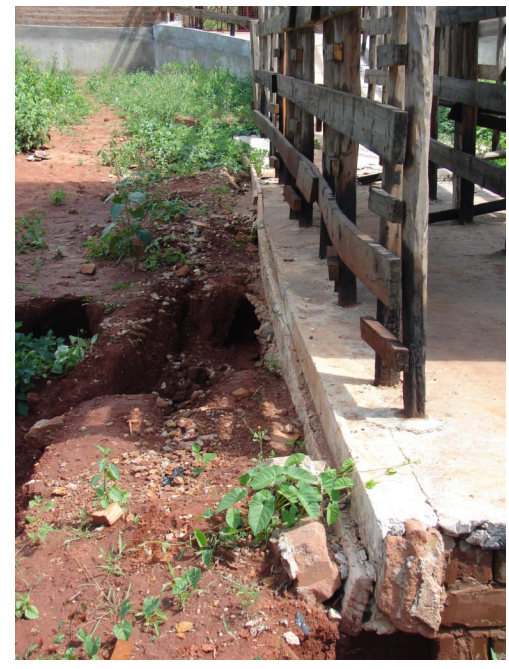

Figure A 10: Eroded soil next to Cattle Boma foundations - Nyumbani Village, Kenya

\section{A.4 Water Tanks}

The water tanks constructed at the Village performed very poorly when filled. Of the 12 water tanks built, 9 developed extensive leaks caused by poor construction and design. The two largest tanks were the most critical with one losing around 300 litres of water per hour and the other losing around 600 (see Figure A 11). The arid environment of the region made water storage a critical element for the success of the Village's agriculture programs. 


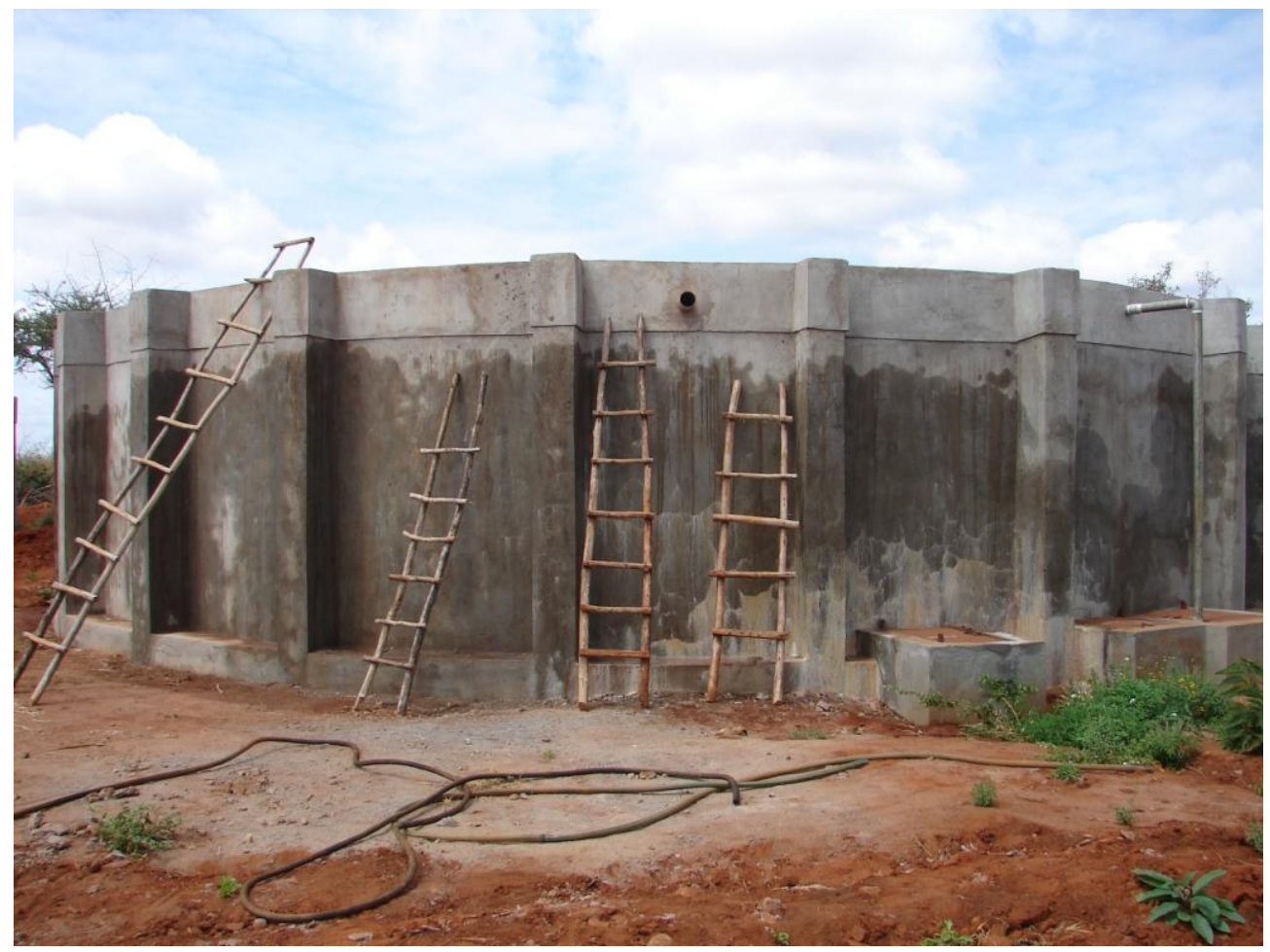

Figure A 11: One of the large water tanks with severe leaks seen in the walls - Nyumbani Village, Kenya

The circular tanks were constructed using cement stabilized soil blocks and cement plaster on the interior and exterior faces. The cement plaster was not properly mixed to provide a water proof barrier. In addition, not enough steel reinforcement was provided to prevent the masonry from cracking under the high loads from the large volume of water contained in the tanks. A single strand of barbed wire was set into the joints between each layer of bricks and run around the full perimeter of the tanks. Steel reinforcing bars were placed in the columns but only went half way up the side of the tank.

The tanks also did not have any reinforcement to prevent cracking due the expansion and contraction of the tank walls from the extreme heat of the sun. As the sun 
heats the tank walls, they expand and then contract during the night. This led to additional cracks developing. During repair work it was discovered that the cement stabilized soil blocks had become so weakened from being saturated with water that they had reverted to mud and were no longer able to support even their own weight (see Figure A 12). The degraded state of the water tanks meant that extensive repairs were required to make the tanks operational. The only tanks that did not develop leaks were the ones placed under ground (see Figure A 13). The support of the soil pressing against the sides of the tanks helped to strengthen the walls and protect them from changes in temperature.

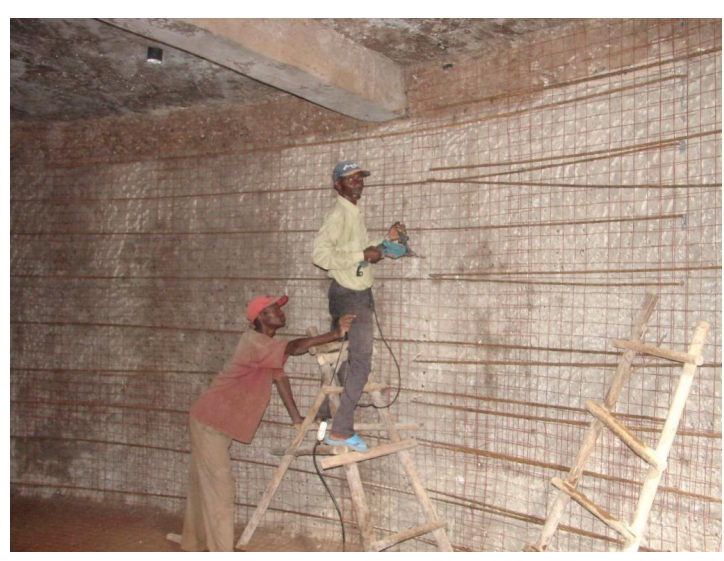

Figure A 12: Water tank repair work in process Nyumbani Village, Kenya

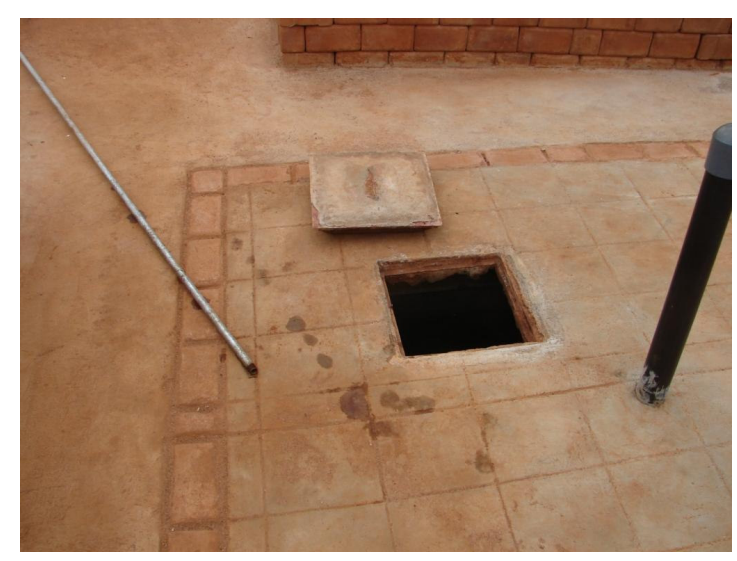

Figure A 13: Underground water tank Nyumbani Village, Kenya 


\section{APPENDIX B}

\section{B.1 Architectural Concept}

\section{Shelters for Living, Learning, and Work}

Written by Prof. Curt Illingworth

From the beginning of the human building experience, there has been a need for shelter.

This little essay on Architecture by Marc Antoine-Laugier reminds us that architecture does not have to be complicated and contorted. Often the simplest forms using locally available materials and constructed by local crafts persons are the most appropriate and beautiful.

It is the same in architecture as in all other arts: Its principles are founded on simple nature, and nature's process clearly indicates its rules. Let us look at man in his primitive state... without any aid or guidance other that his natural instincts. He is in need of a place to rest. On the banks of a quietly flowing brook he notices a stretch of grass; its fresh greenness is pleasing to his eyes, its tender down invites him; he is drawn there and, stretched out at leisure on this sparkling carpet, he thinks of nothing else but enjoying the gift of nature; he lacks nothing, he does not wish for anything. But soon the scorching heat of the sun forces him to look for shelter. A nearby forest draws him to its cooling shade; he runs to find a refuge in its depth, and there he is content. But suddenly mists are rising, swirling round and growing denser, until thick clouds cover the skies; soon, torrential rain pours on this delightful forest. The savage in his leafy shelter, does not know how to protect himself from the uncomfortable damp that penetrates everywhere; he creeps into a nearby cave and, finding it dry, praises himself for the discovery. But soon the darkness and foul air surrounding him make his stay unbearable again. He leaves and resolves to make good by his ingenuity the careless neglect of nature. He wants to make himself a dwelling that protects but does not bury him. Some fallen branches in the forest are the right material for his purpose; he chooses four of the strongest, raises them upright and arranges them in a square; across their top he lays four other branches; on these he hoists from two sides yet another row of branches which, inclining towards each other, meet at their highest point. He then covers this kind of roof with leaves so closely packed that neither sun nor rain can penetrate. Thus, man is housed. Admittedly, the cold and heat will make him feel uncomfortable in this 
house that is open on all sides but soon he will fill in the spaces between two posts and feel secure.

Such is the course of simple nature; by imitating the natural process, art was born. All the splendors of architecture ever conceived have been modeled on the little rustic hut I have just described. It is by approaching the simplicity of this first model that fundamental mistakes are avoided and true perfection is achieved. The pieces of wood set upright have given us the idea of a column, the pieces placed horizontally on top of them the idea of entablature, the inclining pieces form the roof the idea of the impediment. This is what all masters of art have recognized. But take note of this: never has a principle been more fertile in its effect. "The Primitive Hut" From An Essay on Architecture by Marc-Antoine Laugier

The design of the school reminds us of the basic clarity of this type of construction. A structure of posts supporting a pitched roof and surrounded by walls made from local materials provides shelter from the sun, rain, and wind. It has been a model for builders through the ages and one to which they return to again and again. This will be the setting as students begin to learn the lessons that will help them build a life of their own. 


\section{B.2 Architectural Space List}

\begin{tabular}{|c|c|c|c|c|c|c|c|c|c|}
\hline Archite & ctural Space Lis & & & & & & & & \\
\hline Project $\mathrm{N}$ & ame: Same Polyt & echnic & & & & & & & \\
\hline & & & & & & & & & \\
\hline Prelimin & ary Space List & $(1 \mathrm{ft}=.304$ meters $)$ & $(1 \mathrm{Sq} \mathrm{Ft}=.0$ & 229 Sq Meters) & 1 Euro $=1.35$ & Dollars) & & & \\
\hline & & & & & & & & & \\
\hline & & \# of Spaces & Net SF & Total Net SF & Total & Occupancy & Total & Total & Comments \\
\hline & & & & & Gross SF & Factor & Net SM & Gross SM & \\
\hline ADMIN. & [STRATIVE FUN & ICTIONS & & & & & & & \\
\hline & & & & & & & & & \\
\hline & & & & & & & & & \\
\hline Administra & tion & & & & & & & & \\
\hline Lobby/Adn & in Waiting & & 200 & 200 & & & 18.6 & & \\
\hline Secretary & Reception & & 600 & 600 & & $100 \mathrm{sf} / \mathrm{per}$ & 55.7 & & \\
\hline Administrato & I's Office & & 250 & 250 & & $100 \mathrm{sf} / \mathrm{per}$ & 23.2 & & \\
\hline Assit. Direct & or's Office & & 150 & 150 & & $100 \mathrm{sf} / \mathrm{per}$ & 13.9 & & \\
\hline Conference & Room & & 250 & 250 & & $20 \mathrm{sf} / \mathrm{per}$ & 23.2 & & \\
\hline Copy/Work/s & Supply Room & & 150 & 150 & & & 13.9 & & \\
\hline File Storage & & & 100 & 100 & & & 9.3 & & \\
\hline Staff Restro & & & & & & & & & \\
\hline Men & & & 50 & 50 & & & 4.6 & & \\
\hline Women & & & 50 & 50 & & & 4.6 & & \\
\hline Subtotal - & Administration (NSE) & & & 1800 & 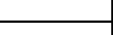 & & 167.2 & & \\
\hline Subtotal - & Administration (GSF & @ $85 \%$ eff.) & & 1,800 & 2,118 & & 167.2 & 196.7 & \\
\hline FACILI & TY SUPPORT & & & & & & & & \\
\hline & & & & & & & & & \\
\hline Facility Su & port & & & & & & & & \\
\hline Bulk Stora & & 1 & 200 & 200 & & & 18.6 & & \\
\hline Public Rest & rooms & & & & & & & & \\
\hline Male & & & 150 & 300 & & & 13.9 & & \\
\hline Female & & & 150 & 300 & & & 13.9 & & \\
\hline Maintenance & Shop & & 1,000 & 1,000 & & & 92.9 & & \\
\hline Electrical $\mathrm{F}$ & $100 \mathrm{~m}$ & & 200 & 200 & & & 18.6 & & \\
\hline Subtotal - & Facility Support (NSF & & & 2,000 & & & 158 & & \\
\hline Subtotal - & Facility Support (GSF & @ 85\% eff.) & & & 2,353 & & & 186 & \\
\hline Laundry & & & & & & & 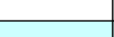 & & \\
\hline Laundry & & & 400 & 400 & & & 37.2 & & \\
\hline Folding & Area & & 100 & 100 & & & 9.3 & & \\
\hline Linen Stol & & & 200 & 200 & & & 18.6 & & \\
\hline Chemcial & Storage & & 50 & 6,000 & & & 557.4 & & \\
\hline Drying ar & & & 100 & & & & & & \\
\hline Subtotal - & Galleries (NSF) & & & 6,700 & & & 622.4 & & \\
\hline Subtotal - & Galleries (GSF@ 85\% & o eff.) & & & 7,882 & & & 732.3 & \\
\hline & & & & & & & & & \\
\hline & & & & & & & & & \\
\hline & & & & & & & & & \\
\hline & & & & & & & & & \\
\hline
\end{tabular}




\begin{tabular}{|c|c|c|c|c|c|c|c|c|c|}
\hline \multicolumn{10}{|c|}{ COMMUNITY FUNCTIONS } \\
\hline \multirow{2}{*}{\multicolumn{10}{|c|}{ Commercial Center }} \\
\hline & & & & & & & & & \\
\hline \multicolumn{9}{|c|}{ see educational fac. } & \\
\hline & & & & & & & & & \\
\hline & & & & & & & & & \\
\hline & & & & & & & & & \\
\hline \multirow{2}{*}{\multicolumn{3}{|c|}{\begin{tabular}{|l|l|l|} 
Subtotal - Auditorium (NSF) & \\
Subtotal - Auditorium (GSF $85 \%$ eff.) \\
\end{tabular}}} & & - & & & - & & \\
\hline & & & & & - & & & - & \\
\hline & & & & & & & & & \\
\hline \multicolumn{10}{|c|}{ Community/Multi-purpose Hall/ student union } \\
\hline \multicolumn{2}{|c|}{ Entry lobby } & 1 & 400 & 400 & & & 37.2 & & open air? Outside \\
\hline \multirow{2}{*}{\multicolumn{3}{|c|}{\begin{tabular}{|l|l} 
Restrooms \\
Men
\end{tabular}}} & & & & & & & \\
\hline & & & 150 & 150 & & & 13.8 & & \\
\hline Women & & 1 & 150 & 150 & & & 13.9 & & \\
\hline Seating & & 1 & 2,400 & 2,400 & & 10 sfiper & 223.0 & & 275 persons \\
\hline Platform & & 1 & 300 & 300 & & & 27.9 & & \\
\hline \multicolumn{2}{|c|}{ Student Lounge } & 1 & 1,000 & 1,000 & & & 92.9 & & \\
\hline \multicolumn{2}{|c|}{\begin{tabular}{l|l} 
Storage & \\
\end{tabular}} & 1 & 300 & 300 & & & 27.8 & & \\
\hline \multirow{2}{*}{\multicolumn{2}{|c|}{ Subtotal - Auditorium (NSF) }} & & & & & & & & \\
\hline & & & & 4,700 & & & 437 & & \\
\hline Subtotal - & Auditorium (GSF 8 & $5 \%$ eff.) & & & 5,529 & & & 513.7 & \\
\hline & & & & & & & & & \\
\hline Multi-Faith & Hall & & & & & & & & \\
\hline Seating & & 1 & 3,000 & 3,000 & & 10 sfiper & 278.7 & & hold 300 people \\
\hline Stage & & 1 & 500 & 500 & & & 48.5 & & \\
\hline Storage & & 1 & 300 & 300 & & & 27.8 & & \\
\hline Restrooms & & & & & & & & & \\
\hline Men & & 1 & 50 & 50 & & & 4.6 & & \\
\hline Women & & 1 & 50 & 50 & & & 4.6 & & \\
\hline & & & & & & & & & \\
\hline Subtotal - & Auditorium (NSF) & & & 3,900 & & & 362 & & \\
\hline Subtotal - & Auditorium (GSF 8 & $5 \%$ eff.) & & & 4,588 & & & 426.2 & \\
\hline & & & & & & & & & \\
\hline Dining $\mathrm{Hal}$ & & & & & & & & & \\
\hline Dining $\mathrm{Hal}$ & & & & & & & & & \\
\hline Seating & & 1 & 2,000 & 2,000 & & 10 sfiper & 185.8 & & hold 200 people \\
\hline Food Prep & & & & & & & & & \\
\hline Kicthen & & 1 & 600 & 600 & & & 55.7 & & \\
\hline Dry gooo & s Storage & 1 & 400 & 400 & & & 37.2 & & \\
\hline Cold sto & age & 1 & 200 & 200 & & & 18.6 & & \\
\hline Freezer & & 1 & 200 & 200 & & & 18.6 & & \\
\hline Pot/dish & washing & 1 & 300 & 300 & & & 27.9 & & \\
\hline Cook's O & Ifice & 1 & 100 & 100 & & & 9.3 & & \\
\hline Staff Restr & ooms & 2 & 50 & 100 & & & 4.6 & & \\
\hline Storage & & 1 & 300 & 300 & & & 27.8 & & \\
\hline Restrooms & & & & & & & & & \\
\hline Men & & 1 & 50 & 50 & & & 4.6 & & \\
\hline Women & & 1 & 50 & 50 & & & 4.6 & & \\
\hline & & & & & & & & & \\
\hline Subtotal- & Auditorium (NSF) & & & 4,300 & & & 395 & & \\
\hline Subtotal - & Auditorium (GSF 8 & $5 \%$ eff.) & & & 5,059 & & & 464.5 & \\
\hline & & & & & & & & & \\
\hline Infirmary & & & & & & & & & \\
\hline Entry/wait: & ing lobby & 1 & 200 & 200 & & & 18.6 & & \\
\hline Nurses Stati & & 1 & 150 & 150 & & 10 sfiper & 13.9 & & \\
\hline Nurses's Off & & 1 & 100 & 100 & & & 8.3 & & \\
\hline Exam Roo & & 2 & 100 & 200 & & & 9.3 & & \\
\hline Patient's r & om & 4 & 150 & 800 & & & 13.9 & & \\
\hline Restroo & & 2 & 50 & 100 & & & 4.6 & & \\
\hline Med-Stora & & 1 & 50 & 50 & & & 4.6 & & \\
\hline Medica Eg & uip. Storage & 1 & 100 & 100 & & & 9.3 & & \\
\hline Restrooms & & & & & & & & & \\
\hline Men & & 1 & 50 & 50 & & & 4.6 & & \\
\hline Women & & 1 & 50 & 50 & & & 4.6 & & \\
\hline & & & & & & & & & \\
\hline Subtotal- & Auditorium (NSF) & & & 1,600 & & & 93 & & \\
\hline Subtotal - & Auditorium (GSF 8 & $5 \%$ eff.) & & & 1,882 & & & 109.3 & \\
\hline
\end{tabular}




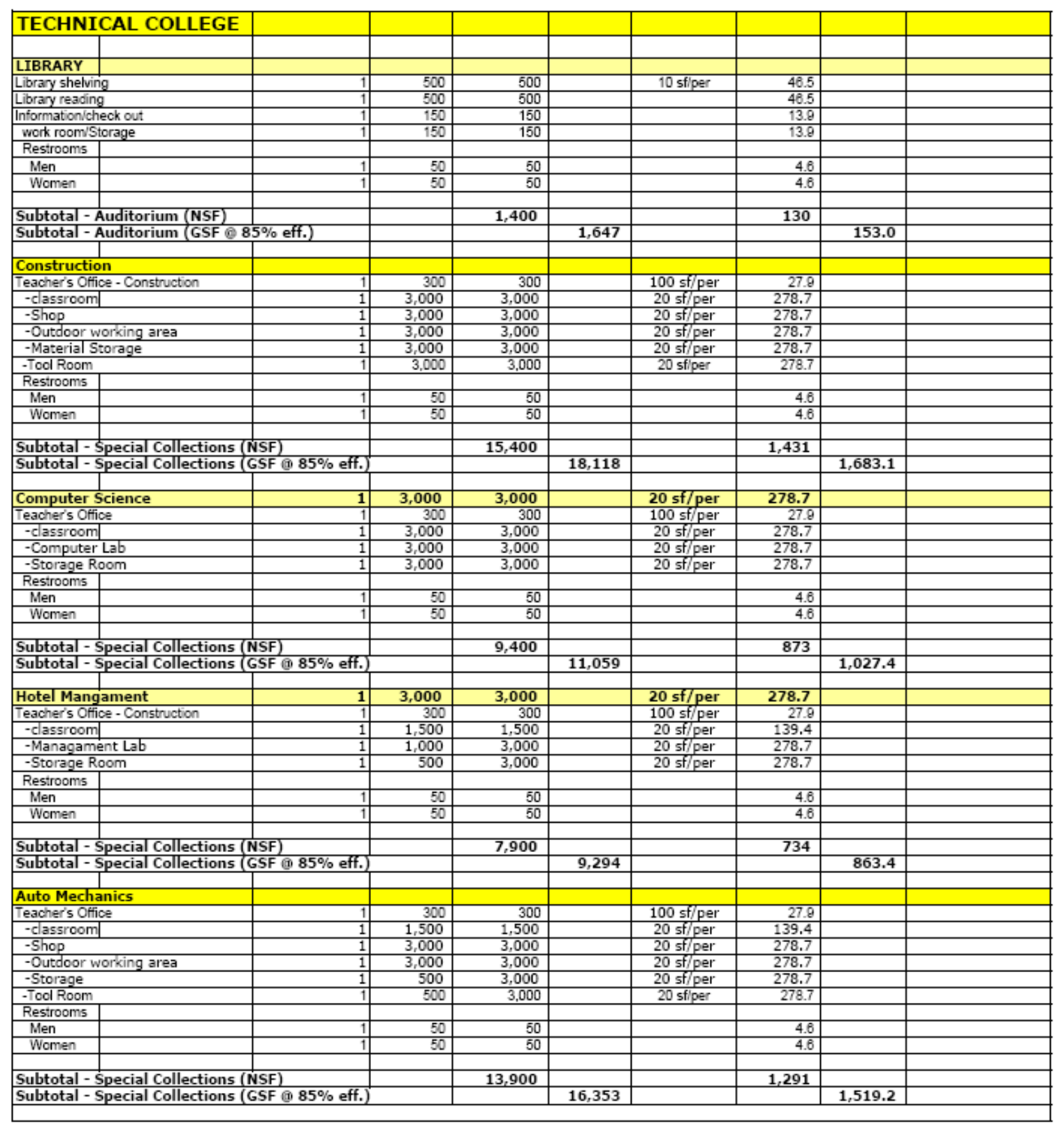




\begin{tabular}{|c|c|c|c|c|c|c|c|c|c|}
\hline HOUSIN & & & & & & & & & \\
\hline & & & & & & & & & \\
\hline Male Stude & int Housing Module & & & & & & & & \\
\hline Study/Rec R & $100 \mathrm{~m}$ & 1 & 500 & 500 & & & 46.5 & & \\
\hline Dorm Module & & & & & & & & & \\
\hline Entry Lobb & & 1 & 100 & 100 & & & 9.3 & & \\
\hline Dorm Roor & & 11 & 150 & 1,650 & & & 13.9 & & 2 persons per room \\
\hline Advisors re & & 1 & 200 & 200 & & & 18.6 & & (2) \\
\hline Bathroom & module & 1 & 300 & 300 & & & 27.9 & & 24 persons per \\
\hline & & & & & & & & & \\
\hline Subtotal - & Galleries (NSF) & & & 2,750 & & & 116 & & \\
\hline Subtotal-c & Galleries (GSF $15^{\circ}$ & eff.) & & & 3,235 & & & 136.6 & \\
\hline & & & 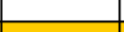 & & & & & & \\
\hline Female Stu & ident Housing Modul & & & & & & & & \\
\hline Study/Rec R & $100 \mathrm{~m}$ & 1 & 500 & 500 & & & 46.5 & & \\
\hline Dorm Module & & & 100 & 100 & & & 93 & & \\
\hline Entry Lobb & & & 100 & 100 & & & 9.3 & & \\
\hline Dorm Roor & & 11 & 150 & 1,650 & & & 13.9 & & 2 persons per room \\
\hline Advisors ro & & 1 & 200 & 200 & & & 18.6 & & \\
\hline Bathroom & module & 1 & 300 & 300 & & & 27.9 & & 24 persons per \\
\hline & & & & & & & & & \\
\hline Subtotal - c & Galleries (NSF) & & & 2,750 & & & 116 & & \\
\hline Subtotal-c & Galleries (GSF $15^{\circ}$ & eff.) & & & 3,235 & & & 154.8 & \\
\hline Staff Housi & & & & & & & & & \\
\hline & & & & & & & & & \\
\hline & & & & & & & & & \\
\hline Mens & & 1 & 1,000 & 1,000 & & & 92.8 & & \\
\hline Womens & & & 1,000 & 1,000 & & & 92.8 & & \\
\hline Subtotal-c & Galleries (NSF) & & & 2,000 & & & 185.8 & & \\
\hline Subtotal-c & Galleries (GSF $15^{\circ}$ & off.) & & & 2,353 & & & 218.6 & \\
\hline & & & & & & & & & \\
\hline Guest cotta & ages & & & & & & & & \\
\hline Unisex Cotta & gges & 6 & 600 & 3,600 & & & 55.7 & & \\
\hline & & & & 3600 & 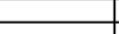 & & 55,7 & & \\
\hline $\begin{array}{l}\text { Subtotal - } \\
\text { Subtotal - }\end{array}$ & (GSF) & & & 3,600 & 4,235 & & 35.7 & 65.6 & \\
\hline RECREA & CTION & & & & & & & & \\
\hline & & & & & & & & & \\
\hline Football Fie & & & & 88,500 & & & & & \\
\hline & & & & - & & & - & & \\
\hline & & & & - & & & - & & \\
\hline & & & & & & & & & \\
\hline & & & & & & & & & \\
\hline Subtotal - & (NSF) & & & - & & & - & & \\
\hline Subtotal - & (GSF (1) 85\% eff.) & & & & - & & & - & \\
\hline Misc, Plavin & & & & & & & & & \\
\hline Misc. Playin & ng Fields & & & & & & & & \\
\hline Mens & & & & - & & & - & & \\
\hline Womens & & & & - & & & - & & \\
\hline Subtotal - & $\begin{array}{l}\text { Galleries (NSF) } \\
\text { Galleries (CSF }\end{array}$ & eff) & & - & - & & - & - & \\
\hline Subtotal-C & & oeff.) & & & - & & & - & \\
\hline
\end{tabular}




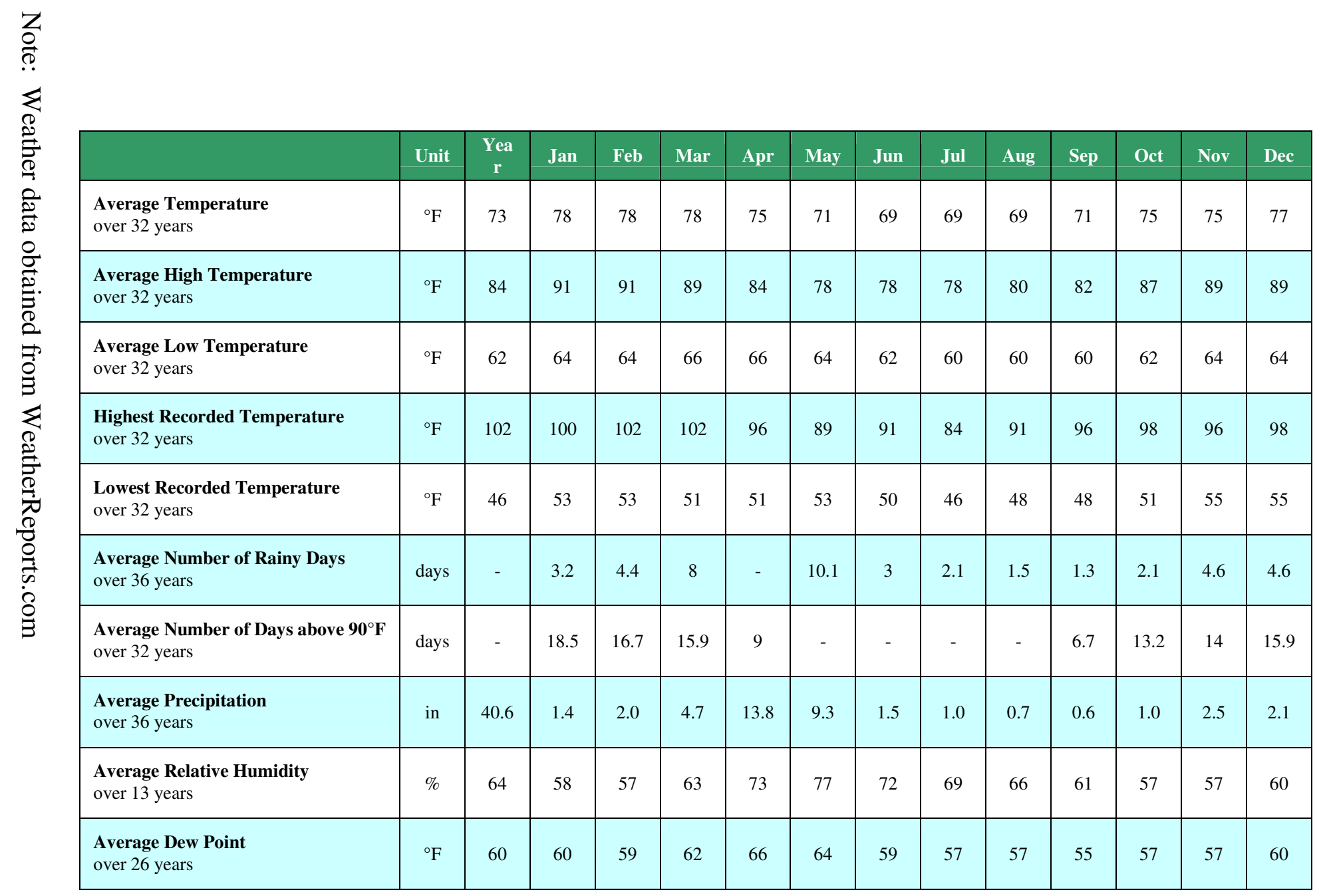




\section{APPENDIX C: MATERIALS PRICE LIST}

\section{C.1 Prices Quoted by Five Star Hardware, Moshi, TZ}

Note: All prices listed in Tanzanian Shillings

\begin{tabular}{|c|c|c|c|c|c|c|}
\hline \multicolumn{2}{|c|}{ Material } & \multicolumn{2}{|c|}{ Size (metric sizes - mm's, cm's) } & Wholesale & \multirow[t]{2}{*}{ Cash } & \multirow[t]{2}{*}{ Credit } \\
\hline MS Plates & & 0.5 & & & & \\
\hline & & 0.6 & & & 41,000 & 42,230 \\
\hline & & 0.8 & & 54,000 & 56,000 & 57,680 \\
\hline & & 1 & & 67,000 & 68,000 & 70,040 \\
\hline & & 1.2 & & 71,000 & 72,000 & 74,160 \\
\hline & & 1.5 & & 88,000 & 90,000 & 92,700 \\
\hline & & 2 & & 114,000 & 116,000 & 119,480 \\
\hline & & $2.0 \times 3 \times 8^{\prime}$ & & & 65,000 & 66,950 \\
\hline & & 2.5 & & 138,000 & 140,000 & 144,200 \\
\hline & & 2.7 & & & & \\
\hline & & 3 & & 171,000 & 173,000 & 178,190 \\
\hline & & 4 & & 230,000 & 260,000 & 267,800 \\
\hline & & 4.5 & & & 350,000 & 360,500 \\
\hline & & 6 & & & 420,000 & 432,600 \\
\hline & & 8 & & & 520,000 & 535,600 \\
\hline & & 10 & & & 750,000 & 772,500 \\
\hline & & 12 & & & 850,000 & 875,500 \\
\hline & & 15 & & & $1,160,000$ & $1,194,800$ \\
\hline & & 20 & & & $1,505,000$ & $1,550,150$ \\
\hline & & 25 & & & $1,725,000$ & $1,886,850$ \\
\hline Plate & & 50 & & & $3,200,000$ & $3,296,000$ \\
\hline \multirow[t]{8}{*}{ Chord Plate } & & $1.5 \mathrm{~mm}$ & & & 135,000 & \\
\hline & & $2.0 \mathrm{~mm}$ & & & 14,500 & 149,350 \\
\hline & & $2.5 \mathrm{~mm}$ & & & 195,000 & \\
\hline & & $3 \mathrm{~mm}$ & & & 215,000 & 221,450 \\
\hline & & $4.0 \mathrm{~mm}$ & & & 325,000 & 334,750 \\
\hline & & $4.5 \mathrm{~mm}$ & & & 350,000 & 360,500 \\
\hline & & $6 \mathrm{~mm}$ & & & 400,000 & 412,400 \\
\hline & & $8 \mathrm{~mm}$ & & & 480,000 & 494,400 \\
\hline \multirow{8}{*}{ Galvanized } & Sheot & $04(26 a)$ & & & 32000 & $220 \bullet$ \\
\hline & & 0.5 & & & 40,000 & 41,200 \\
\hline & & 0.6 & & & 48,000 & 49,440 \\
\hline & & 0.8 & & & 63,000 & 64,440 \\
\hline & & 1 & & & 80,000 & 82,400 \\
\hline & & 1.2 & & & 98,000 & 100,940 \\
\hline & & 1.5 & & & 125,000 & 128,750 \\
\hline & & 2 & & & 165,000 & 169,950 \\
\hline \multirow[t]{7}{*}{ Aluminum Sh } & Sheets & $0.4 \mathrm{~mm}$ & & & & \\
\hline & & 0.45 & & & 50,000 & 51,500 \\
\hline & & 0.5 & & & 50,000 & 51,500 \\
\hline & & 0.55 & & & 52,000 & 53,560 \\
\hline & & 0.6 & & & 62,000 & 63,860 \\
\hline & & 0.7 & & & 71,000 & 73,130 \\
\hline & & 0.8 & & & 75,000 & 77,250 \\
\hline
\end{tabular}




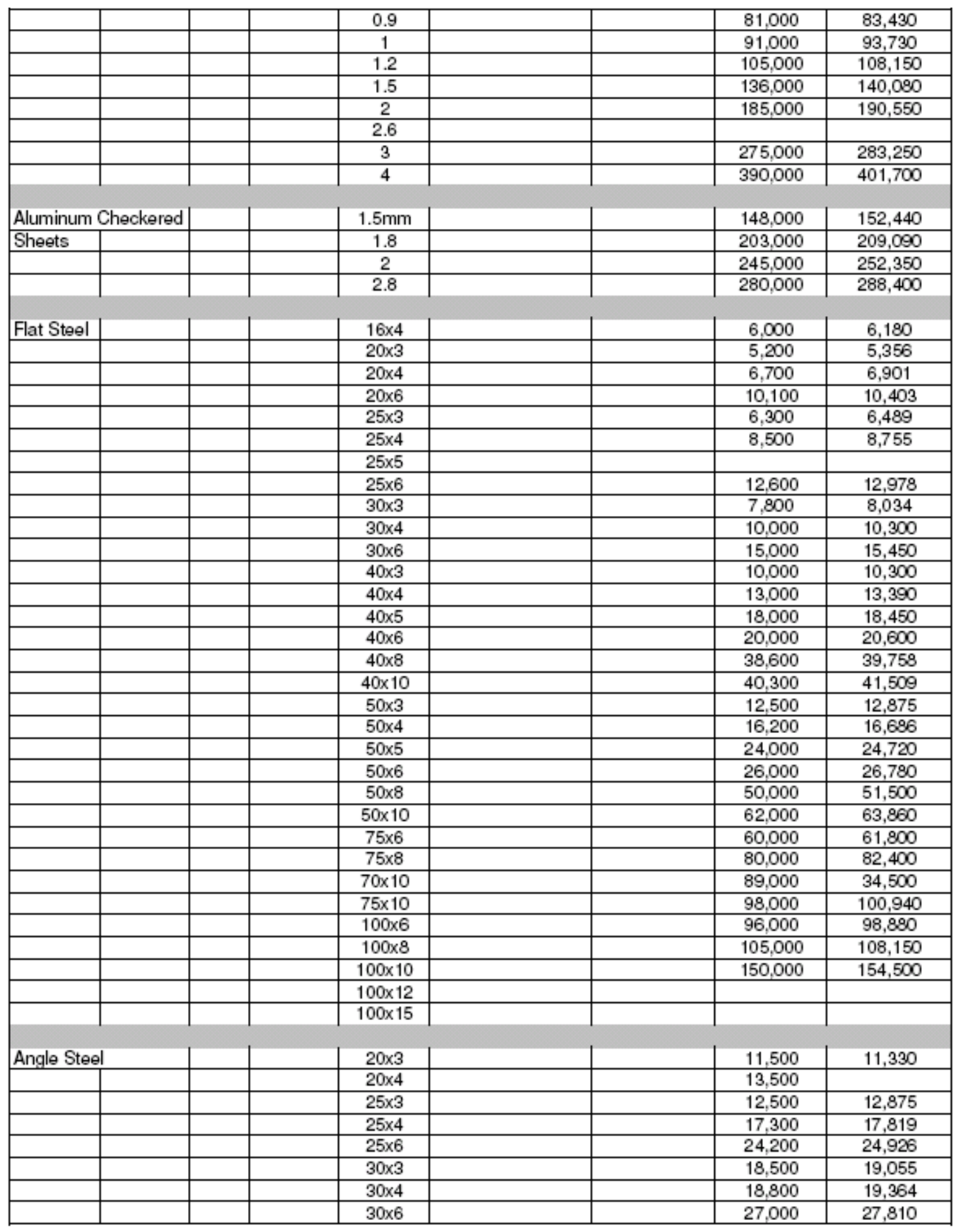




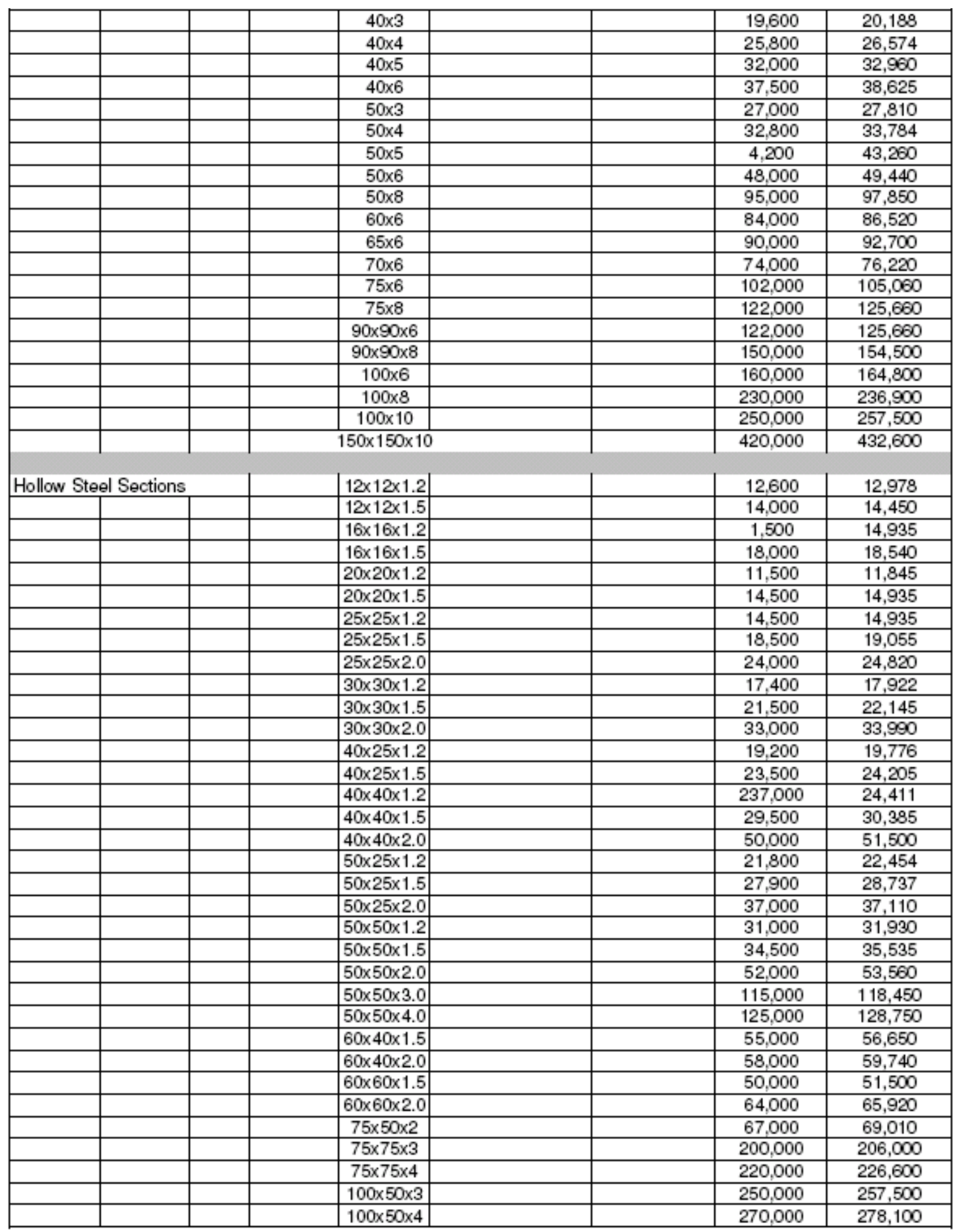




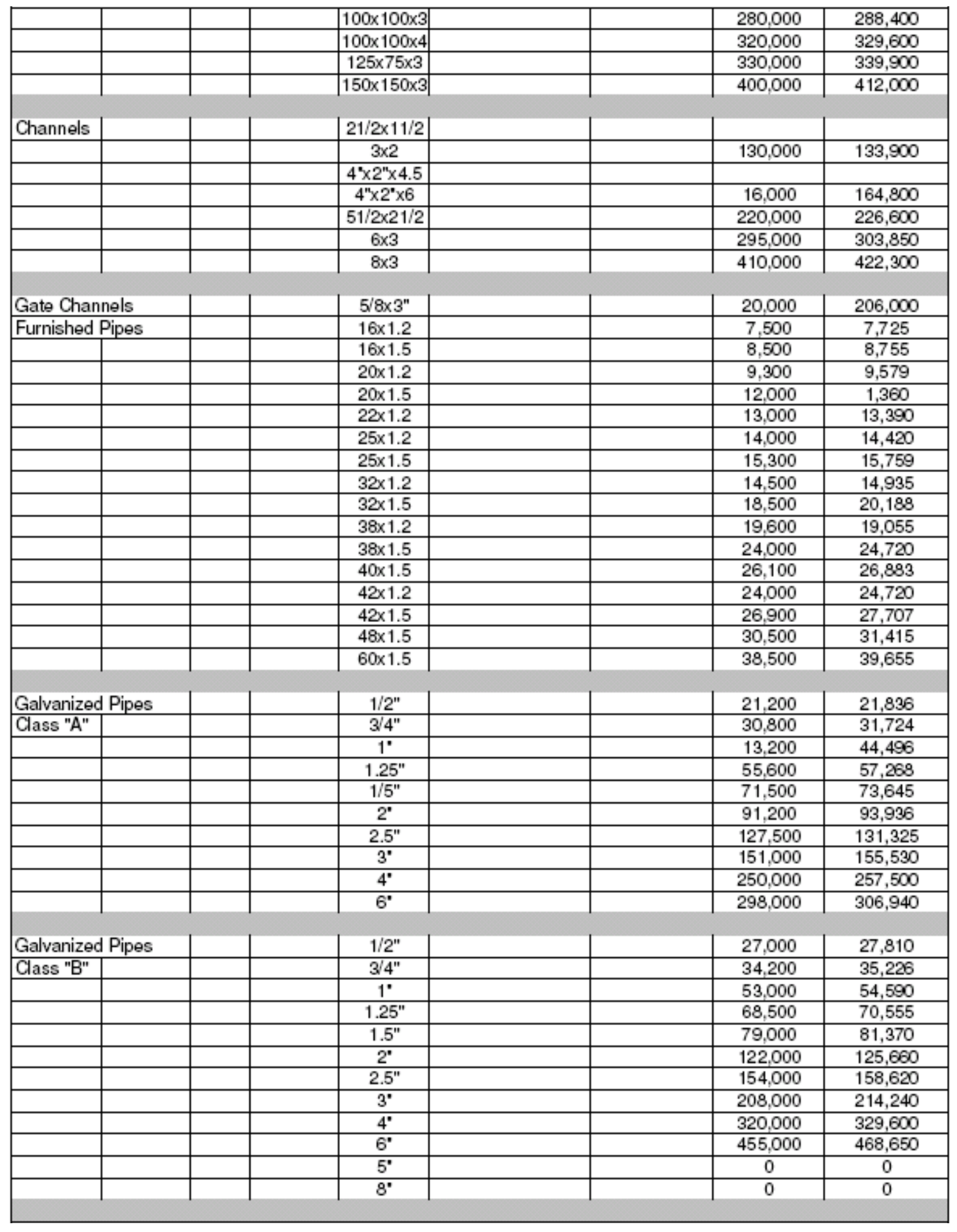




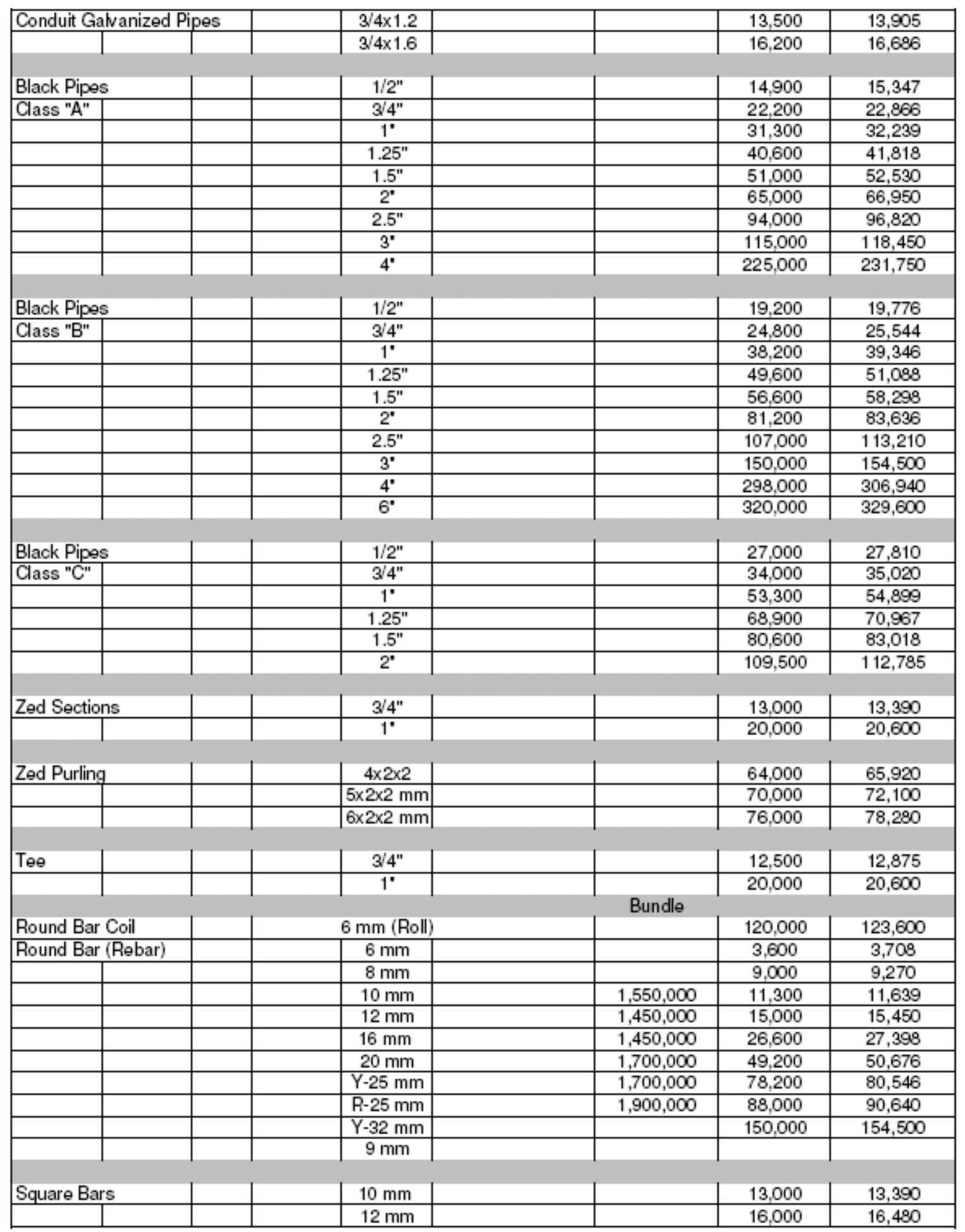




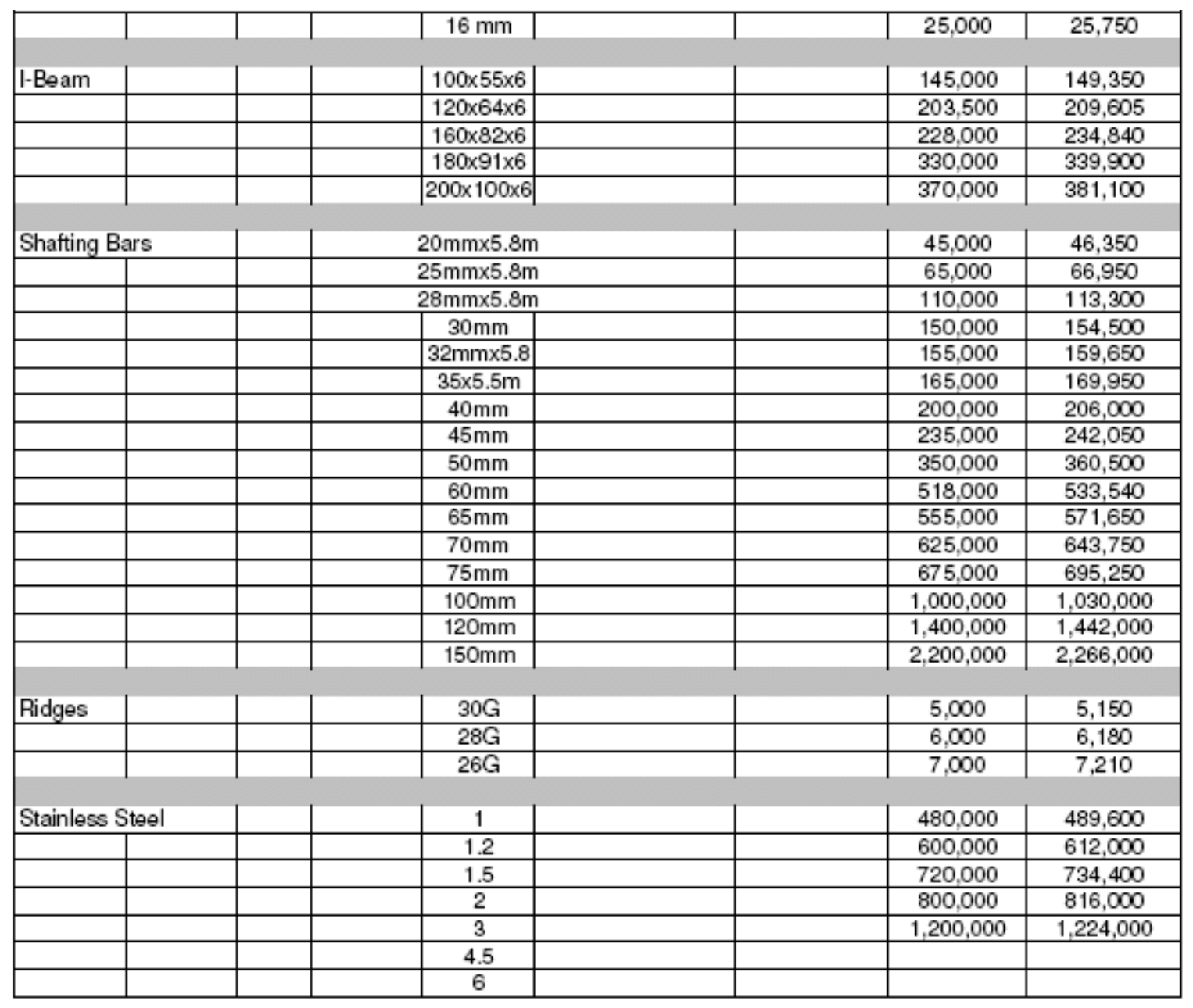

\begin{tabular}{|c|c|c|c|c|c|}
\hline G.C.I Sheets (Galco) & & $2 \mathrm{~m}$ & $2.5 \mathrm{~m}$ & $3.0 \mathrm{~m}$ & Bundle \\
\hline & $26 \mathrm{~g}$ & 17,285 & 22,000 & 26,900 & 26,000 \\
\hline & $28 g$ & 12,950 & 16,650 & 19,350 & 246,000 \\
\hline & $30 \mathrm{~g}$ & 10,150 & 12,300 & 14,600 & 246,000 \\
\hline & $32 g$ & 8,100 & 10,150 & 12,150 & 256,000 \\
\hline \multirow[t]{4}{*}{ G.C.I Sheets (Kiboko) } & & $2 \mathrm{~m}$ & $2.5 \mathrm{~m}$ & $3.0 \mathrm{~m}$ & Bundle \\
\hline & $28 \mathrm{~g}$ Kibokd & 12,200 & 15,650 & 18,300 & 237,000 \\
\hline & $30 \mathrm{~g} \mathrm{Kiboko}$ & 9,550 & 11,550 & 13,700 & 237,000 \\
\hline & $32 \mathrm{~g}$ Kibokd & 7,650 & 9,555 & 11,450 & 247,000 \\
\hline
\end{tabular}




\section{C.2 Prices Quoted by Nandra Hardware, Moshi, TZ}

Note: All prices listed in Tanzanian Shillings

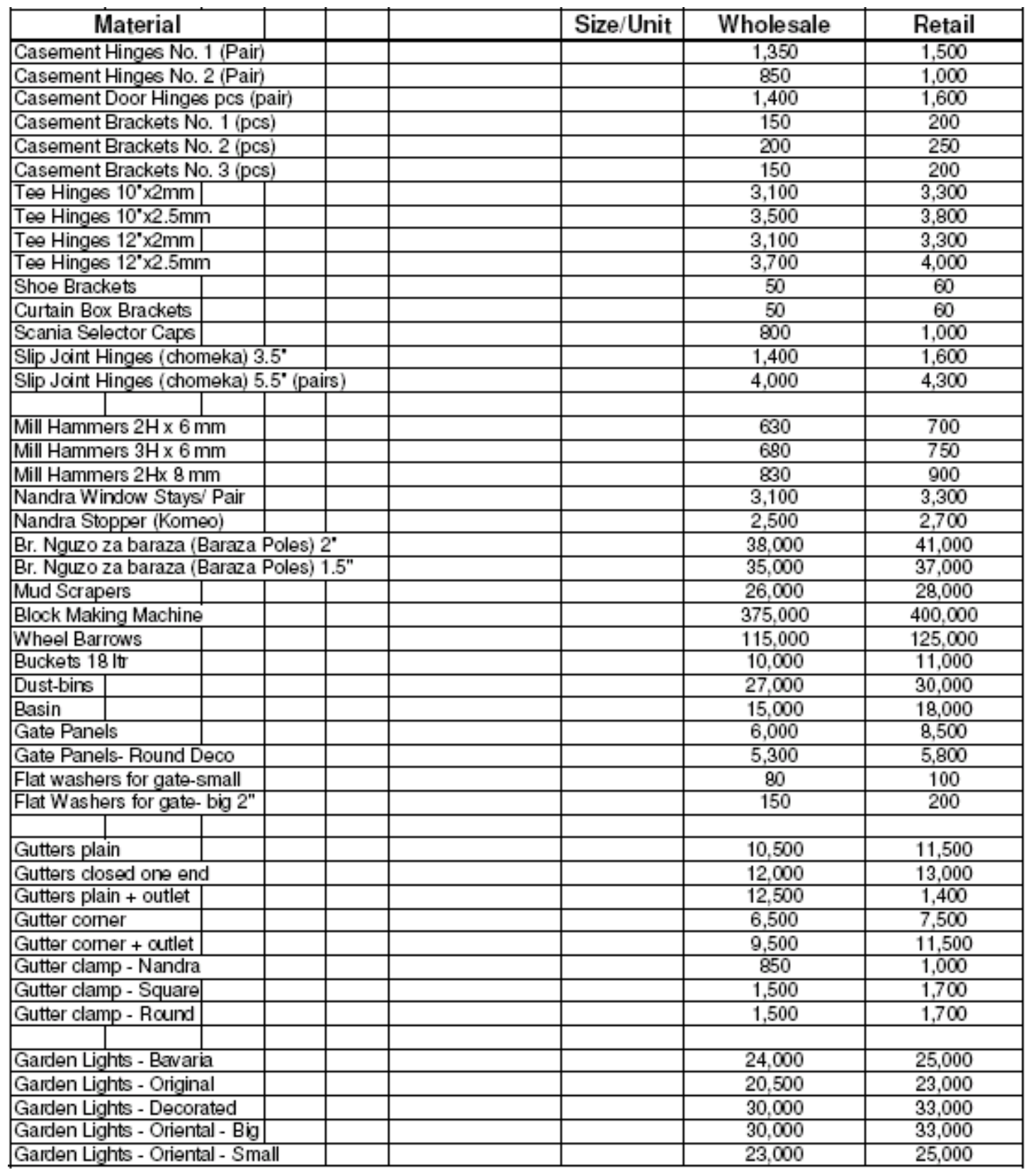




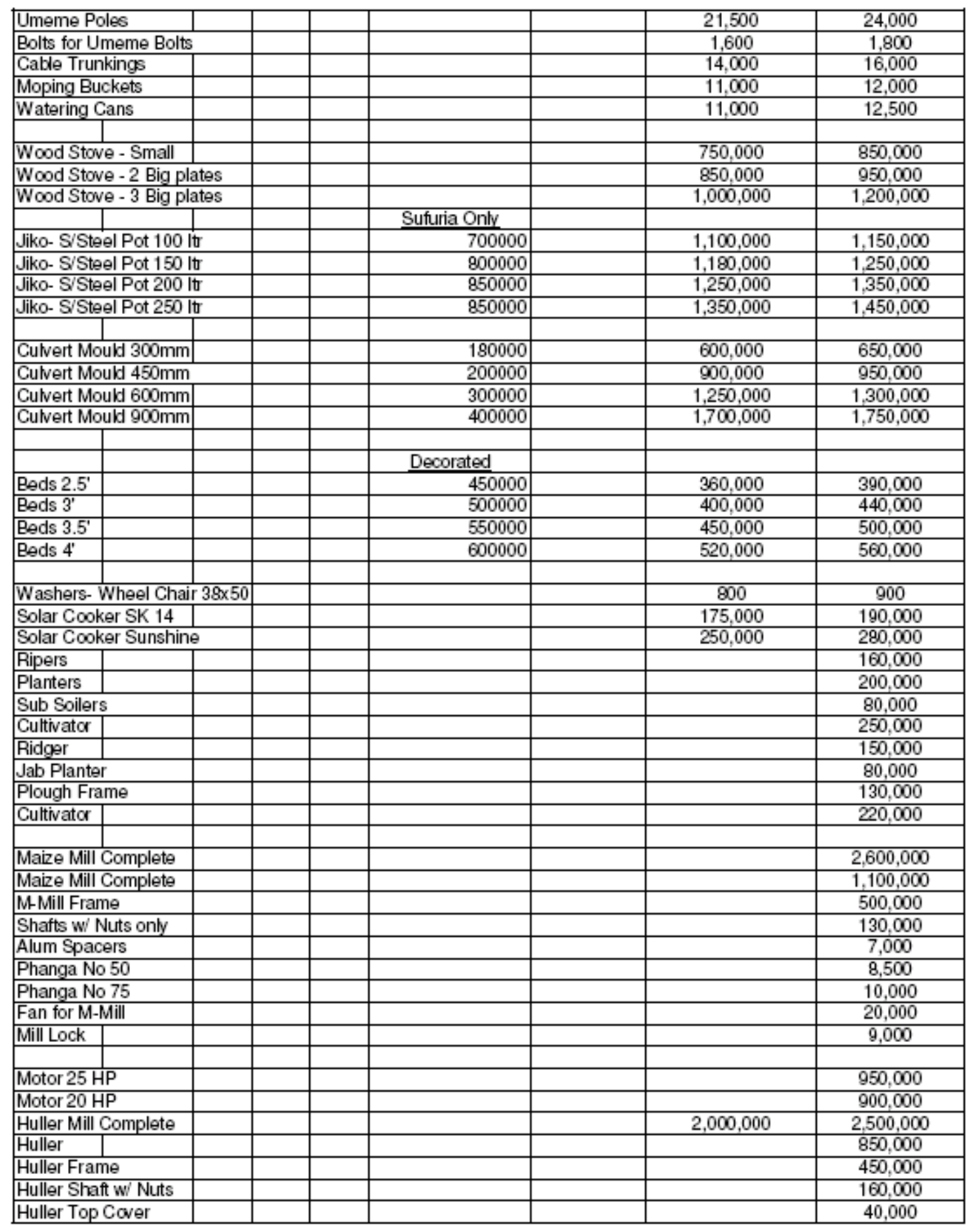




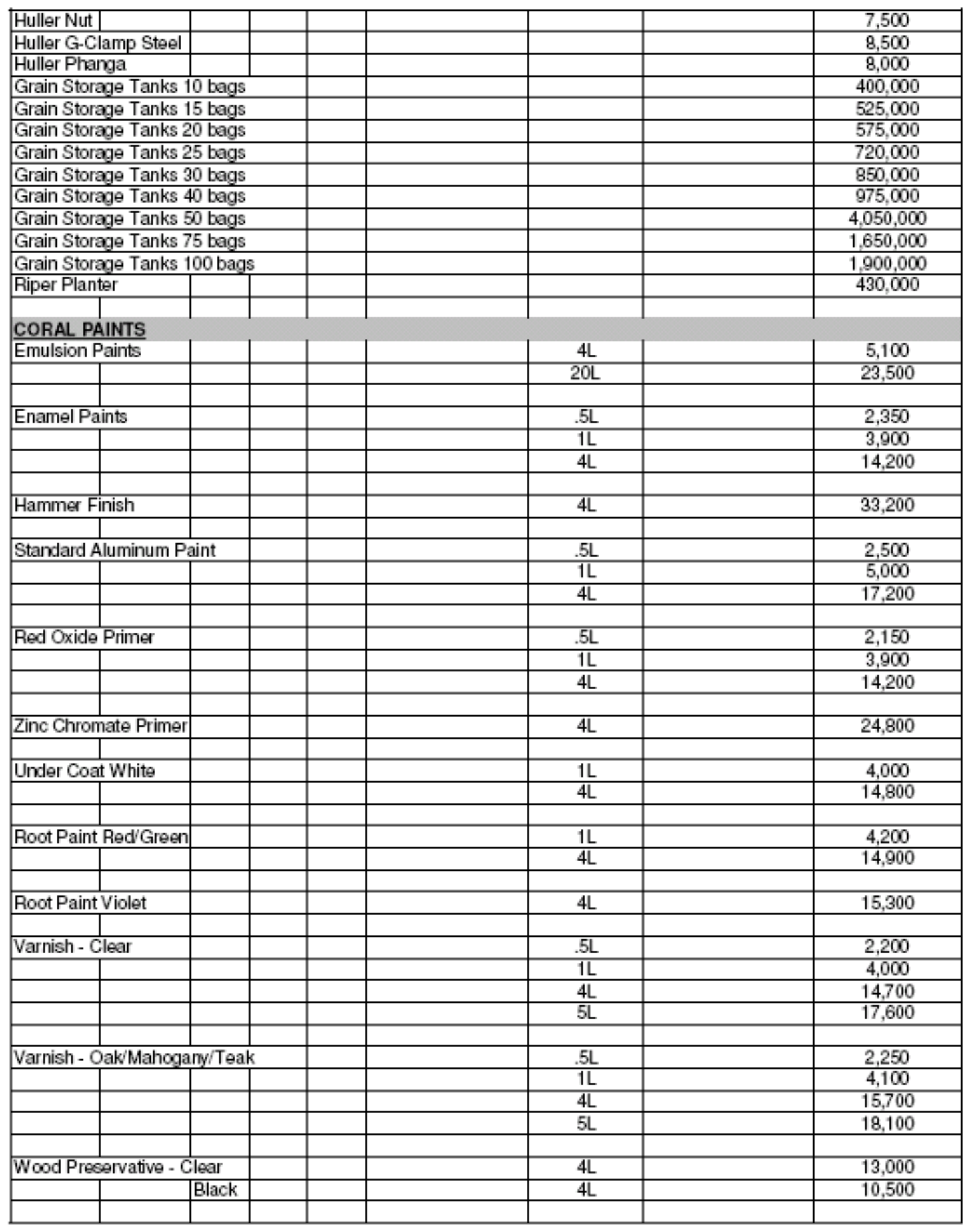




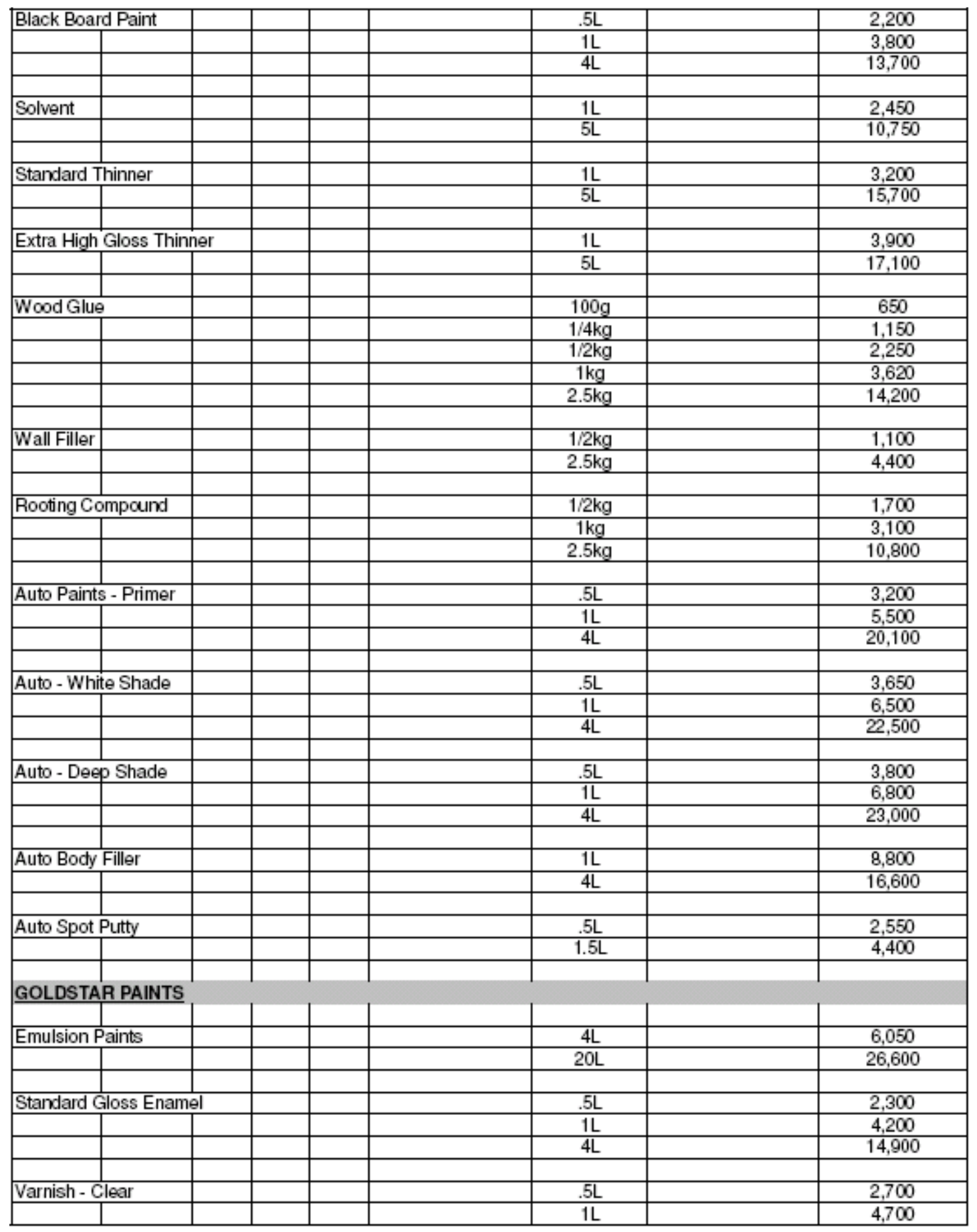




\begin{tabular}{|c|c|c|c|c|c|c|c|c|}
\hline & & & & & & $4 \mathrm{~L}$ & & \\
\hline \multicolumn{2}{|c|}{} & & & & & & & \\
\hline \multicolumn{2}{|l|}{ Varnish - OakMahogary/Teak } & & & & $.5 \mathrm{~L}$ & & \\
\hline \\
\hline
\end{tabular}




\section{APPENDIX D: PLANT SPECIES LIST}

\section{Acacia abyssinica}

Flat-top acacia

Mimosoideae

Shade Tree

Height: $6-20 \mathrm{~m}$

Uses: good for fuel (wood, charcoal) and timber (posts, bridge building), large amounts of shade.

Appropriate because: grows well in Eastern Africa grasslands 1200 - 2300 m, good for outdoor gathering, little maintenance and mess, indigenous to E. Africa

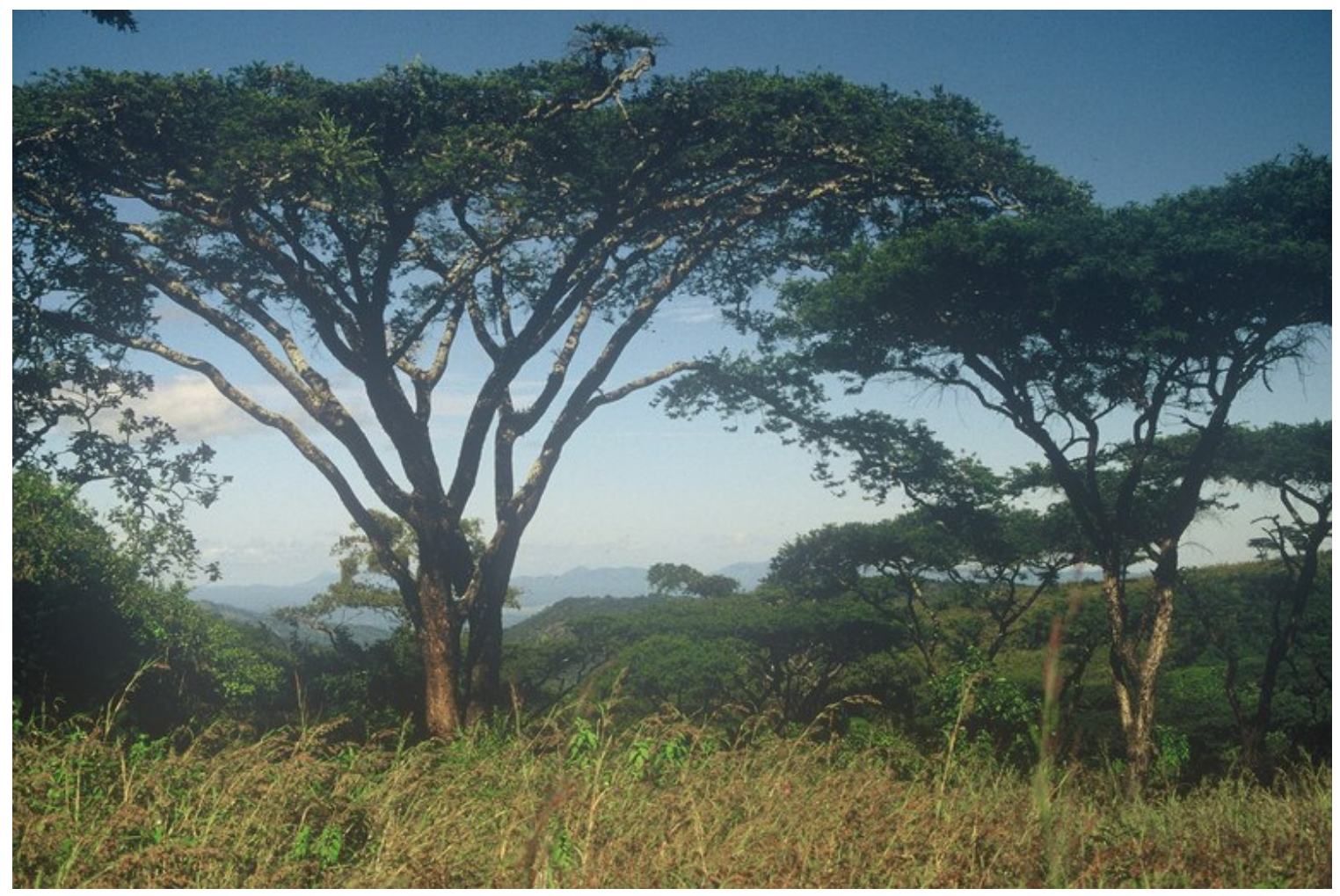




\section{Acacia xanthophloea}

Fever tree, Naivasha thorn

Mimosoideae

\section{Shade Tree}

Height: up to $25 \mathrm{~m}$

Uses: wood used as fuel and timber, serves as bee forage, shade

Appropriate because: grows well in E. Africa 600 - 2000 m, attractive yellow green bark and small yellow/red flowers, indigenous

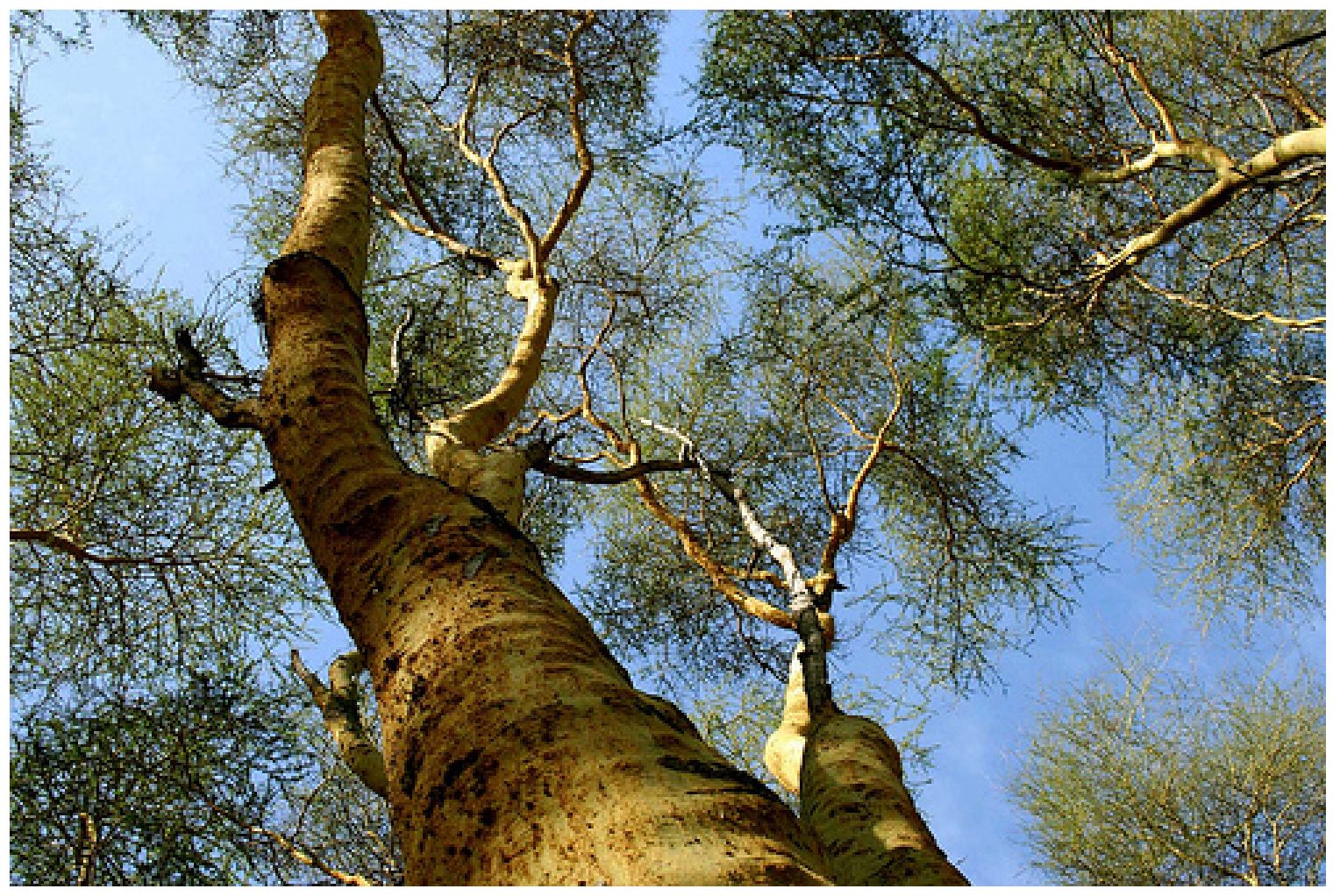




\section{Albizia grandi bracteata}

Large-leafed albizia

Mimosoideae

\section{Shade Tree}

\section{Height: up to $15 \mathrm{~m}$}

Uses: wood for fuel and timber, attractive shade tree, roots are medicinal (treat tonsillitis)

Appropriate because: grows well in E. Africa 1200 - 1800 m, attractive flat crown shade tree, indigenous

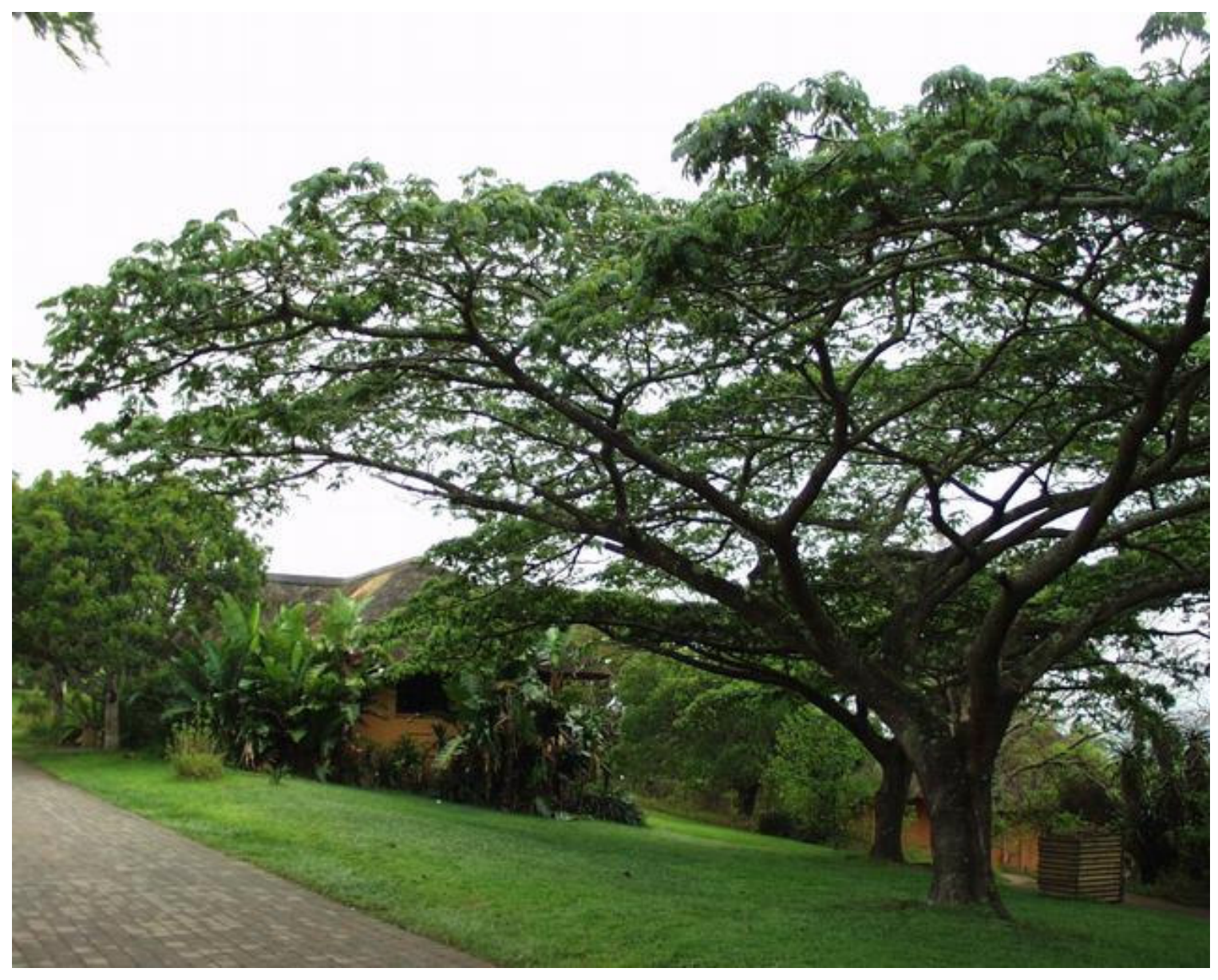


Calodendrum capense

Cape chesnut

Rutaceae

Ornamental Tree

Height: up to $20 \mathrm{~m}$

Uses: beautiful ornamental (large showy pink flowers), bendable, tough wood

Appropriate because: grows well in E. Africa 1600 - 2300 m, attractive flowers, indigenous

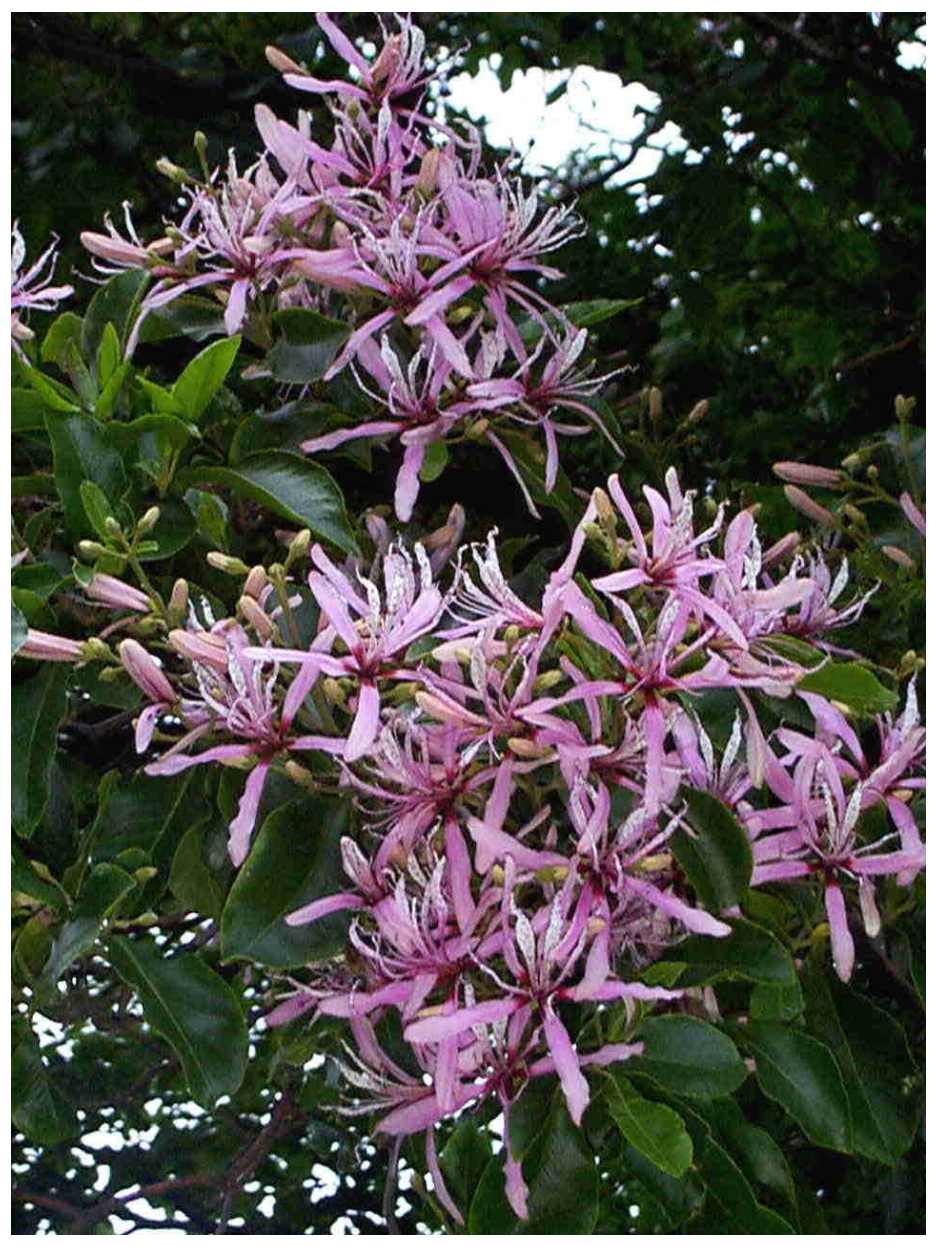


Delonix Regis

Flamboyant

Caesalpinioideae

Ornamental Tree

Height: $10-15 \mathrm{~m}$

Uses: beautiful ornamental (showy red flowers), bee forage

Appropriate because: brilliant amounts of color, grows well in E. Africa

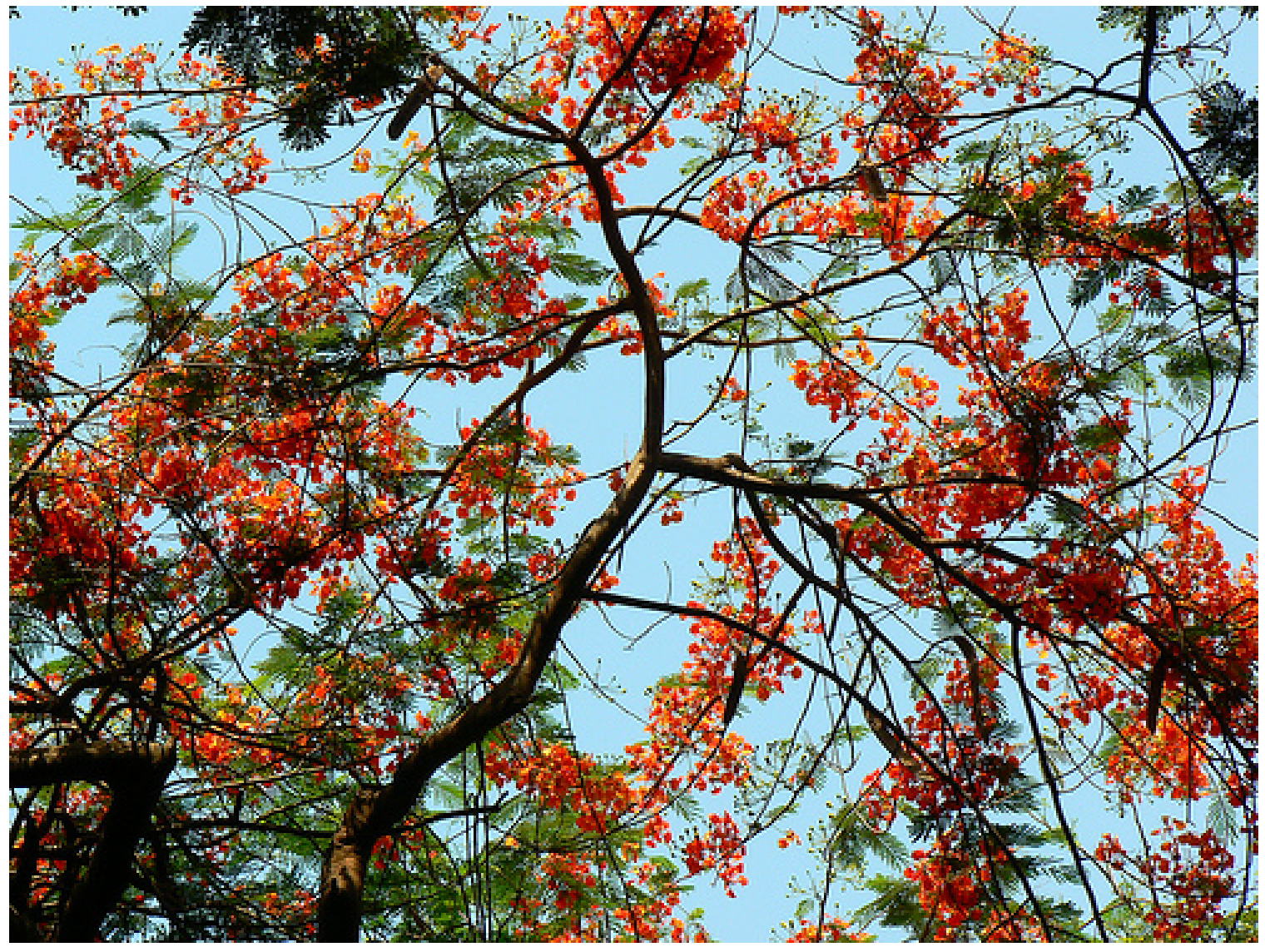




\section{Jacaranda mimosifolia}

Jacaranda

Bignoniaceae

\section{Ornamental Tree}

Height: up to $20 \mathrm{~m}$

Uses: beautiful ornamental (purple clusters), general timber

Appropriate because: grow well in E. Africa (up to $2200 \mathrm{~m}$ ), attractive tree (possibly for entrance)

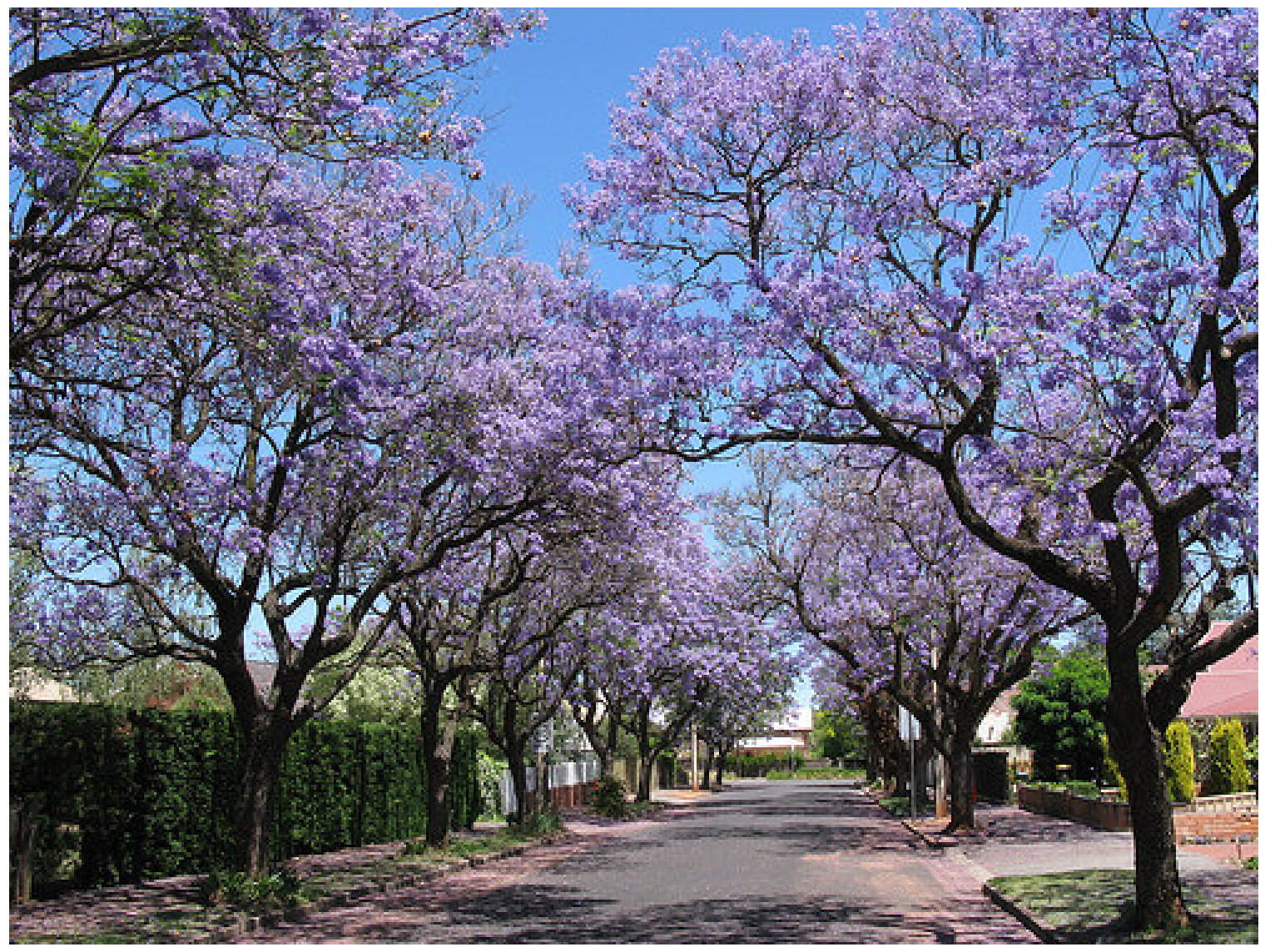


Eriobotrya japonica

Loquat

Rosaceae

Fruit Tree

Height: up to $7 \mathrm{~m}$

Uses: fruit can be eaten raw or made into jam, jelly or syrup, attractive flowers, good timber

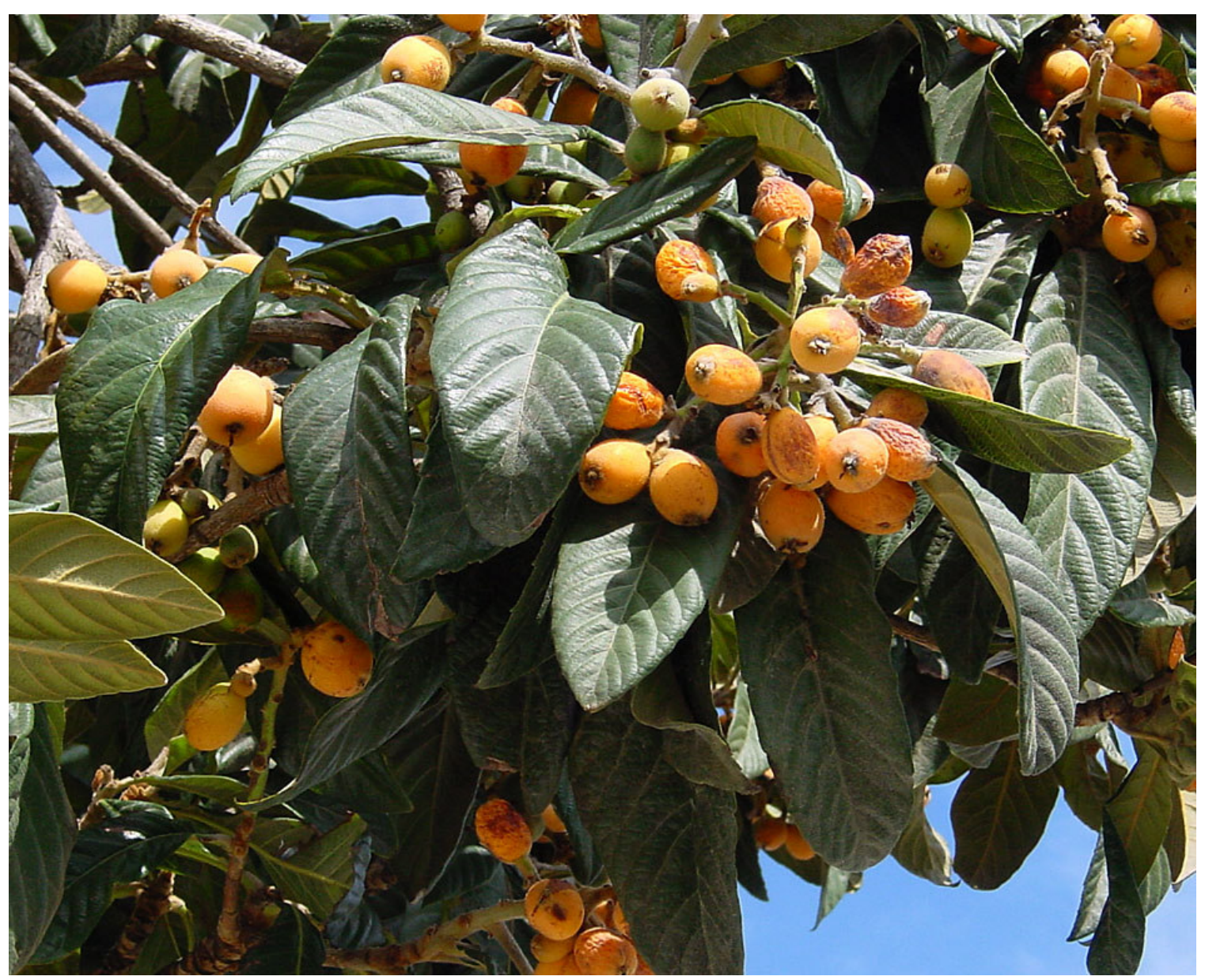


Musa sapientum

Sweet banana

Musaceae

Fruit Tree

Height: $2-6 \mathrm{~m}$

Uses: fruit eaten raw or fried, can be made into jam or syrup

Appropriate because: important for consumption and trade

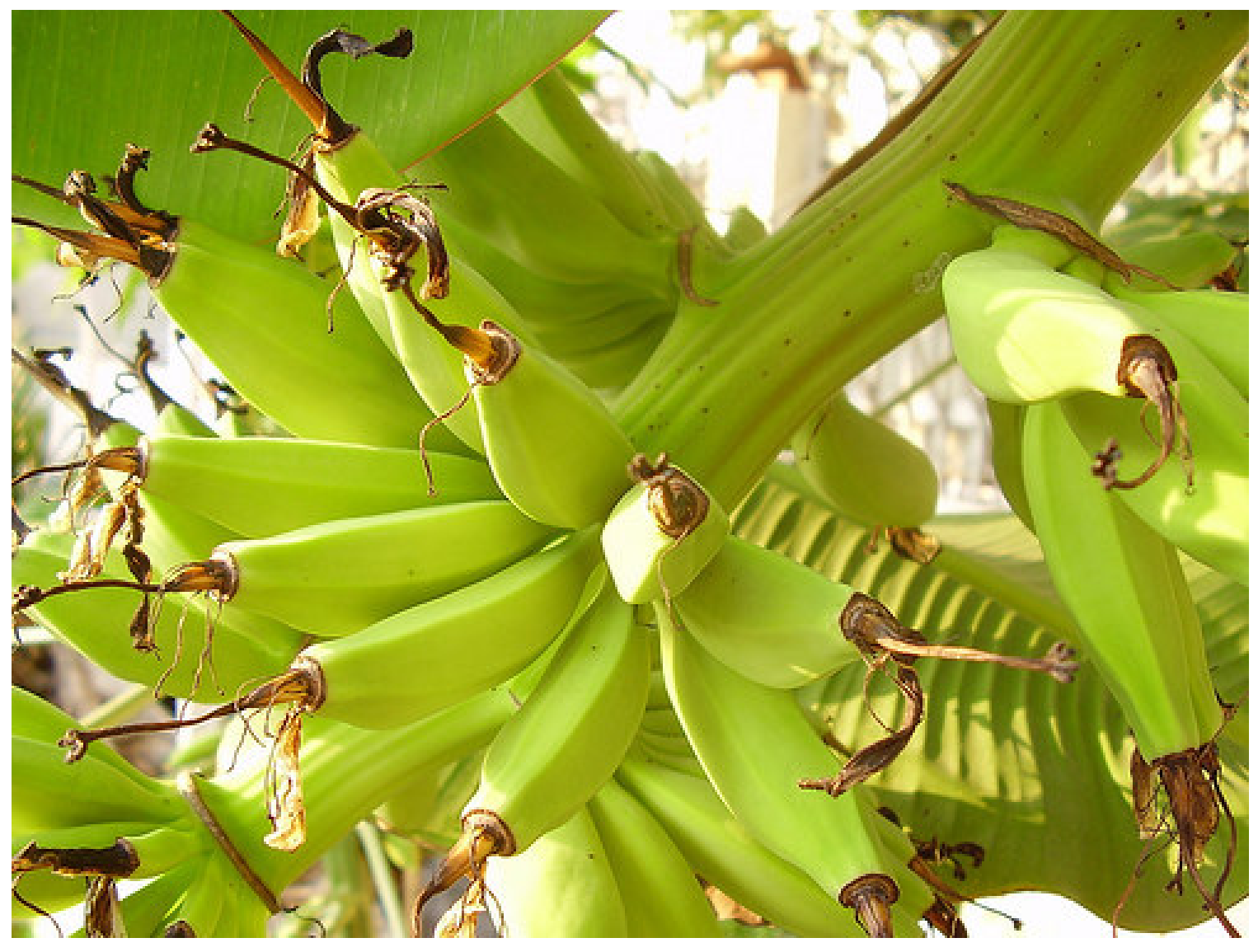


Persea Americana

Avocado

Lauraceae

Fruit Tree

Height: up to $10 \mathrm{~m}$

Uses: edible nutrient rich fruit

Appropriate because: nutrient rich fruit available for consumption

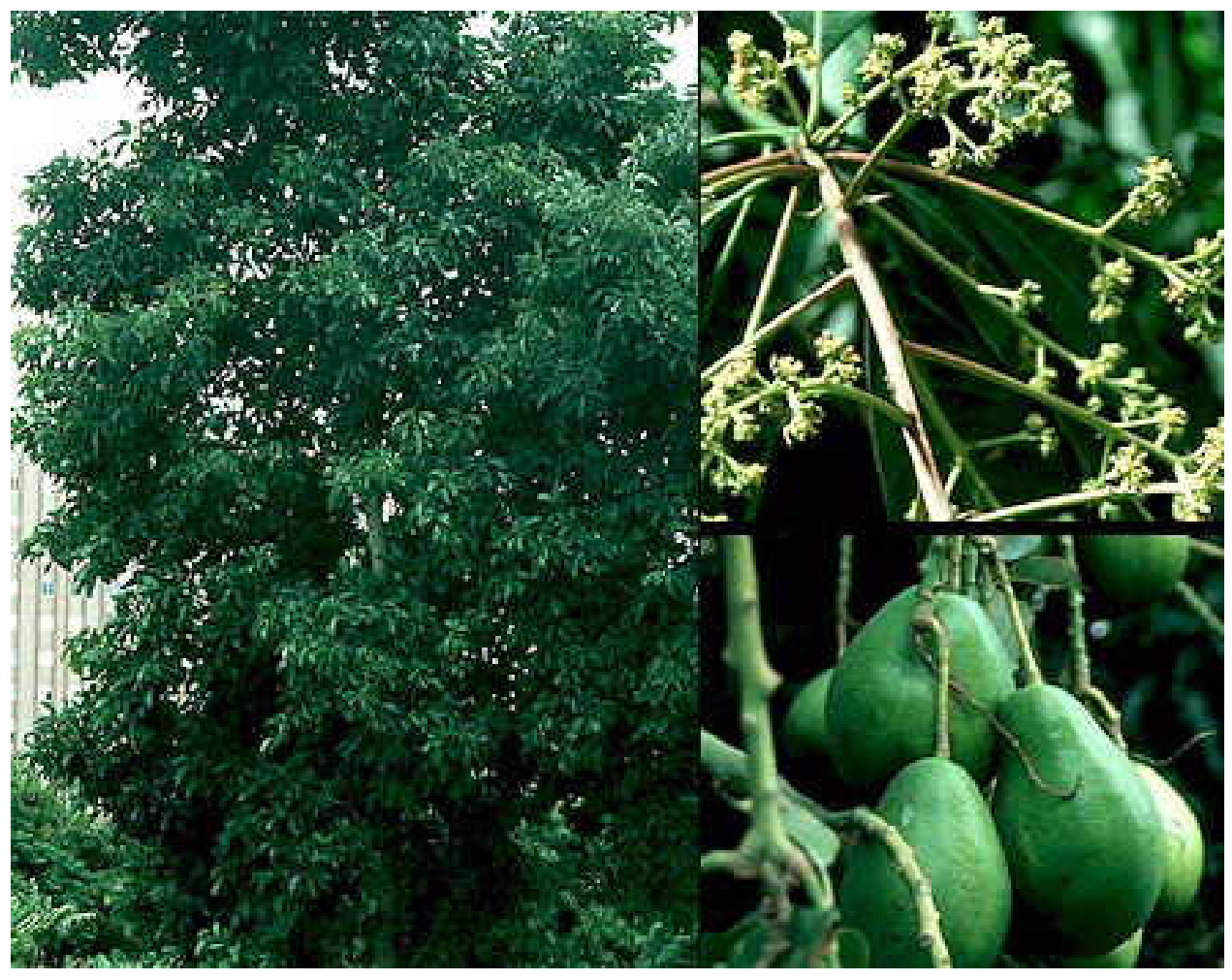


Psidium guajava

Guava

Myrtaceae

Fruit Tree

Height: up to $8 \mathrm{~m}$

Uses: edible fruit, used for jam, jelly, syrup, birds and bats love it

Appropriate because: grow well in E. Africa, edible fruit important for consumption and trade

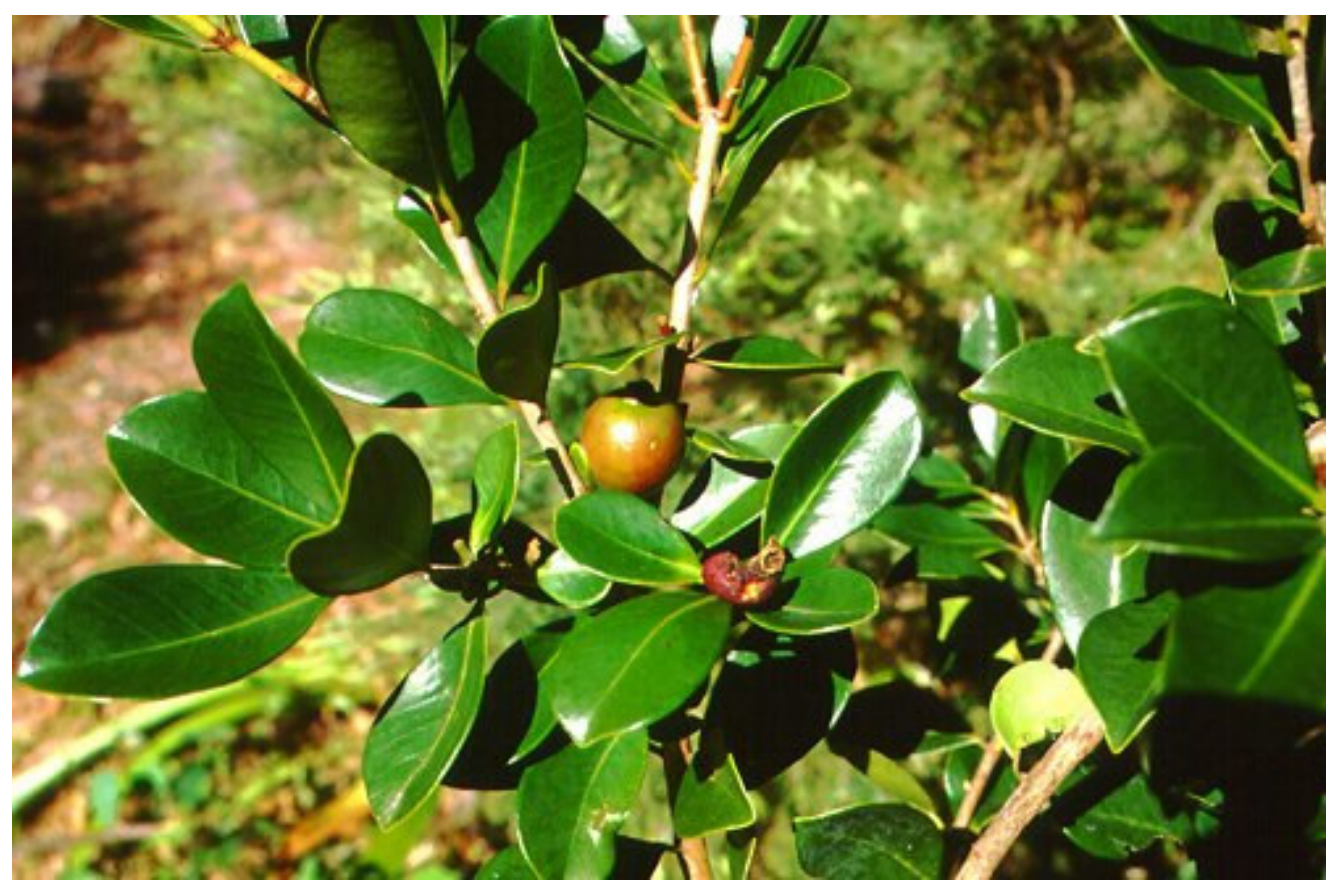




\section{Arundinaria alpinia}

Mountain bamboo

Gramineae

\section{Large Shrub}

Height: up to $25 \mathrm{~m}$

Uses: construction of fences, poles, water pipes, baskets

Appropriate because: grows well in E. Africa (2300 - 3300 m), excellent for construction purposes, indigenous

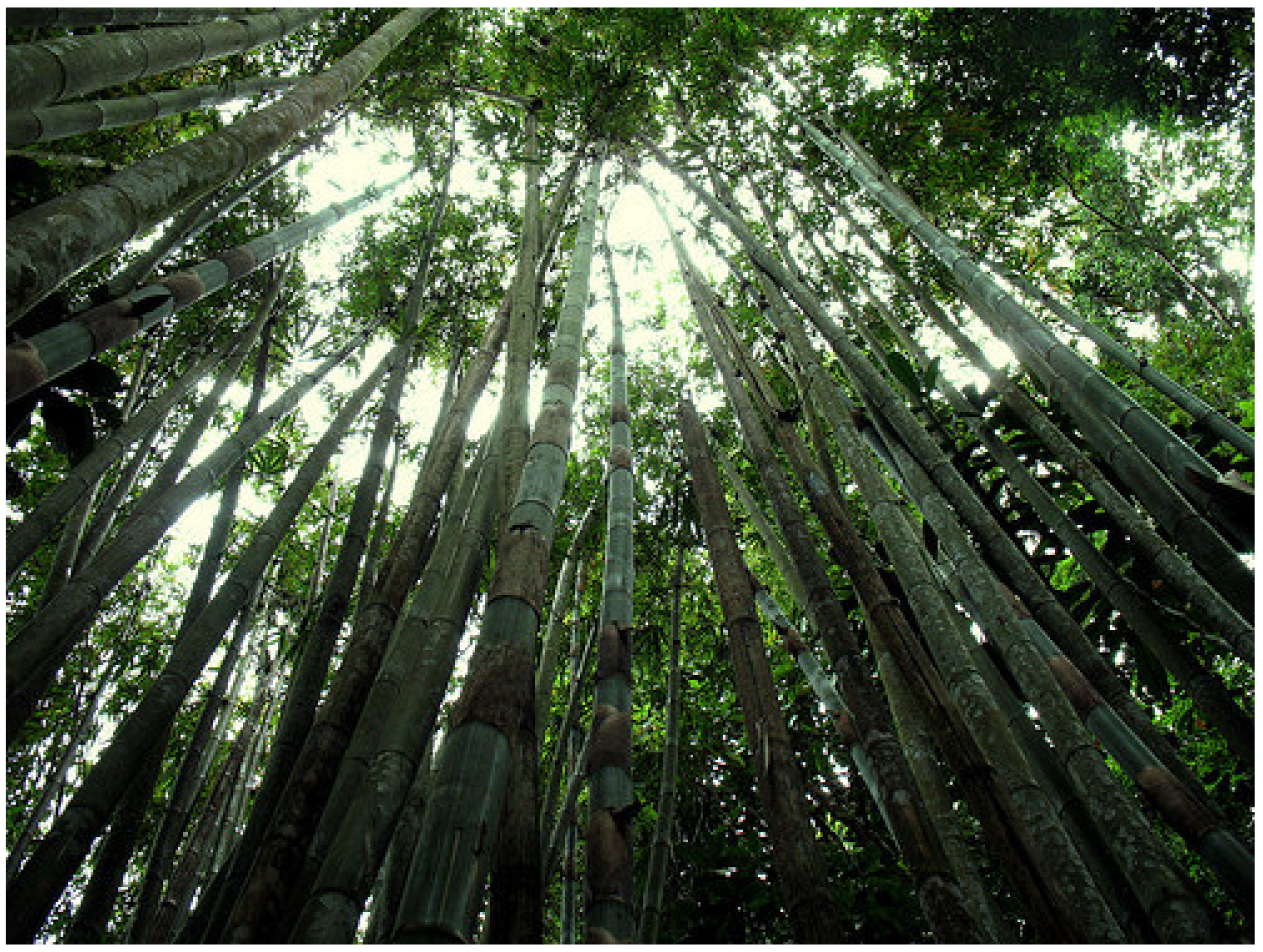


Ravenala madagascariensis

Traveller's palm

Streliziaceae

Large Shrub/Tree

Height: up to $10 \mathrm{~m}$

Uses: attractive specimen (maybe for entrance)

Appropriate because: grows well in E. Africa, attractive specimen plant

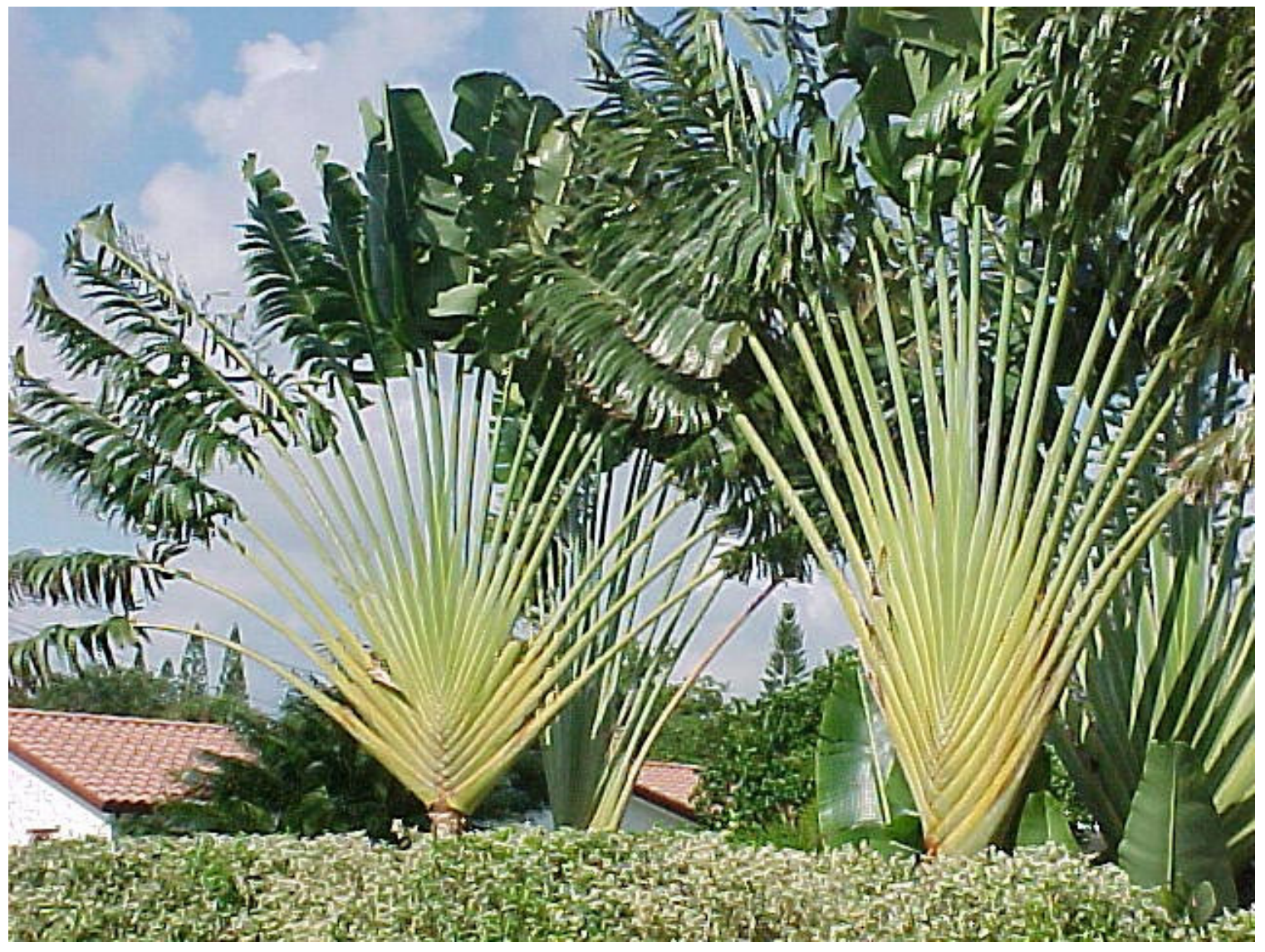




\section{Bougainvillea glabra}

Bougainvillea

Nyctaginacae

\section{Small Shrub}

Height: depends - shrub and climber

Uses: decorative plants, put on fences (screens), living walls, very showy foliage

Appropriate because: grows well in E. Africa (up to $2000 \mathrm{~m}$ ), robust attractive foliage,

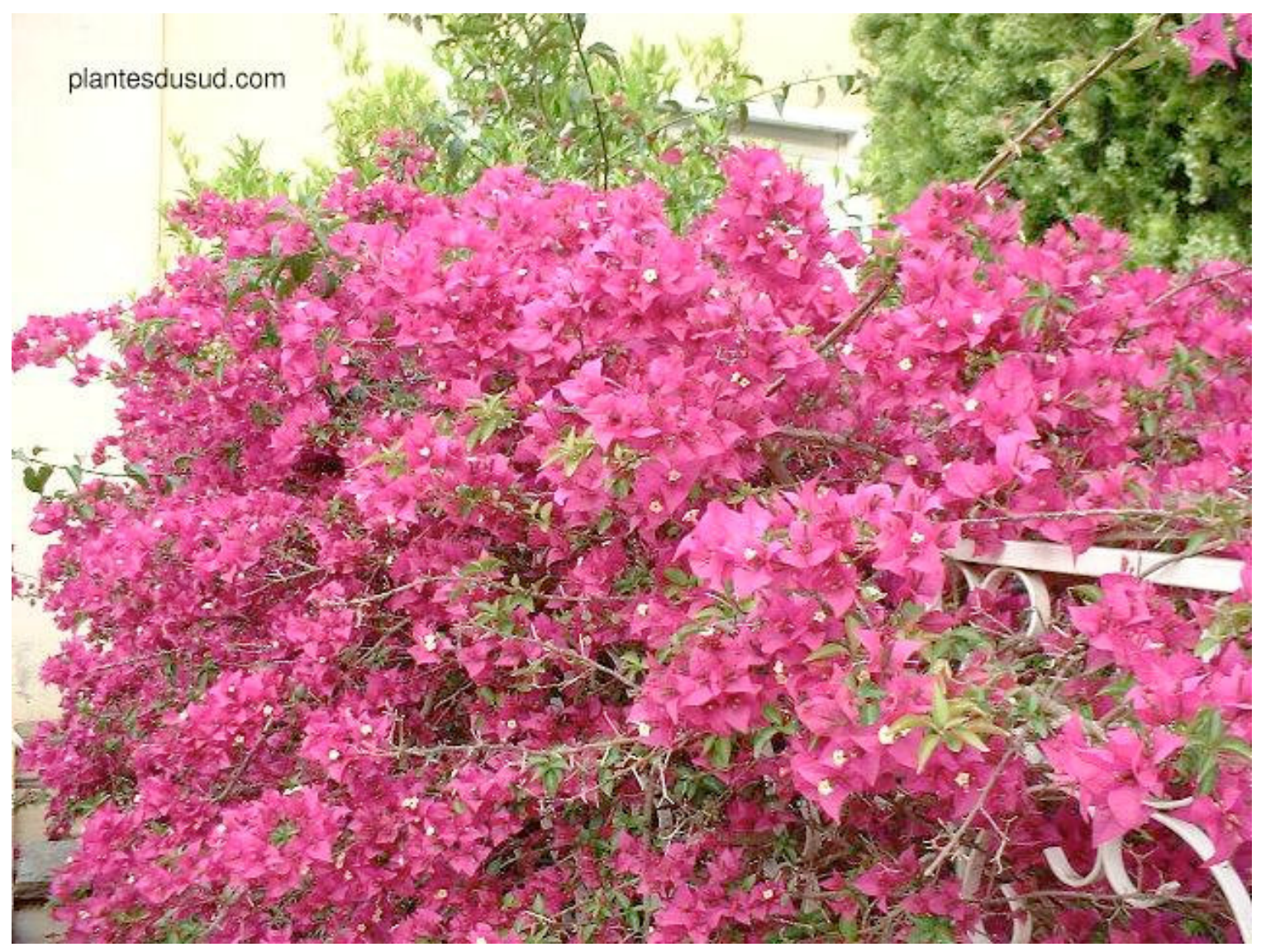


Hypericum revolutum

Giant St. John's wort

Guttiferae

\section{Small Shrub}

Height: $1-10 \mathrm{~m}$

Uses: attractive yellow flowers, medicial plant

Appropriate because: grow well in E. Africa $(2100-3250 \mathrm{~m})$, showy foliage, medicinal purposes (diarrhea, rheumatism, wounds, burns), indigenous

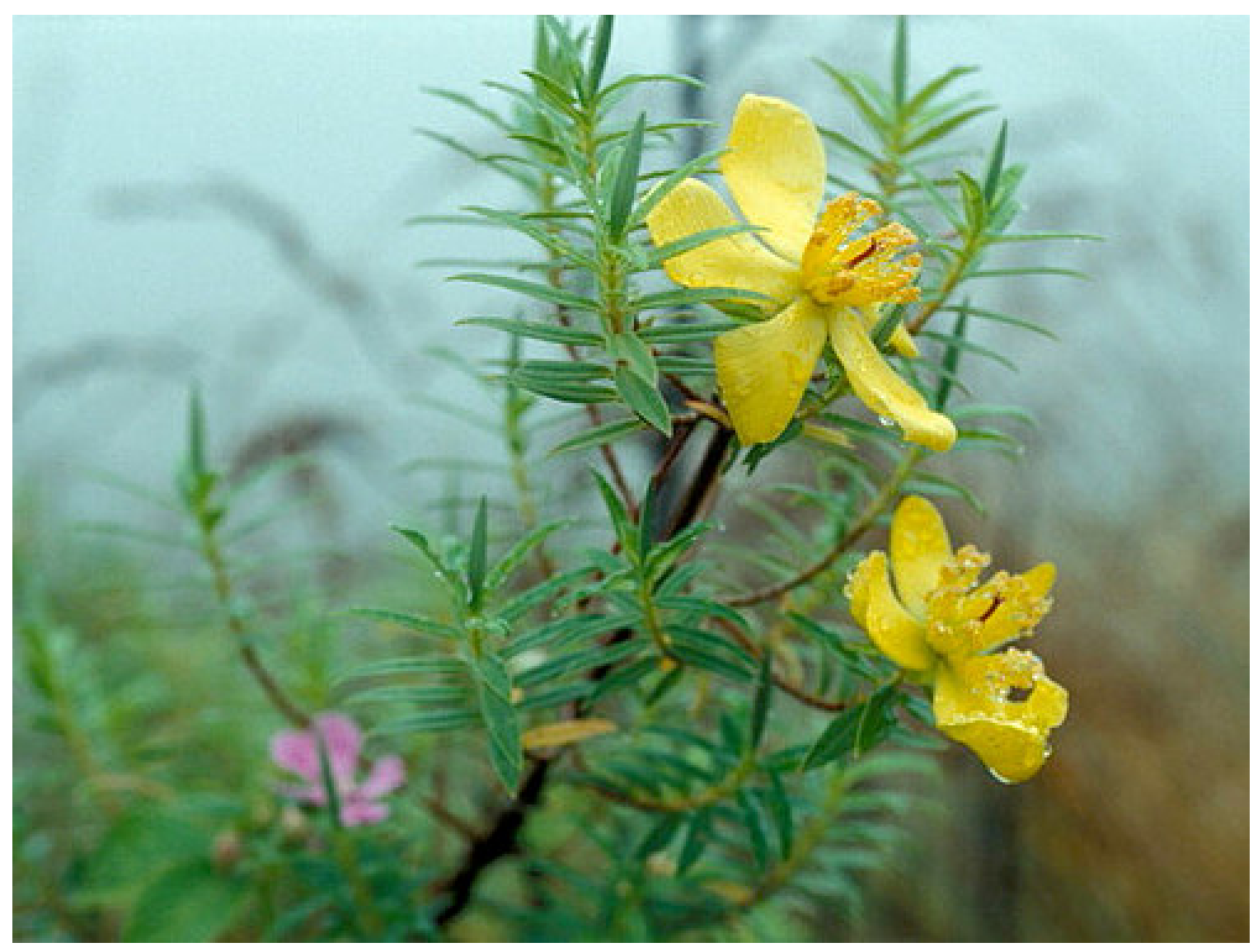

